\title{
A spatial simultaneous growth equilibrium modeling of agricultural land development in the Northeast United States
}

\author{
Yohannes G. Hailu \\ West Virginia University
}

Follow this and additional works at: https://researchrepository.wvu.edu/etd

\section{Recommended Citation}

Hailu, Yohannes G., "A spatial simultaneous growth equilibrium modeling of agricultural land development in the Northeast United States" (2006). Graduate Theses, Dissertations, and Problem Reports. 2487. https://researchrepository.wvu.edu/etd/2487

This Dissertation is protected by copyright and/or related rights. It has been brought to you by the The Research Repository @ WVU with permission from the rights-holder(s). You are free to use this Dissertation in any way that is permitted by the copyright and related rights legislation that applies to your use. For other uses you must obtain permission from the rights-holder(s) directly, unless additional rights are indicated by a Creative Commons license in the record and/ or on the work itself. This Dissertation has been accepted for inclusion in WVU Graduate Theses, Dissertations, and Problem Reports collection by an authorized administrator of The Research Repository @ WVU. For more information, please contact researchrepository@mail.wvu.edu. 


\title{
A Spatial Simultaneous Growth Equilibrium Modeling of Agricultural Land Development in the Northeast United States
}

\author{
Yohannes G. Hailu \\ Dissertation submitted to the \\ Davis College of Agriculture, Forestry, and Consumer Sciences \\ at West Virginia University \\ in partial fulfillment of the requirements \\ for the degree of \\ Doctor of Philosophy \\ in \\ Natural Resource Economics \\ Cheryl Brown, Ph.D., Chair \\ Timothy T. Phipps, Ph.D. \\ Tesfa G. Gebremedhin, Ph.D. \\ Dale Colyer, Ph.D. \\ Brian Cushing, Ph.D.
}

Agricultural and Resource Economics Program

Division of Resource Management

Morgantown, West Virginia

2006

Key words: Growth equilibrium, Land use, Agricultural land, Land conversion, Spatial model. 


\title{
ABSTRACT \\ A Spatial Simultaneous Growth Equilibrium Modeling of Agricultural Land Development in the Northeast United States
}

\author{
Yohannes G. Hailu
}

With population growth and expansion of economic activities, urbanized places have expanded; and with growing per capita income, residential location preferences have shifted towards suburban and rural locations. In many places, such new growth has been accommodated with the development of agricultural lands. The concern from natural resource economics perspective is that agricultural lands are multifunctional. They have production uses, for which there are efficient markets, and amenity and environmental benefits, for which there are no efficient markets to value these attributes. This multifunctionality and the possible under-valuation of agricultural lands, irreversibility of development, and speculative effects of development on farm efficiency have attracted policy intervention in many States.

This study aims to understand the relationship between regional growth in population, employment, and per capita income and agricultural land development in the Northeast United States. This region comprises 13 states and one of the fastest agricultural land developments in the nation. A system of spatial and non-spatial simultaneous equations models are introduced and estimated using three-stage-leastsquares method. County level data on population, employment, income, land value, agricultural land stock, county characteristics, fiscal factors, local infrastructure, agricultural land use policies, and spatial information are used to estimate the models.

The major findings of this study are that population growth facilitates agricultural land development, more so if the growth is in a neighboring county; own county growth in income induces agricultural land development while neighboring county income growth reduces it; counties with high per acre value of agricultural land and counties surrounded by other counties that have high land values experience high agricultural land development; road accessibility and location near urbanized locations induce agricultural land development; northeastern states that implemented tax easement and transferable development rights policies experienced more agricultural land development than those that did not; and the performance of the agricultural sector in terms of income and employment creation was not significant in reducing agricultural land development.

The study recommends that agricultural land protection policies can be better coordinated at a regional level and could be more effective if integrated within state economic development programs. 


\section{ACKNOWLEDGEMENTS}

This dissertation would have never been improved and enhanced to its current state if it were not for the support and encouragement of those who invested their time and energy in it.

I would like first to recognize and appreciate my advisor, Cheryl Brown (PhD), for her critical review, intellectual perspective, constructive criticism, and guidance. Her inputs have greatly improved this dissertation.

I am grateful to my committee members, Timothy T. Phipps (PhD), Tesfa G. Gebremedhin (PhD), Dale Colyer (PhD), and Brian Cushing (PhD) for their critical comments, review of the manuscript, and helpful insights.

I am also grateful to Lisa A. Lewis, Melanie Jimmie, and Ellen Hartley-Smith for their administrative assistance and willingness to help at any time, and to Michael Strager and Jacquelyn Strager for providing me assistance with GIS data.

I am indebted to the Division of Resource Management, Davis College of Agriculture, Forestry, and Consumer Sciences, for providing the research assistantship for my graduate studies both in Agricultural and Resource Economics (M.Sc) and Natural Resource Economics (Ph.D).

Last, but not least, I am thankful to all my friends, colleagues, and family for the moral support.

I thank you all. 


\section{DEDICATION}

This work is dedicated to individuals who have a significant bearing and an important role on my accomplishments. I dedicate this work to Gebremeskel H. Gebremariam, for his efforts that made it possible for me to reach where I am today, Dr. Tesfa G.

Gebremedhin and his family, for the support and encouragement they provided me,

Ahadu T. Tekle, for her support and inspiration, and my family, for their encouragement and lifelong devotion. 


\section{TABLE OF CONTENTS}

Abstract $\quad$ ii

Acknowledgements iii

Dedication $\quad$ iv

List of Tables vii

List of Figures viii

\section{CHAPTER 1: INTRODUCTION}

1.1. Introduction and Problem Statement 1

1.2. Overview of the Study Area 5

1.3. Objective of the Study 10

$\begin{array}{ll}\text { 1.4. Hypotheses } & 10\end{array}$

1.5. Methodology 12

1.6. Organization of the study 13

\section{CHAPTER 2: LITERATURE REVIEW}

2.1. The Economic Meaning of Sprawl on Agricultural Land 14

2.2. Review of Factors Associated with Regional Growth and $\begin{array}{ll}\text { Agricultural Land Development } & 15\end{array}$

2.3. Review of Land Use Modeling Approaches and Findings 19

2.3.1. Geographic Information Systems (GIS) and Remote Sensing 20 Studies

2.3.2. Ordinary Least Squares (OLS) Studies 22

2.3.3. Hedonic and Contingent Valuation (CV) Studies 23

2.3.4. Discrete Choice Studies $\quad 24$

2.3.5. Logit Model Studies 26

2.3.6. Survival, Duration, and Threshold Analysis Studies 27

2.3.7. Dynamic and Dual Profit and Cost Function Studies 29

2.3.8. Urban and Regional Growth Studies $\quad 30$

2.4. Agricultural Land Use Policies in the Northeastern U.S. 31

2.4.1. Tax-based Agricultural Sector Support Programs 34

2.4.2. Economic Support Programs 37

2.4.3. Market Development and Promotion Programs 39

2.4.4. Farmland Protection Programs 42

CHAPTER 3: THE ECONOMIC THEORY OF LAND ALLOCATION, AGRICULTURAL LAND DEVELOPMENT AND RATIONALE FOR PUBLIC SECTOR INTERVENTION

3.1. Microeconomic Foundation of Household Location Demand:

A Mathematical Approach 
3.2. Microeconomic Foundation of Developer's Decision:

A Mathematical Approach $\quad 50$

3.3. Urban Sprawl: Combining Household and Developer Demand for Land 55

3.4. Farmland Externalities, the Efficiency of Land Markets, and

Rationale for Land Market Intervention

CHAPTER 4: EMPIRICAL MODELS AND DESCRIPTION OF DATA

4.1. Growth Equilibrium Model (Model 1) 63

4.2. Spatial Growth Equilibrium Model (Model 2) 71

4.3. Definitions of Data and Statistical Summary 78

\section{CHAPTER 5: EMPIRICAL RESULTS AND NALYSIS}

5.1. Empirical Estimation $\quad 85$

5.2. Analysis of Results: Growth Equilibrium Model 92

5.2.1. Population Density Change 92

5.2.2. Employment Density Change 95

5.2.3. Per Capita Income Change 97

5.2.4. Per Acre Agricultural Land Value Change 99

5.2.5. Agricultural Land Density Change 100

5.2.6. Major Findings of the Growth Equilibrium Model 103

5.3. Analysis of Results: Spatial Growth Equilibrium Model 105

5.3.1. Population Density Change 105

5.3.2. Employment Density Change 108

5.3.3. Per Capita Income Change 111

5.3.4. Per Acre Agricultural Land Value Change 113

5.3.5. Agricultural Land Density Change 117

5.3.6. Major Findings of the Spatial Growth Equilibrium Model 120

5.4. Revisiting Stated Hypotheses 123

\section{CHAPTER 6: SUMMARY AND CONCLUSION}

6.1. Summary and Conclusion $\quad 130$

6.2. Policy Recommendations $\quad 135$

6.3. Limitations and Future Research 137

6.3.1. Limitations 137

6.3.2. Future Research 138

REFERENCES 140

$\begin{array}{ll}\text { APPENDIX } & 148\end{array}$ 


\section{LIST OF TABLES}

Table 1.1. Rank of Northeastern States in Land Allocated to Development

Table 1.2. Agricultural Land Development and Preservation Effort by each Northeastern State

Table 2.1. Estimates of the Value of Preventing Farmland Development

Table 2.2. Tax-Based Farmland Protection Policies in the Northeast

Table 2.3. Economic Viability and Farm Development Policies in the Northeast 37

Table 2.4. Market Development and Promotion Policies in the Northeast

Table 2.5. Farmland Protection Policies Implemented in the Northeast

Table 3.1. Comparative Static Summary for City Size, Housing Price, Land Rent, and Capital-Land Ratio

Table 4.1. Definition and Data Source for Endogenous and Initial Condition Variables

Table 4.2. Definition and Data Source for Agricultural Performance Variables and Farmland Protection Policies

Table 4.3. Definition and Data Source for Employment, Government Taxes and Expenditures, and Local County Characteristics Variables

Table 4.4. Descriptive Statistics - Endogenous and Initial Condition Variables

Table 4.5. Descriptive Statistics - Agricultural Performance Variables and Farmland Protection Policies

Table 4.6. Descriptive Statistics - Employment, Government Taxes and Expenditures, and Local County Characteristics Variables

Table 5.1. Moran's I Statistics for Spatial Autocorrelation

Table 5.2. Growth Equilibrium Model Econometric Estimation Results

Table 5.3. Spatial Growth Equilibrium Model Econometric Estimation Results

Table 5.4. Spatial Growth Equilibrium Model Econometric Estimation Results (continued) 


\section{LIST OF FIGURES}

Figure 1.1. Map of the United States and the Northeastern Geographical Area 6

Figure 1.2. Spatial Distribution of Residential and Recreational Home Development in the Northeast

Figure 4.1. A Market Showing the Impact of Regional Growth on Agricultural Land Development and Value

Figure 5.1. Actual and Predicted Change in Population Density 90

Figure 5.2. Actual and Predicted Change in Employment Density 90

Figure 5.3. Actual and Predicted Change in Per Capita Income 91

Figure 5.4. Actual and Predicted Change in Per Acre Value of Farmland 91

Figure 5.5. Actual and Predicted Change in Agricultural Land Density 92 


\section{CHAPTER 1}

\section{INTRODUCTION}

\subsection{INTRODUCTION AND PROBLEM STATEMENT}

Spatial distribution of economic activity has attracted great interest from economists concerned with industrial location decisions (agglomeration), urban growth, consumer

residential preferences, real estate markets, regional growth, land use change, and natural resource policy. Recent changes in spatial economic structure, accelerated through technology, income growth, investment, and in some cases government policy, have resulted in concerns regarding the interaction between economic activities and natural and environmental resources.

From an economic perspective, the spatial distribution of economic resources (activities) under perfect capital and labor mobility results in long-term convergence in the economic price of resources and may result in an efficient spatial allocation. However, the valuation and allocation of certain resources with fixed spatial distribution and non-market intrinsic attributes poses significant theoretical and empirical challenges in economic analysis. Hence, the interaction of spatially mobile economic activities with spatially fixed resources poses numerous challenges. Agricultural land development falls in this category of analysis.

Proper understanding of development of agricultural land requires a detailed understanding of the economic forces that lead to land allocation for different uses. Theoretically, since land use decisions are typically determined by households, businesses, the government, and foreign trade sectors of the economy, economic forces 
shaping spatial patterns of economic activities have to be linked with the microeconomics of utility and profit motives, as well as government policy and foreign trade shocks to the system.

Development of suburban and rural lands may have a series of benefits as perceived by economic agents. Suburban places may offer a lifestyle that may be characterized as "high quality." In fact, 45 percent of survey respondents in medium and large cities preferred to live in a small town or rural community 30 or more miles away from the cities (Brown et al. 1997). Besides, rural markets may provide relatively cheaper land for single family homes. Rural areas may also provide a quality environment and scenic vistas as well as outdoor recreation opportunities. The value of these rural attributes to households can be estimated using 'willingness-to-pay' methods. Heimlich and Anderson (2001), for instance, estimated the willingness-to-pay of U.S. residents to conserve farmland and open space in rural areas at $\$ 1.4$ to $\$ 26.6$ billion per year. Development may also bring increased opportunities to farmers in terms of off-farm employment and increased demand for local agricultural products along with higher tax income for local government. All these benefits are, of course, valuable to communities and add to welfare benefits associated with development.

Development also brings its own set of negative externalities that are not socially desirable. One known impact of development of suburban and rural areas is the conversion of agricultural land to development uses. The direct effects of the loss of farmland can be measured in terms of output reduction and income losses. However, indirect impacts on the farming communities may include regulatory restrictions on farming practices, technical impacts, and speculative influences. When farmers become 
uncertain about the future viability of agriculture in their area, farmland production falls, as does farming income. Ultimately, the critical mass of farming needed to sustain the local farming economy may collapse (Daniels and Nelson 1986; Daniels 1986; Lapping and Fitzsimmon 1982; Lynch and Carpenter 2003).

Another challenge arises from positive externalities of agricultural land that may not be captured in the market value for land. Recently, attention has focused on preserving local benefits from agricultural land such as open space, environmental quality, and impediments to urban sprawl. Many of these benefits have public characteristics and, as a consequence, will tend to be undersupplied by private producers (Lopez, Shah and Altobello 1994; Plantinga and Miller 2001). In addition, there is value attached to open space, green surroundings, and the peace and serenity some associate with farmland (Bowker and Didychuk 1994; Kline and Wichelns 1996; Ready, Berger and Blomquist 1997; Rosenberger and Loomis 1999; Rosenberger and Walsh 1997). The problem for surrounding communities is that the cash-driven marketplace often does not recognize these amenities (Gardner 1977).

It may be argued that land markets efficiently allocate rural and suburban lands among competing economic uses. Therefore, there is no need for interference with the workings of these land markets. This argument can be challenged from a different perspective. First, it can be argued that when it comes to maintaining adequate agricultural land in the long-run, the market may fail to keep sufficient land in agriculture. Agricultural lands are "multifunctional" in the sense that they not only act as a factor of production in agriculture (to generate profit), for which there is a competitive market to value the resource and its allocation, but they also are a significant source of 
rural livelihood, scenic beauty, and open space benefits that are not necessarily accounted for in the market price. A number of studies (Plantinga and Miller 2001; Irwin and Bockstael 2001; Bowker and Didychuk 1994; Kline and Wichelns 1996; Ready, Berger, and Blomquist 1997; Rosenberger and Loomis 1999; and Rosenberger and Walsh 1997) indicate the non-market benefits of agricultural lands and how the market may fail to internalize these externalities. The existence of these positive externalities associated with agricultural production signals that, from society's perspective, market allocation of agricultural land may not necessarily serve social welfare. Hence, in the long-run, whether the market can keep enough land in agriculture is highly debatable and questionable.

Second, it can be argued on the grounds of irreversible development that land markets may not maintain a socially efficient amount of agricultural land. Resourcebased rural land use change is dynamic, shifting from one use to another as economic factors favor different resource uses at different times. However, urban uses are an absolute use category because the conversion of agricultural land to urban uses is irreversible. Once the land is paved over or built-upon, it is most likely lost forever to agricultural use. The fact that many current land use choices have irreversible effects adds a sense of urgency to this subject (NRCRD 2002).

It is this multifunctionality of land in agriculture that keeps it in the public eye and on many research agendas (Batie 2003; Abler 2004). As a result, most states have initiated some type of land use policy tools to manage the loss of agricultural land and its associated private and public benefits (Nickerson and Hellerstein 2003). 
There are at least two reasons why development proceeds the way it does today, (1) current development continues to be popular because of the short-term benefits households and businesses accrue as opposed to the long-term social costs, and (2) the costs of unmanaged development have not been made explicit to the public (Burchell and Shad 1998). Thus, the ability to understand long-term patterns in land use change is important for policy makers interested in maintaining sustained economic growth as well as a balanced attention to natural resource and environmental management (Bell and Irwin 2002).

In light of these facts, it is important to evaluate the effects of urbanization, income growth, population decentralization, and economic growth upon the development of agricultural land for residential, commercial, and industrial uses. Empirical findings may have important implications for the appropriate institutional (public and private) role in land use and agricultural retention programs (Endicott 1993).

This study uses county level data for the northeastern U.S. to study, among other things, the relationship between growth and agricultural land development.

\subsection{OVERVIEW OF THE STUDY AREA}

The northeastern U.S. is the study area selected to analyze the relationship between growth pressure and agricultural land development. This region is made up of West Virginia, Maryland, Pennsylvania, Delaware, New Jersey, New York, Connecticut, Rhode Island, Massachusetts, Vermont, New Hampshire, Maine, and the District of Colombia. ${ }^{1}$ This Northeast region contains 22 percent of the U.S. population, but it

\footnotetext{
${ }^{1}$ This study uses the Northeastern U.S. states as listed by the Northeast Regional Center for Rural Development (see http://www.cas.nercrd.psu.edu/Toolbox/index.htm).
} 
constitutes only 6.7 percent of the land area. It also contains the largest consolidated metropolitan areas, as well as some of the most rural states in the nation (Goetz 2002). Figure 1.1 highlights the study area.

Figure 1.1. Map of the United States and the Northeastern Geographical Area.

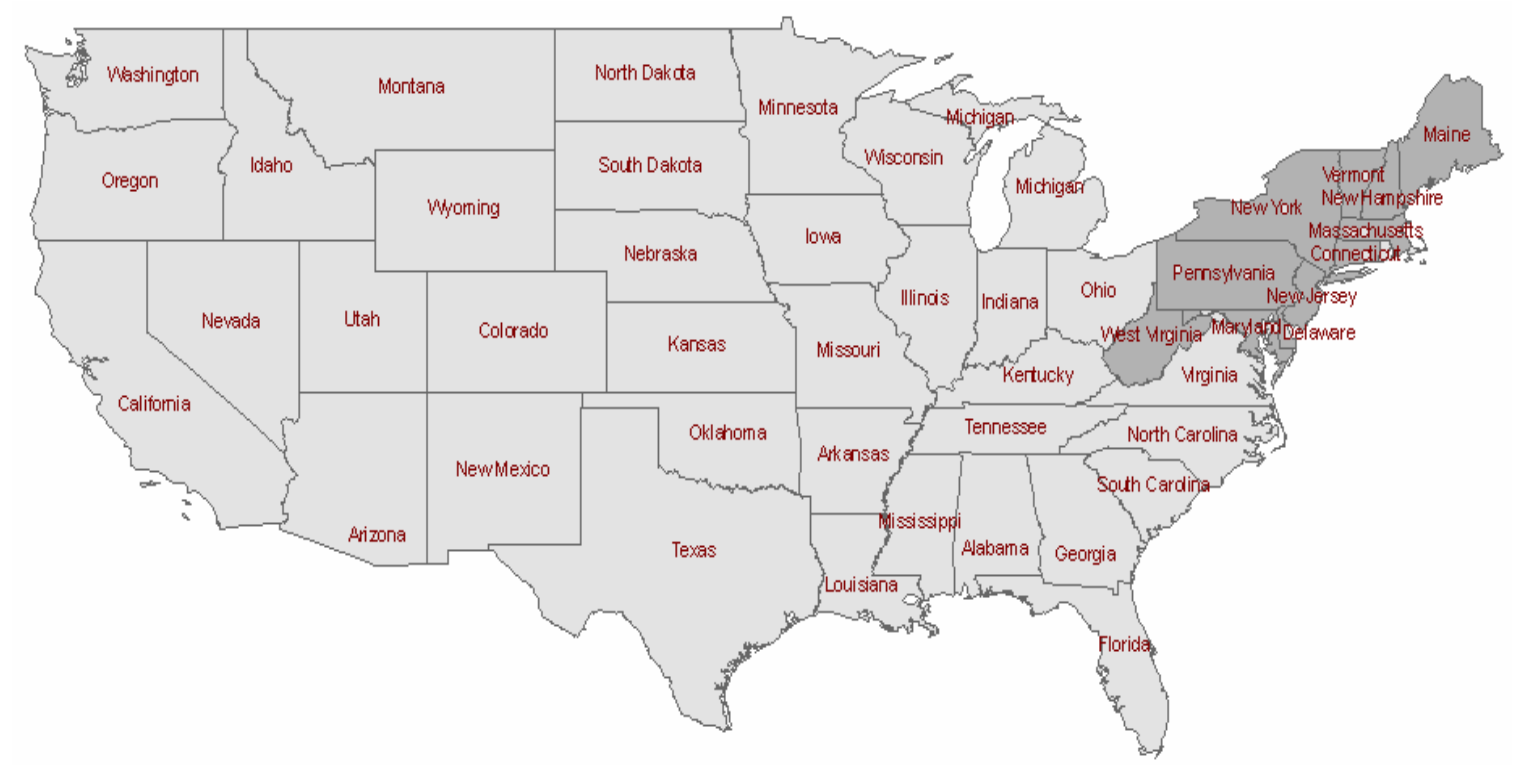

The northeastern region is used for a number of reasons. First, the Northeast has one of the highest land development rates and economic expansion rates in the U.S., while at the same time it has some very rural states. This variability in growth and land development provides heterogeneity in the data from this study area that should enable efficient identification of econometric relationships. Second, this study area also contains significant agricultural activity and agricultural land as a proportion of total county land (refer to Table 4.5 in chapter 4). This enables testing of the relationship between rapidly growing regions and their agricultural land base. Third, the northeastern region of the United States is made up of states with some of the earliest implemented agricultural land preservation policies (Maryland and New York) as well as states with limited or no 
statewide farmland preservation initiatives (West Virginia). This wide spectrum of agricultural land preservation policies provides a policy rich environment under which the effect of these policies on development can be tested. Finally, this study extends a study of farm land development in West Virginia into the Northeast to use regional data to test an already developed model.

In terms of land development, a number of northeastern states rank among the top ten in percentage of developed non-federal lands. Table 1.1 summarizes this information by ranking all states in the country according to their level of developed land. States in the Northeast are in italics. Though the actual developed acreage may vary depending on the size of the state, the percentage of developed land indicates the high level of land development in the northeastern United States compared to the rest of the country.

Table 1.1. Rank of Northeastern States in Land Allocated to Development.

\begin{tabular}{crrr}
\hline Rank & $\begin{array}{r}\text { Acres of Developed } \\
\text { Land in 1997 }\end{array}$ & $\begin{array}{r}\text { Percent Non-federal Land that } \\
\text { was Developed Land in 1997 }\end{array}$ & $\begin{array}{r}\text { Total Acres of Land } \\
\text { Developed, 1992-97 }\end{array}$ \\
\hline 1 & Texas & New Jersey & Texas \\
2 & Rhode Island & Georgia \\
3 & California & Massachusetts & Florida \\
4 & Florida & Connecticut & California \\
5 & Pennsylvania & Puerto Rico & Pennsylvania \\
6 & Georgia & Maryland & North Carolina \\
7 & North Carolina & Delaware & Tennessee \\
8 & Ohio & Florida & Ohio \\
9 & Michigan & Pennsylvania & Michigan \\
10 & New York & Ohio & South Carolina \\
\hline
\end{tabular}

Source: Adapted from http://www.cas.nercrd.psu.edu/morgantown.2002.ppt.

The spatial distribution of the development of land in the northeastern region is crucial for understanding the relationship between development and the stock of farmland. Figure 1.2 provides the spatial distribution of two sources of development pressure on farmland: (1) expansion of cities reducing farmland at suburban locations and 
(2) development of rural lands for recreational housing. As indicated in Figure 1.2, significant development of single-family homes between 1990 and 2000 was concentrated mainly along the eastern coastal counties, particularly in Maryland, Washington D.C., eastern Pennsylvania, Delaware, New Jersey, New York, Massachusetts, and the eastern panhandle of West Virginia. However, significant housing development also occurred in rural counties when measured in terms of recreational homes as a percentage of all homes in 2000. Development of recreational homes is generally concentrated in the western counties of the northeastern region, but is particularly concentrated in New England.

\section{Figure 1.2. Spatial Distribution of Residential and Recreational Home Development in the Northeast.}

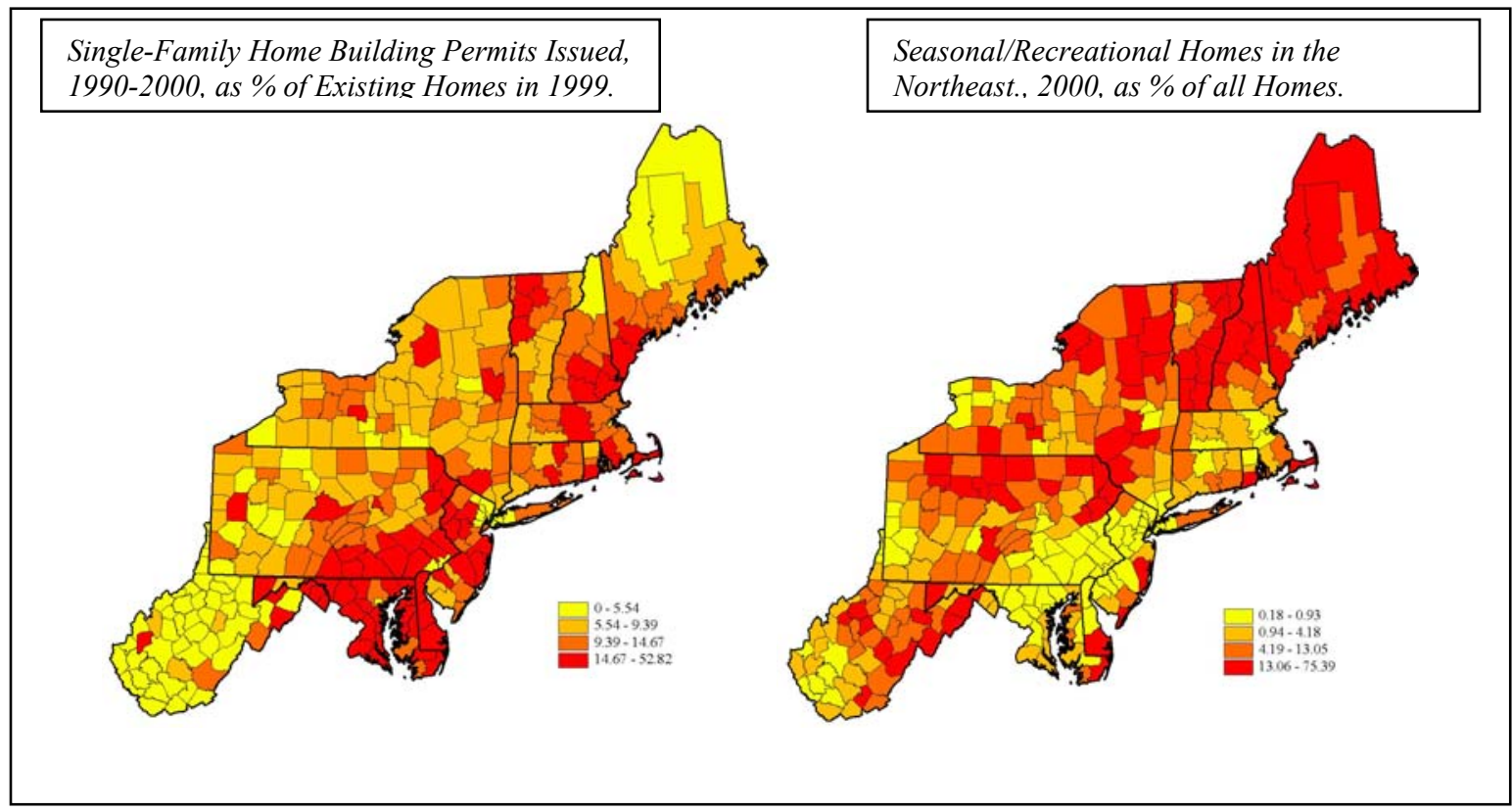

Source: Stephan J. Goetz, Northeast Regional Center for Rural Development, available http://www.cas.nercrd.psu.edu/.

It can be expected that the high level of development in the Northeast may have a negative impact on the stock of agricultural land over time as development may demand 
more flat and less expensive land, like agricultural land, for construction purposes. Table

1.2 reveals the extent of state developed farmland, the extent of agricultural land

preservation activities, and state spending on farmland preservation programs for 2002

and 2003 for the northeastern United States.

Table 1.2. Agricultural Land Development and Preservation Effort by each Northeastern State

\begin{tabular}{lrrrrrrrr}
\hline State & $\begin{array}{r}\text { Dev Ag } \\
\text { Land } \\
\text { (acres) }\end{array}$ & $\begin{array}{r}\text { \% Dev } \\
\text { Ag } \\
\text { Land }\end{array}$ & $\begin{array}{r}\text { Dev } \\
\text { Rate } \\
\text { (acres) }\end{array}$ & $\begin{array}{r}\text { Prime Dev } \\
\text { Ag Land } \\
\text { (acres) }\end{array}$ & $\begin{array}{r}\text { Prot Ag } \\
\text { Land } \\
\text { 2002 }\end{array}$ & $\begin{array}{r}\text { Prot Ag } \\
\text { Land } \\
\text { 2003 }\end{array}$ & $\begin{array}{r}\text { PACE Spending } \\
\text { 2002 (million \$) }\end{array}$ & $\begin{array}{r}\text { PACE Spending } \\
\text { 2003 (million \$) }\end{array}$ \\
\hline NJ & 74,000 & 9 & 14,800 & 43,700 & 87,547 & 100,706 & 256.02 & 310.03 \\
MA & 27,200 & 6 & 5,440 & 10,800 & 50,664 & 52,75 & 126.06 & 135.91 \\
MD & 97,100 & 4 & 19,420 & 37,800 & 247,896 & 275,109 & 518.00 & 566.33 \\
ME & 21,700 & 3 & 4,340 & 4,400 & 2,555 & 2,744 & 1.62 & 0.77 \\
PA & 244,500 & 3 & 48,900 & 96,000 & 239,398 & 273,713 & 500.18 & 602.73 \\
NH & 7,300 & 3 & 1,460 & 1,000 & 9,471 & 9,894 & 11.27 & 13.36 \\
DE & 16,000 & 3 & 3,200 & 12,300 & 65,117 & 70,667 & 69.38 & 74.60 \\
CT & 8,100 & 2 & 1,620 & 4,500 & 28,173 & 28,866 & 82.21 & 84.26 \\
WV & 53,500 & 2 & 10,700 & 11,400 & 0 & 0 & 0.00 & 0.00 \\
RI & 1,000 & 2 & 200 & 900 & 3,719 & 3,983 & 15.02 & 10.79 \\
NY & 132,100 & 2 & 26,420 & 51,800 & 17,181 & 19,164 & 90.45 & 102.48 \\
VT & 4,800 & 0 & 960 & 700 & 96,000 & 100,651 & 50.00 & 38.41 \\
\hline
\end{tabular}

Source: Adopted from National Resource Inventory, USDA and American Farmland Trust Reports available http://www.farmlandinfo.org/agricultural_statistics/index.cfm?function=statistics_view\&stateID=_National.

Note: Dev Ag Land = agricultural land converted to development (acres); \% Dev Ag Land = percentage of agricultural land converted to development; Dev Rate = average annual rate of agricultural land converted to development (acres); Prime Dev Ag Land = Prime agricultural land converted to developed uses (acres); Prot Ag Land 2002 (or 2003) = agricultural land protected by state and local PACE (Purchase of Agricultural Conservation Easements) programs (acres) in 2002 (or 2003 ); and PACE Spending 2002 (or 2003) = funds spent as of 2002 (or 2003) by state and local PACE programs (millions).

Ten of the twelve Northeast states are ranked in the top 15 with respect to agricultural land conversion. This trend has triggered agricultural land protection efforts in many states in the northeastern region. As indicated in Table 1.2, an increasing percentage of farmland in this region is being protected from development pressure through state and local initiatives. However, there is a wide range of farmland protection 
results in the study area. For instance, as of 2002, the state of Maryland has managed to preserve 247,896 acres of farmland while the state of West Virginia has yet to preserve any farmland through state initiatives. In terms of state spending on farmland protection programs, similar disparities among states in the Northeast are observed. For example, Maryland and Pennsylvania have each spent about \$560 million on farmland preservation programs while Maine spent less than $\$ 1$ million on farmland protection activities and West Virginia did not spent anything during the stated period.

\subsection{OBJECTIVE OF THE STUDY}

The overall objective of this study is to analyze the relationship between changes in regional growth and agricultural land use. The specific objectives are:

1. To develop a spatial simultaneous growth equilibrium model that captures the interactions among growth patterns, income changes, land price differentials, and changes in agricultural land density;

2. To empirically test the model using northeastern U.S. data;

3. To determine the relationship between regional growth patterns, spatial income distribution, land price differentials, land use policies, and agricultural land development; and

4. To draw relevant empirical conclusions based on econometric results.

\subsection{HYPOTHESES}

This study attempts to empirically test economic relationships between growth factors and agricultural land development. Following economic theory and rational expectations, 
the following direction of relationships are hypothesized, which are subject to empirical tests using northeastern U.S. data.

Hypothesis \#1: Regional growth, as measured by population and employment density changes and changes in per capita income, increases land development, reducing the amount of farmland.

Hypothesis \#2: A more competitive agricultural sector, as measured by higher income per farm and agriculture's contribution to employment in the county, can limit the loss of farmland to development.

Hypothesis \#3: Regional growth in per capita income can accelerate regional population and employment growth and reduce the stock of farmland.

Hypothesis \#4: Government transfer payments to farmers and state farmland protection programs are effective in reducing agricultural land development.

Hypothesis \#5: Accessibility factors, such as road density, distance from major metropolitan centers, and being adjacent to growing communities, can increase the susceptibility of farmland to development.

Hypothesis \#6: Agricultural land prices play a key role both in determining patterns of regional growth and the extent of agricultural land development.

Hypothesis \#7: Economic, demographic, income, agricultural land price, and agricultural land stock changes in a county are significantly affected by trends in neighboring counties. Hence, spatial distribution of economic activity and spatial land price differentials are important in shaping agricultural land development. 


\subsection{METHODOLOGY}

This study focuses primarily on understanding the relationship between changes in regional growth and agricultural land use by systematically bringing the agricultural land development problem into a regional growth framework. In so doing, it uses an extension of growth equilibrium models that have been applied to study regional economic problems. Departing from previous studies, it applies regional growth equilibrium methods particularly to an agricultural land use change study in a data-rich and heterogeneous regional study area. It also brings into the modeling process particular endogenous variables of interest such as income, land prices, employment and population growth, and agricultural land development to better explain regional agricultural land development trends.

To capture the impact of inter-temporal changes in employment density, population density, income, and farmland prices on agricultural land, a growth equilibrium model is introduced. Growth equilibrium models were developed to simultaneously explain employment and population changes for a region. These types of models capture the direct and indirect linkages between population and employment migration patterns and other exogenous factors important in explaining these patterns. This study builds on growth equilibrium models by developing a system of equations model that integrates per capita income, agricultural land use, and farmland price change equations into the growth equilibrium system. This enables a study of the impact of growth and resource price changes on agricultural land development.

This study departs from and adds to the existing literature on growth equilibrium models by integrating income, land price, and agricultural land stock changes into the 
basic growth equilibrium model. Furthermore, it develops the modeling process by integrating spatial considerations. Land use change is a dynamic process and has distinct

spatial patterns. As such, effective modeling of the problem calls for proper integration of spatial econometrics.

\subsection{ORGANIZATION OF THE STUDY}

This study is comprised four additional chapters. Chapter 2 provides an extensive review of literature in agricultural land development and appropriate modeling approaches. Chapter 3 provides the theoretical foundation for modeling agricultural land development decisions and a theoretical explanation for expansion of urban areas onto farmland. Chapter 4 discusses specification of the empirical model and of the nature and sources of data. Chapter 5 provides analysis of results from model estimation and a summary of the major findings of the study and implications for agricultural land protection. Finally, Chapter 6 provides a summary, conclusions, and recommendations for policy measures to improve land use management. 


\section{CHAPTER 2}

\section{LITERATURE REVIEW}

\subsection{THE ECONOMIC MEANING OF SPRAWL ON AGRICULTURAL LAND}

A starting point to understanding the issues related to sprawl requires putting the definition of sprawl on agricultural land into some perspective. Sprawl has been defined in different ways by different people. Some refer to sprawl as a low-density development that consumes unnecessarily large tracts of agricultural land. Others view it as a geographic separation of work, home, shopping and school areas. Or sprawl can be seen as a phenomenon that is increasingly dependent on automobile use.

A reflection of the difficulty of arriving at a comprehensive and proper definition and scope for sprawl is evidenced in the U.S. House of Representatives' description of sprawl from 1980: "when you can not tell where the country ends and a community begins, that is sprawl. Small towns sprawl, suburbs sprawl, big cities sprawl, and metropolitan areas stretch into giant megalopolises, formless webs of urban development like Swiss cheese with more holes than cheese" (as quoted in Heimlich and Anderson 2001, p. 9).

Indeed, there is some element of the aforementioned definitions in sprawl. Sprawl does consume patches of unplanned land, as it creates low density development and dependence on automobiles. Integrating these attributes of sprawl, the Pennsylvania $21^{\text {st }}$ Century Environmental Commission defines sprawl as a spreading, low-density, automobile dependent development pattern of residential and business development that unnecessarily wastes land. 
From an economic perspective, it is not the transfer of land per se from one economic activity to another that matters, but the efficiency of markets for doing so and the extent to which such reallocation of land takes social welfare into account. The transfer of a parcel of land from housing to an office building, for instance, may not cause concern from a social perspective as there are only limited positive externalities lost in this land allocation process and the land market captures well the opportunity costs associated with this reallocation. However, with the development of farmland for nonagricultural uses, the non-market attributes associated with farmland are often undercompensated for in the land market, and hence, such a reallocation may not improve social welfare. Thus, the economic perception of farmland development or sprawl is not necessarily in the physical transfer of land from one economic activity to the other, but rather in the efficiency of markets to compensate for environmental or other amenity services which society loses when farmland is developed. Based on this perspective, sprawl can be understood as an unordered process of development of rural and suburban socially-undervalued land for non-agricultural uses that may result in a reduced flow of services to society. This gives a general economic framework within which characteristics and implications of agricultural land development can be discussed.

\subsection{REVIEW OF FACTORS ASSOCIATED WITH REGIONAL GROWTH AND AGRICULTURAL LAND DEVELOPMENT}

The development of agricultural land for non-agricultural uses is a complex process that involves the interaction of an array of factors. On the suburban and rural side, the farmer's decision to sell a farm for development may be motivated, among other things, by farm income, government transfer payments, local land use policy, and rural land 
market speculation. On the urban and suburban developer's side, a growing demand for urban expansion and desire to maximize profit may provide incentives for farmland development. From the point of view of the public, the decisions of farmers and urban and suburban land developers may not result in efficient land allocation and thus motivate a call for policy intervention.

Though the factors associated with farmland development vary spatially, there are some common development pressures that are discussed in the literature. Several studies have modeled the interaction between growth and changes in rural and suburban agricultural land use (Brueckner and Fansler 1983; Mieszkowski and Mills 1993). However, the scope of these studies is different. Frey (1993), for instance, argues that the rate at which small towns develop depends in part on global and regional restructuring which affect the spatial organization of production processes and suburbanization. Other studies have focused on regional and local growth patterns determined by "rural renaissance" and "urban flight", a shifting economic base, and a change in employment opportunities (Dissart and Deller 2000; Power 1996; Lewis, Hunt and Plantinga 2002).

Despite the scope of these studies, many agree that urban "push factors" and rural and suburban "pull factors" determine the spatial patterns of development and hence agricultural land use change. The urban "push factors" are negative amenities associated with urban life that motivate suburban migration. Fiscal and social problems associated with central cities: high taxes, low quality public schools and other government services, crime, congestion and low environmental quality are expected to lead residents to migrate to suburban places (Mieszkowski and Mills 1993). Kusmin (1994) and Wasylenko (1991) also argue for the adverse effect of high taxes on economic growth of communities. 
Public investment in transportation technologies and improved access, which have significantly affected transportation costs for producers and commuting cost for households, affects the spatial equilibrium of location decisions. Studies show that investment in highways and transportation facilities increases local economic growth and productivity (Chandra and Thompson 2000; Keeler and Ying 1988; Garcia-Mila and McGuire 1992). Greater interstate highway density is also associated with higher levels of manufacturing and other sector employment (Carlino and Mills 1987). Thus, investment in better access will ultimately affect the spatial organization of economic activity and resulting land use changes.

Following location equilibrium theory, it can be argued that rising per capita income is also associated with growth of communities if it leads to shifts in the demand for location-specific amenities. Since changes in consumption of location-specific amenities can only be possible through relocation (Knapp and Graves 1989), in the longrun, these changing demands may lead to migration to more desirable locations (Graves 1983).

Reinforcing the urban flight (sprawl) process, the rural environment, including agricultural land, provides scenic views, recreational opportunities, and other non-market environmental benefits that attract new development (Irwin and Bockstael 2001; Bowker and Didychuk 1994; Kline and Wichelns 1996; Ready, Berger, and Blomquist 1997; Rosenberger and Loomis 1999; Rosenberger and Walsh 1997, Dissart and Deller 2000). These rural qualities and endowments (pull factors) affect urban migration decisions, as households are drawn to areas with higher quality of life or amenity factors (Dissart and Deller 2000). A 1988 survey reinforces this argument by indicating that 70 percent of 
Americans preferred a rural or small town setting which is within 30 or more miles of a city with population over 50,000 (Fuguitt and Brown 1990).

Deller et al. (2001) argue that in addition to local characteristics like taxes and income, a significant relationship between amenities, quality of life, and local economic performance exists. Similarly, Gottlieb (1994), English et al. (2000), Roback (1988), and Henry et al. (1999) indicate that the inclusion of amenity factors in explaining regional growth differences appears powerful.

Following Peterson and Vrooman (1992), economic growth may be defined as the "sustenance" of income, employment, and population of a community or geographic area. The sources of suburban and rural growth that determine inter-temporal land use change are numerous and may well extend to factors other than the ones already discussed. Aldrich and Kusmin (1997), for instance, briefly discussed determinants of suburban and rural growth to include variables such as taxation, public spending, the unemployment rate, urbanization, minority population concentration, and local fire protection rates; Bell and Irwin (2002) mention spatial factors like proximity to employment and other activities, natural features, surrounding land use patterns, and land use policies that may affect the pattern of land use change. However, the major sources of development of suburban and rural agricultural land may be aggregated into forces of population growth, household formation, income growth (Heimlich and Anderson 2001), and employment growth, which in turn are affected by the above mentioned socio-economic variables. 


\subsection{REVIEW OF LAND USE MODELING APPROACHES AND FINDINGS}

The study of agricultural land use change and early land use patterns has led to numerous theoretical and empirical works to explain and predict land use change. In fact, the study of land use in economics can be traced to periods as early as Cantilon's, whose work demonstrated that land use allocation depends on the return different activities are expected to bring to the use of that land (Cantilon 1755). The works of Ricardo and Von Thunen are also fundamental early contributions. However, the proper theoretical analysis and utilitarian based mathematical construction of land use patterns emerged in more recent works such as Alonso (1964).

Following microeconomic behavioral assumptions, Alonso (1964) demonstrated that the utility of households depends on housing characteristics, distance from the city, and all other possible consumption goods. To maximize utility, the consumer allocates his/her budget among these choices with various trade-offs. Alonso then demonstrates that there is an inverse relationship between land rents and distance from the center of the city. With perfect information, households will achieve a location equilibrium that maximizes their utility based on their income, commuting costs, and land rents at different locations. To achieve a location equilibrium that maximizes utility, consumers will bid based on their income and strength of preference for a location. The distribution of land to different activities will be determined by land owners who allocate land to the highest bidders, and the process continues in the land market by allocating lower rent lands towards the city edges. This early work of Alonso is further extended by the works of Muth (1969), Mills (1972) and Wheaton (1974) which provide in-depth theoretical and mathematical bases for framing land use theory in an economic perspective. 
Based on early theoretical advances, a number of empirical land use change studies have been conducted by employing different methodologies and econometric techniques. The following section reviews econometric methodologies used and results derived from land use studies.

\subsubsection{Geographic Information Systems (GIS) and Remote Sensing Studies}

One recently developed and commonly applied methodology in land use studies uses Geographic Information Systems (GIS). The development of GIS enabled extensive spatial analysis of land cover, and a significant number of studies of land use change have employed this technique. GIS is a powerful tool for understanding spatial relationships and conducting spatial-dependence analysis. Though many of these studies do not rely on econometric procedures, imagery spatial analysis is used to show trends regarding land use change and to predict future land use patterns.

Allen, Lu, and Potts (1999) used GIS to investigate the impact of tourism development and associated commercial and residential development on coastal land use changes in Murrells Inlet, South Carolina. This GIS-based methodology allowed the authors to predict coastal land use change due to development. Their study indicated that primary roads, commercial clusters, commercial zoning, and land availability were significant predictors of commercial land use. They concluded that beachfront, an open view, residential zoning, land availability, primary roads, and commercial centers were predictors of residential development.

Similarly, Hunter et al. (2003) used GIS analysis and integrated remote sensing imagery with demographic, economic, and biophysical data to examine the implications 
of land use patterns as related to population and development within the context of the California Mojave Desert ecosystem. The study examined the land requirements for varying levels of population growth and density, as well as the natural habitat implications of those requirements. Spatial and statistical models were developed to identify possible alternative land use 'futures'. Based on the spatial analysis, their results indicated that high density development could reduce by over 80 percent a conflict with regions providing potential habitat for threatened species.

Seto and Kaufmann (2003) analyzed the socioeconomic drivers of urban land use change in the Pearl River Delta of China by combining high resolution remote sensing data with economic and demographic factors. Their study concluded that urban expansion is associated with foreign direct investment and the relative rates of productivity generated by land associated with agricultural and urban uses. They suggested that large scale investments in industrial development rather than local land users play the major role in urban land conversion in their study area.

Vesterby and Heimlich (1991) investigated the relationship between demographic change and resulting land use changes by using aerial photographic data. Land use change related to population and household growth was studied from the early 1970s and 1980s and compared to results of a similar study of the 1960s. The authors concluded that less populated counties and counties experiencing rapid growth used more than an acre of urban land per added household, while more populous counties and counties growing more slowly had marginal land consumption of only one-third to one-half acre. 


\subsubsection{Ordinary Least Squares (OLS) Studies}

Ordinary Least Squares (OLS) econometric techniques are widely used to test different hypotheses in land use studies. The simplicity and parsimonious nature of OLS techniques have attracted a wide array of applications for land use analysis. The advantage of this econometric modeling approach is that statistically testable theories can be analyzed with relative ease and relevant policy information can be generated.

Vaillancourt and Monty (1985) examined the impact of zoning on the price of farmland using an OLS model for Quebec, Canada. The value of the natural logarithm of the deflated price of an acre of land was explained by the natural log of lot size, linear distance to Montreal, and dummy variables for water service, neighborhood quality and zoning. The authors used a transcendental function due to a nonlinear relationship between the price per acre of land and lot size. Among other conclusions, their study indicated that zoning is negatively and significantly related with land price per acre.

Shi, Phipps, and Colyer (1997) employed a gravity based OLS model to test the influence of urbanization on agricultural land values using West Virginia data. Farmland values were regressed on expected net real returns to land, expected real capital gains, urban influence potential, the real interest rate, and other variables. The study concluded that both farm income and urban influences have been important factors affecting the value of farmland in West Virginia.

Henneberry and Barrows (1990) used OLS to test the hypothesis that the price effect of exclusive agricultural zoning varies with the characteristics of a parcel subject to the regulations, using data from Rock County, Wisconsin. Sales price per acre was estimated as a function of total acres per parcel, value of any building, miles to nearest 
cities, population change, miles to nearest commercial area, and land characteristics for cropland. Their results indicated that land price varied directly with proportion of quality land and inversely with parcel size.

\subsubsection{Hedonic and Contingent Valuation (CV) Studies}

Other commonly applied methodologies for the study of land use change and land use amenity estimation include hedonic and contingent valuation (CV) approaches. These approaches are aimed primarily at measuring the non-market attributes of farmland that may not be directly measured using market data. By employing techniques from environmental economics, these studies use hedonic estimation to approximate the value of non-market attributes of land, based on market price information and data on spatially varying attributes of property sold in a market (Vitaliano and Hill 1994; Irwin 2002). Contingent valuation methods are used to measure the value associated with a given land use pattern by eliciting the willingness to pay for preserving land in a given use, particularly in agriculture. Numerous studies have modeled the land use development decision using contingent valuation techniques (Zollinger 1998; Smith and Krannich 2000; Inman, McLeod, and Menkhaus 2002). These studies employ hypothetical scenarios to elicit consumer values regarding those scenarios, providing information on consumers' willingness to pay or accept compensation for a land use change.

Ready, Berger, and Blomquist (1997) estimated the amenity value to Kentucky residents from horse-farm land development. The authors used both contingent valuation and hedonic pricing approaches to compare residents' value for preserving land in horse farms. The results, from a value function estimated from dichotomous choice $\mathrm{CV}$ 
responses, showed that the value of a change in the level of the horse-farm amenity was sensitive to the size of the change. The willingness-to-pay to avoid a decrease of one farm was $\$ 0.43$. The contingent valuation estimate was $\$ 0.49$. The authors argued that the difference is the non-use value for the resource.

Irwin and Bockstael (2001) estimated open space spillovers using a hedonic pricing model with residential property sales and offered an explanation as to why the positive amenity value of open space may not always be empirically detected. The authors' model tested whether valuation of open space amenities is hampered by the fact that a parcel's land use is in part determined by its residential value. Their study revealed that OLS estimation biases downwards the estimated marginal value of open space. The authors recommended that instrumental variable estimation techniques be used to test for the existence of spillover effects from residential property values.

Nickerson and Lynch (2001) applied hedonic equations to test the effect of development restrictions imposed by permanent farmland protection easements on farmland prices using Maryland data. They found that there is little statistical evidence that voluntary permanent preservation programs significantly decrease the price of farmland in Maryland.

\subsubsection{Discrete Choice Studies}

Land use studies aimed at identifying the probability associated with particular land use policy preferences increasingly rely on discrete choice models. One study, which focused on agent-based decision modeling of land use change, utilized discrete choice models 
(Plantinga and Miller 1997). These types of models help to understand the underlying factors associated with land development decisions.

Johnson et al. (2003) examined the relationship between the rural public's support for land management and conservation policies using a discrete choice approach. Preferences were considered within the context of alternative proposals to manage residential growth and preserve landscape attributes in southern New England. Stated preferences were estimated from a multi-attribute choice survey of rural residents, and a Likert-scale assessment of strength of support for 21 growth management and preservation policy tools. A discrete choice model of land use preferences was developed and tested using survey data. The major finding of their study was that preferences for management outcomes are sometimes correlated with support for associated policy tools.

Claassen and Tegene (1999) analyzed the choice between crop production and pasture in the Corn Belt region of Iowa using a discrete choice probability model of land allocation. Their results indicated that Corn Belt land owners appear to be less inclined to remove land from crop production than to convert land to crop production from land that was not eligible for the Conservation Reserve Program (CRP). CRP eligibility significantly increased the probability of removing land from crop production.

McLeod, Woirhaye, and Menkhaus (1999) analyzed the factors influencing support for rural land use control using a discrete choice voting model for Sublette County, Wyoming. The primary focus of this study was to determine respondent characteristics which contribute to the support for land use controls, including zoning, cluster development, and purchase of development rights. Survey data was collected concerning preferences for private land use and land use controls. Following public 
choice theory, a discrete choice voting model was introduced as a function of private and public voting interests to identify what type of public policies the individual is likely to support. A logit equation was estimated. The primary finding of this study was that individual demographic characteristics are important factors in determining voting for a particular land use policy.

Roe, Irwin, and Morrow-Jones (2004) similarly developed a choice-based conjoint model to analyze the effects of farmland policies and farmland amenities on housing values and residential growth. The authors noted that the public's increased demand for farmland preservation coincided with the expansion of urban areas into a once agriculture-dominated landscape. Using stated preference data from a choice-based conjoint analysis survey, willingness-to-pay (WTP) was estimated for the presence of neighboring land that is dedicated to agricultural use versus a developed land use. Estimates provided information on the extent to which households would pay a premium for living near farms and preserved farmland. The expression derived for compensating variation was used to estimate an individual's WTP. This study indicated that respondents prefer shorter commutes, more surrounding agricultural land and local parks, better schools and a higher safety rating in terms of police and fire protection.

\subsubsection{Logit Model Studies}

Inman, McLeod, and Menkhaus (2002) explored preferences for use and sale of agricultural land in Subtle County, Wyoming. The study compared land use preferences with expected external conditions to ascertain which type of agricultural land is more likely to be developed. A logistic regression of land use preference was used to determine 
the likely characteristics that may lead to a particular land development decision. The results indicated that well-established residents prefer recreational use of remote landscapes, and wealthier and part-time residents were more likely to prefer residential use of farmland.

McMillen (1989) studied urban fringe land use patterns. The study used an empirical model of land use in an urban fringe area of Chicago to predict land use change. Three land uses, agricultural, residential and vacant, were considered. A multinomial logit model was estimated to determine the probability that a property was in a given use at the time of sale. The study concluded that a pattern of decentralized residential development is observed, and distance from nearby towns does not have a significant effect on the probability that land is in residential use.

\subsubsection{Survival, Duration, and Threshold Analysis Studies}

Other studies of land use are concerned with the timing of development of farmland. These studies employ different econometric techniques, including survival analysis, where a continuous probability density function is estimated based on other explanatory variables. The results of these models show the rate of land development at different times given certain conditions. Duration models and threshold analysis models are also common (Irwin and Bockstael 2001).

Irwin, Bell, and Geoghegan (2003) observed that as many local and state governments in the United States face increasing growth pressures, the need to understand the economic and institutional factors underlying these pressures has increased. The authors argue that individual land use decisions play a crucial role in the 
manifestation of growth pressures. A microeconomic model of land conversion decisions for residential land use change at the rural-urban fringe was developed using parcel level data from Calvert County, Maryland. They estimated a probabilistic model of residential land use change using a duration model, and the parameter estimates were employed to simulate possible future growth under alternative scenarios of growth management. They found that smart growth objectives are best met when policies aimed at limiting growth in target areas are implemented side by side with policies designed to preserve rural land or open space.

Hite, Sohngen, and Templeton (2003) similarly analyzed zoning, development timing, and agricultural land use patterns at the suburban fringe using parcel level data for Delaware County, Ohio. The study used competing risk survival analysis to investigate tax and zoning policy impacts on residential, commercial and industrial development timing. They assumed that the landowner's objective is to maximize the value of land at time zero by choosing the date of development using a given value function. Parametric and nonparametric survival models were estimated and suggest that higher taxes slow down development, and commercial development follows residential development. The results further stressed that taxes have more impact than zoning policies on development timing.

Lynch and Carpenter (2003) developed an econometric model to test for the existence of critical mass in the farming sector. The authors suggested that ongoing farmland loss has led county planners to ask if there is a critical mass of farmland needed to retain a viable agricultural sector. To determine the existence of a threshold, differences in the rate of farmland loss for counties with varying levels of farmland 
acreage over time were identified and analyzed. Rate of farmland loss was modeled as a function of the number of productive agricultural acres, the net return to agricultural uses, the net value in residential use, the existence of agricultural preservation policies, and possible off farm income opportunities. A random effect econometric model was estimated and the authors concluded that some evidence of a critical mass exists for the study area. However, the scale of agricultural activity in the latter part of the study period did not impact the rate of farmland loss.

\subsubsection{Dynamic and Dual Profit and Cost Function Studies}

A group of other land use studies relies on methodologies that are directly related to farm production economics, farm level resource decisions, farm adaptation to development, and the relationship of these factors to farmland development. In these studies, dynamic models of profit and cost, dual profit functions, and farm adaptation models are widely used. The aim of these studies is to understand farmers' responses to development pressure through production adjustments, market assimilation, and farmland development decisions.

Crihfield (1994), for instance, developed a dynamic land use model to understand the conditions under which farmers allocate their farmland to agricultural production or convert it to mining development in Iowa. The author noted that not all landowners share a desire to cultivate crops or raise livestock; some would rather sell their land to mining companies. By assuming that there are two alternative uses for land - farming and mining - the land owner maximizes the present value of land in mining and land in farming. By constructing a dynamic model, the first order conditions identify the opportunity costs of 
land put in any activity. The results indicate that under circumstances where future coal prices are expected to rise, speculation would drive more land into mining.

Lopez, Adelaja and Andrews (1988) developed a model to capture the effects of suburbanization on agricultural sector adaptation. The study analyzed the effects of suburban population density and land speculation on agricultural production choices, prices, and profits. A dual profit function model and a system of reduced-form price equations were used to estimate the effects of suburbanization on agricultural adaptation in New Jersey. The results of their study indicate that vegetable production is the only agricultural sub-sector to benefit from suburbanization, while livestock is the most adversely affected. The authors further concluded that suburbanization reduces responsiveness to agricultural prices and discourages capital and land use.

\subsubsection{Urban and Regional Growth Studies}

A limited number of agricultural land development studies focus on modeling agricultural land development problems from a regional perspective by identifying regional growth patterns. Most of the methodical approaches discussed above are conducted using local or state level data with limited internalization of regional growth impacts on farmland development. A small number of studies, however, tried to model farmland development from a regional growth approach aimed at understanding the relationship between trends in regional growth and the associated demand for development of agricultural land.

Hailu and Rosenberger (2004) used a growth equilibrium model to capture the effect of growth on agricultural lands in West Virginia. A system of equations model 
designed to measure the interaction between intertemporal changes in population, employment, and agricultural land densities was developed. The model was applied to county level West Virginia data for the period 1990-1999. Consistent with previous findings, this study concluded that counties with better farm sector performance saw less pressure from development, and more land use change occurred in bedroom communities.

Wu, Adams, and Plantinga (2004) developed an urban equilibrium model to estimate the effects of open space and other amenities on housing prices and development density in Portland, Oregon. The model includes households' residential choices and developers' decisions. Housing price, household density, and house size endogenous variables are estimated using a set of instrumental variables. The results of this study suggest that households are more willing to pay for houses located in lower density areas, near more open space, with less traffic congestion, better views, and near amenity locations.

\subsection{AGRICULTURAL LAND USE POLICIES IN THE NORTHEASTERN U. S.}

The northeastern United States is a region with some of the oldest agricultural land preservation programs in the nation. With increasing development pressure on agricultural land in this region, local, county, and state level farmland protection policies have been enacted and implemented. This section reviews a wide range of agricultural land preservation and agricultural sector viability enhancement policies and their implementation in the Northeast. 
The motivation for enacting and implementing land preservation policies and "smart growth" programs is rooted in a myriad of economic and socio-political reasons. Generally, from an economic perspective, the justification for farmland protection initiatives radiates from the failure of rural land markets to correctly signal the social value of farmland. The agricultural sector provides direct benefits (agricultural commodities, income opportunities, tax revenue, and so on) that have direct market value, but also indirect benefits (air quality, open space, landscape beauty, and other environmental and recreational benefits) which may not have markets associated with them. Hence, market values do not correctly reflect agricultural land's true social values or opportunity costs.

It is difficult to exclude people from consuming the positive externalities associated with agricultural land, thus reducing the potential for the creation of markets. However, the rational decision to locate in natural amenity areas to benefit from open space and environmental quality will collectively lead to the eventual diminishing of those qualities that triggered the decision in the first place. This is a result of the lack of markets reflecting the true value of those environmental qualities and open space benefits giving a wrong signal to decision makers. Heimlich and Anderson (2001) observed that if the value of these amenities were included, housing costs would be much higher and the demand lower than it is now. Developers in this case have no incentive to inform housing customers who value environmental benefits and rural amenities that there is likely to be further development. This process, if unchecked, may raise public interest in farmland preservation programs to protect rural and suburban land from the pressure of development. 
The support of suburban and rural communities for state and local level farmland protection programs is reflected in their willingness-to-pay for preserving a given level of farmland from development. A number of studies in the Untied States have documented the public's willingness-to-pay to preserve farmland. Table 2.1, for instance, summarizes some of these studies compiled by the Economic Research Service, USDA (2001). The results of these studies indicate the value society attaches to the non-market benefits of farmland, which provide the economic rational for agricultural land preservation policies.

Table 2.1. Estimates of the Value of Preventing Farmland Development.

\begin{tabular}{|c|c|c|c|}
\hline Study by & Geographic Area & Valuation to prevent: & $\begin{array}{l}\text { Annual value per } 1,000 \\
\text { acres per household in } \\
2000 \text { constant dollars }\end{array}$ \\
\hline Halstead 1984 & Massachusetts & $\begin{array}{l}\text { Development of } \\
\text { farmland }\end{array}$ & $\$ 17.82-\$ 49.80$ \\
\hline Bergstrom et al. 1985 & South Carolina & $\begin{array}{l}\text { Development of } \\
\text { farmland }\end{array}$ & $\$ 0.21-\$ 0.54$ \\
\hline Beasley et al. 1986 & Alaska & $\begin{array}{l}\text { Development of } \\
\text { farmland }\end{array}$ & $\$ 17.56$ \\
\hline $\begin{array}{l}\text { Bowker and Didychuk } \\
1994\end{array}$ & $\begin{array}{c}\text { New Brunswick, } \\
\text { Canada }\end{array}$ & $\begin{array}{l}\text { Development of } \\
\text { farmland }\end{array}$ & $\$ 1.08-\$ 2.45$ \\
\hline $\begin{array}{l}\text { Ready, Berger and } \\
\text { Blomquist } 1997\end{array}$ & Kentucky & $\begin{array}{l}\text { Development of } \\
\text { horse farm }\end{array}$ & $\$ 4.34-\$ 4.94$ \\
\hline Krieger 1999 & Illinois & $\begin{array}{l}\text { Development of } \\
\text { farmland }\end{array}$ & $\$ 2.93$ \\
\hline
\end{tabular}

Source: Economic Research Service, USDA. "Development at the Urban Fringe and Beyond” AER-803.

Note: All value estimates are determined using the contingent valuation method except for the study of Ready, Berger, and Blomquist (1997) which used hedonic property value estimation.

States in the northeastern United States have implemented a broad range of farmland protection and farm sector viability policies in the face of development 
pressure. The policies can generally be categorized into four broad classes, tax policies to support the agricultural sector's financial viability, economic support programs that provide loans, technical assistance, and technology support to farms, market development programs that promote state-grown agricultural products, market support, and foreign trade assistance, and farmland protection programs that are aimed at preserving agricultural land in its current use.

\subsubsection{Tax-based Agricultural Sector Support Programs}

With development pressure, the value of land increases. This rise in land value raises property taxes, and thus the tax burden on agriculture. To counteract this, assessing agricultural land based on its use for agriculture rather than for development lowers the property taxes on farms. Tax based agricultural support programs thus focus on lowering agricultural taxes to improve the sector's viability in the face of development pressure. Tax policies are also used to provide incentives for farmers to participate in farmland preservation programs. Table 2.2 provides a list of tax-based agricultural support policies in the northeastern United States and states which have implemented policies. The various policies are described below.

Differential or Use-Value Property Tax Assessment: These programs reduce farmers' property taxes by changing the criteria under which local governments assess the value of farmland. The value of agricultural land is assessed based on its value in agriculture instead of its value for development. For instance, farmers in Delaware do not pay property taxes on undeveloped farmland. Rhode Island passed a law in 2002 that gave towns a choice to exempt farmland from property taxes, and New York allows a farm's first 250 acres of productive farmland to be exempt from the school portion of 
property taxes; above 250 acres there is a $50 \%$ exemption on a farmer's acreage

(NSAWG 2003).

Table 2.2. Tax-Based Farmland Protection Policies in the Northeast.

\begin{tabular}{|c|c|c|c|c|c|c|c|}
\hline \multirow[t]{2}{*}{ State } & \multicolumn{4}{|c|}{ Property Tax Policies } & \multicolumn{3}{|c|}{ Other Tax Policies } \\
\hline & $\begin{array}{c}\text { Differential/Use } \\
\text { Value Property } \\
\text { Tax } \\
\text { Assessment } \\
1\end{array}$ & $\begin{array}{l}\text { Circuit } \\
\text { Breaker }\end{array}$ & $\begin{array}{c}\text { Property Tax } \\
\text { Exemption on } \\
\text { Farm } \\
\text { Machinery } \\
1\end{array}$ & $\begin{array}{c}\text { Property Tax } \\
\text { Exemption on } \\
\text { Farm } \\
\text { Buildings } \\
0\end{array}$ & $\begin{array}{c}\text { Sales Tax } \\
\text { Exemption on } \\
\text { Farm Equipment } \\
\text { and Supplies } \\
1\end{array}$ & $\begin{array}{c}\text { Tax Incentives for } \\
\text { Donation of } \\
\text { Farmland Protection } \\
\text { Easements } \\
1\end{array}$ & $\begin{array}{c}\text { Other Tax } \\
\text { Laws that } \\
\text { Help } \\
\text { Agriculture } \\
0\end{array}$ \\
\hline $\mathrm{DE}$ & 1 & 0 & 1 & 0 & 1 & 1 & 1 \\
\hline ME & 1 & 0 & 1 & 0 & 1 & 1 & 1 \\
\hline MD & 1 & 0 & 1 & 0 & 0 & 0 & 1 \\
\hline MA & 1 & 0 & 0 & 0 & 0 & 0 & 0 \\
\hline $\mathrm{NH}$ & 1 & 0 & 1 & 1 & 1 & 0 & 0 \\
\hline NJ & 1 & 0 & 0 & 1 & 1 & 0 & 0 \\
\hline NY & 1 & 1 & 0 & 1 & 1 & 0 & 1 \\
\hline PA & 1 & 0 & 0 & 0 & 1 & 0 & 0 \\
\hline RI & 1 & 0 & 1 & 1 & 1 & 0 & 0 \\
\hline VT & 1 & 1 & 1 & 1 & 1 & 1 & 1 \\
\hline WV & 1 & 0 & 1 & 0 & 1 & 1 & 0 \\
\hline
\end{tabular}

Source: Adapted from "Agricultural Policy in the Northeast States: Inventory and Innovation," Northeast Sustainable Agriculture Working Group, 2003.

Note: A one means the state has the policy, zero otherwise.

Circuit Breaker Laws: These laws are aimed at reducing farmers' taxes by offsetting their property taxes with tax credits funded by the state government. They are usually applicable when a farmer's property taxes exceed a certain percentage of his/her income. This program is not widely implemented in the Northeast. It is currently only in New York and Vermont.

Property Tax Exemption on Farm Machinery and Farm Buildings: This program provides property tax exemptions for farm machinery and livestock and tax exemptions or breaks for farm buildings. In Massachusetts, people who claim farming as their 
principle occupation pay a lower tax rate on their farm machinery and livestock. Maine also provides exemptions, but they are limited to machinery used for hay and field crops, with an exemption ceiling of $\$ 10,000$. New York provides farmers with a ten-year property tax exemption on a new or remodeled agricultural building. Rhode Island passed legislation that allows communities to tax farm buildings according to the services they provide (NSAWG 2003).

Sales Tax Exemptions: Most states provide sales tax exemptions on the purchase of agricultural equipment and supplies. This program is also focused on making farming more viable in the face of development. It is widely applied in the Northeast, with the exceptions of Maryland and Massachusetts.

Tax Incentives for Donation of Farmland Protection Easements: Agricultural easements are a voluntary arrangement where the development right to farmland is restricted to maintain the land in agriculture. Farmers keep the right to use the farmland for agriculture, but the right to develop the land is restricted. Farmers who contribute easements that qualify as charitable donations are eligible in some states to reduce their federal income taxes. The program is primarily aimed at acquiring easements for permanent farmland preservation through the provision of tax benefits to farmers. This program is not widely implemented in the Northeast (NSAWG 2003).

The effectiveness of the above tax-based farm support programs depends on how large the tax incentive is vis-à-vis the increasing development value of farmland. Though the programs can be effective tools for increasing the financial viability of farming, farmers may use these programs while holding their land for speculative purposes; hence, the long-term effectiveness of these programs is questionable. 


\subsubsection{Economic Support Programs}

Economic support programs are focused on providing grants and loans, technology support, business development and planning assistance, along with integration of farm programs into the overall state development plans to make agriculture a more viable economic sector. From a farmland protection policy perspective, the underlying rationale is that a more viable and productive agricultural operation is more capable of resisting development pressures. Table 2.3 provides a list of economic support policies in the Northeast.

Table 2.3. Economic Viability and Farm Development Policies in the Northeast.

\begin{tabular}{lcccccccc}
\hline State & $\begin{array}{c}\text { Farm } \\
\text { Viability } \\
\text { Program }\end{array}$ & $\begin{array}{c}\text { Technology } \\
\text { Program }\end{array}$ & $\begin{array}{c}\text { Loan and } \\
\text { Grant } \\
\text { Assistance }\end{array}$ & $\begin{array}{c}\text { Business Planning } \\
\text { \& Development } \\
\text { Assistance }\end{array}$ & $\begin{array}{c}\text { Collaboration with } \\
\text { State Dept. of Econ. } \\
\text { Development }\end{array}$ & $\begin{array}{c}\text { Farm Link } \\
\text { Program }\end{array}$ & $\begin{array}{c}\text { Assistance } \\
\text { for New } \\
\text { Farmers }\end{array}$ & Other \\
\hline CT & 0 & 1 & 1 & 0 & 1 & 1 & 0 & 1 \\
DE & 0 & 0 & 0 & 1 & 0 & 0 & 1 & 0 \\
ME & 1 & 1 & 1 & 1 & 0 & 1 & 0 & 0 \\
MD & 0 & 0 & 0 & 1 & 1 & 1 & 1 & 1 \\
MA & 1 & 1 & 1 & 1 & 0 & 1 & 0 & 1 \\
NH & 0 & 0 & 0 & 1 & 0 & 1 & 1 & 0 \\
NJ & 0 & 1 & 1 & 1 & 0 & 1 & 0 & 1 \\
NY & 1 & 1 & 1 & 1 & 1 & 1 & 0 & 0 \\
PA & 0 & 1 & 1 & 1 & 1 & 1 & 1 & 0 \\
RI & 1 & 0 & 1 & 1 & 1 & 1 & 0 & 1 \\
VT & 0 & 1 & 1 & 1 & 1 & 1 & 1 & 1 \\
WV & 0 & 0 & 1 & 1 & 0 & 0 & 1 & 0 \\
\hline
\end{tabular}

Source: Adapted from "Agricultural Policy in the Northeast States: Inventory and Innovation," Northeast Sustainable Agriculture Working Group, 2003.

Note: A one means the state has the policy, zero otherwise.

Farm Viability Programs: These programs contain a range of economic supports for farmers including business planning, grants, and farmland protection consultations. For instance, Massachusetts's farm viability enhancement program provides business 
planning assistance to farmers accepted into the program in exchange for keeping their land in agriculture for five or ten years. Similarly, Maine has an Agricultural Farms for the Future Grant program that provides economic assistance to farmers who agree to keep their land in agriculture for ten years (NSAWG 2003).

New Technology Programs: These programs are widely implemented in the Northeast. States support farmer adoption of new technologies that increase his/her agricultural competitiveness. These programs aim at providing technology adoption education, outreach, and technology-related grants.

Loan and Grant Assistance Programs: These programs are widely implemented in the Northeast to alleviate barriers to farmers' access to capital. For instance, Maine's Agricultural Marketing Loan Fund Program provides farmers with low interest loans for capital improvement projects. Connecticut's Farm Enhancement Program gives grants for capital investments which enhance the farm operation. New York's Farm Viability Program provides matching funds for projects that aim at improving farm profitability and environmental management. Massachusetts's Agriculture Grants Program provides grants to farmers to develop and install new technologies. West Virginia's Rural Rehabilitation Loan Fund provides loans for different agricultural projects. Pennsylvania's Agricultural and Rural Youth Grant gives matching funds to youth organizations for agricultural education and outreach projects (NSAWG 2003).

Business Planning and Development and Farm Link Programs: Business planning programs are implemented in all northeastern states except Connecticut. The programs provide technical assistance to farmers for developing sound business plans and also provide some financial assistance. Farm link programs provide a matching service 
between farmers looking for farmland and owners of agricultural properties. This service helps to transfer agricultural land to farmers rather than to developers.

Collaboration with State Departments of Economic Development: Six states in the Northeast coordinate support for the agricultural sector with other state offices to access additional financial resources for the sector. The resources may be used to support farm viability and to encourage farmland protection.

\subsubsection{Market Development and Promotion Programs}

Market development and promotion programs are aimed at providing better market access and improved farm income through promotion of 'locally grown' farm products, state and regional market information and assistance provision, and international market access assistance coordinated with the U.S. Department of Agriculture's (USDA) Foreign Agricultural Service. Access to markets enhances farm profitability and economies of scale, which may assist in making farming a viable economic activity. Table 2.4 provides a list of market development and promotion policies in the northeastern United States.

State Grown Promotion Programs: All northeastern states, except Delaware, have an agricultural product branding program to promote food grown in the state. These programs are aimed at creating demand for locally-produced farm products and to encourage consumers to give preference to in-state agricultural products to support the state's farm sector.

Multi-state Domestic Promotion Programs: These programs provide promotion for regional agricultural products through supermarket chains. The programs are widely implemented in New England. For instance, the Harvest New England program promotes 
agricultural products from Connecticut, Massachusetts, New Hampshire, Rhode Island, Vermont, and Maine (HNE 2003).

Agricultural Marketing Matching Grant: These programs are available in all northeastern states, except Maryland and Rhode Island. The programs assist farmers by providing matching funds for farm product promotion purposes, providing indirect farm market support.

Farmers' Market Support: All states in the Northeast provide assistance to farmers' markets. Farmers' markets are, in many cases, small local markets that are aimed at giving better market access and support to small scale farmers.

Table 2.4. Market Development and Promotion Policies in the Northeast.

\begin{tabular}{|c|c|c|c|c|c|c|c|c|c|}
\hline & $\begin{array}{c}\text { State-Grown } \\
\text { Promotional } \\
\text { Program }\end{array}$ & $\begin{array}{c}\text { Multi-State } \\
\text { Promotional } \\
\text { Program }\end{array}$ & $\begin{array}{c}\text { Ag. } \\
\text { Marketing } \\
\text { Matching } \\
\text { Grant } \\
\text { Program }\end{array}$ & $\begin{array}{c}\text { Farmers' } \\
\text { Market } \\
\text { Support }\end{array}$ & $\begin{array}{c}\text { Food Commodity } \\
\text { Boards, Advisory } \\
\text { Councils, or } \\
\text { Producer } \\
\text { Associations }\end{array}$ & $\begin{array}{c}\text { Foreign } \\
\text { Trade } \\
\text { Assistance }\end{array}$ & $\begin{array}{l}\text { Farm to } \\
\text { School } \\
\text { Marketing } \\
\text { Efforts }\end{array}$ & $\begin{array}{l}\text { Institutional } \\
\text { and State } \\
\text { Agency } \\
\text { Purchasing of } \\
\text { State-grown } \\
\text { Produce }\end{array}$ & Other \\
\hline $\mathrm{CT}$ & 1 & 1 & 1 & 1 & 1 & 1 & 0 & 1 & 0 \\
\hline $\mathrm{DE}$ & 0 & 1 & 1 & 1 & 0 & 1 & 1 & 1 & 1 \\
\hline $\mathrm{ME}$ & 1 & 1 & 1 & 1 & 1 & 1 & 0 & 1 & 1 \\
\hline MD & 1 & 1 & 0 & 1 & 1 & 1 & 0 & 0 & 0 \\
\hline MA & 1 & 1 & 1 & 1 & 1 & 1 & 1 & 1 & 1 \\
\hline $\mathrm{NH}$ & 1 & 1 & 1 & 1 & 1 & 1 & 0 & 0 & 0 \\
\hline NJ & 1 & 0 & 1 & 1 & 1 & 1 & 0 & 1 & 0 \\
\hline NY & 1 & 0 & 1 & 1 & 1 & 1 & 1 & 1 & 1 \\
\hline PA & 1 & 0 & 1 & 1 & 1 & 1 & 0 & 1 & 1 \\
\hline RI & 1 & 1 & 0 & 1 & 1 & 1 & 1 & 1 & 1 \\
\hline VT & 1 & 1 & 1 & 1 & 1 & 1 & 1 & 1 & 1 \\
\hline WV & 1 & 0 & 1 & 1 & 1 & 1 & 0 & 1 & 0 \\
\hline
\end{tabular}

Source: Adapted from "Agricultural Policy in the Northeast States: Inventory and Innovation," Northeast Sustainable Agriculture Working Group, 2003.

Note: A one means the state has the policy, zero otherwise. 
Foreign Trade Assistance: All states in the Northeast have programs to support local farmers by linking them with the federal Foreign Agricultural Service of USDA to facilitate the export of agricultural commodities to foreign countries. The programs help connect local exporters and foreign importers, enabling local farmers to export to global markets. This program helps by providing better market access for domestic producers.

Farm-to-School Marketing Programs: Five states in the Northeast run farm-toschool programs with federal funding which encourage schools to use locally grown food. This program creates a market for farm products and supports local farmers by protecting them from out-of-state competition.

Institutional and State Agency Purchasing of State-grown Produce: These programs provide preferential treatment by the state for locally grown agricultural products to help farmers in that state. For instance, Connecticut's state food purchase program provides preferential treatment to local producers to supply food to correctional facilities. New Jersey uses a similar program. Rhode Island requires produce grown in-state to be purchased by local retailers if it is the same price and quality. Vermont and Maine encourage state institutions to buy locally grown produce, with Maine requiring institutions to buy at least 10 percent from local producers. Pennsylvania gives preferential treatment to local growers to supply school systems. West Virginia has laws that allow preferential bid treatments for products grown in the state such that local produce can be $5 \%$ more expensive than the least costly option and still win the bid. New York has similar laws that encourage state agencies and educational institutions to alter their bid process to provide preferential treatment for local growers (NSAWG 2003). 


\subsubsection{Farmland Protection Programs}

Agricultural land preservation programs are aimed at protecting farmland from development. These programs may be of particular interest to farmers near urbanizing areas where non-preservation based programs may not effectively compete against development pressures. Table 2.5 provides a list of farmland protection policies in the northeastern United States.

Agricultural Districts: These programs are voluntary land protection initiatives where farmers enroll their land into an agricultural district. In many cases, no mandatory restrictions are placed on the way the land within the district can be used. Agricultural districts may help protect farmland from development by allowing farmland to be concentrated within a protected area.

Agricultural Protection Zoning: This farmland protection program designates zones specifically for agriculture, usually on the basis of soil quality, farm suitability, and other relevant criteria. The nature of zoning in these programs varies from the strictest zoning that allows no other activity within the agricultural area to more relaxed zoning that allows some residential development within the agricultural zone. Only the states of Delaware, Maryland, and Pennsylvania have implemented agricultural zoning programs in the northeastern U.S.

Transfer of Development Rights (TDR): These programs are operational in many Northeast states. Developers in a high density receiving location (usually an already urbanized area) purchase development rights from farmers in a low density sending location. Transfer of development rights can also be exercised by local governments 
which sell development rights and in turn use the funds to buy development rights in sensitive agricultural and wetland areas.

Table 2.5. Farmland Protection Policies Implemented in the Northeast.

\begin{tabular}{|c|c|c|c|c|c|c|c|c|c|c|c|}
\hline & $\begin{array}{l}\text { Agri. } \\
\text { Districts }\end{array}$ & $\begin{array}{c}\text { Agri. } \\
\text { Protection } \\
\text { Zoning }\end{array}$ & PDR & TDR & $\begin{array}{l}\text { Right } \\
\text { to Farm }\end{array}$ & $\begin{array}{c}\text { State } \\
\text { Development } \\
\text { Plan }\end{array}$ & $\begin{array}{l}\text { Agri. } \\
\text { Impact } \\
\text { Statute }\end{array}$ & $\begin{array}{c}\text { Eminent } \\
\text { Domain } \\
\text { Statute }\end{array}$ & $\begin{array}{c}\text { Hybrid } \\
\text { Programs }\end{array}$ & $\begin{array}{l}\text { Executive } \\
\text { Orders }\end{array}$ & Other \\
\hline CT & 0 & 0 & 1 & 1 & 1 & 1 & 0 & 0 & 0 & $\overline{0}$ & $\overline{0}$ \\
\hline $\mathrm{DE}$ & 1 & 1 & 1 & 0 & 1 & 1 & 0 & 0 & 0 & 1 & 0 \\
\hline ME & 0 & 0 & 1 & 0 & 1 & 1 & 0 & 0 & 1 & 0 & 0 \\
\hline MD & 1 & 1 & 1 & 1 & 1 & 1 & 0 & 0 & 0 & 1 & 0 \\
\hline MA & 1 & 0 & 1 & 1 & 1 & 0 & 1 & 1 & 1 & 1 & 1 \\
\hline $\mathrm{NH}$ & 0 & 0 & 1 & 0 & 1 & 1 & 0 & 0 & 0 & 0 & 0 \\
\hline NJ & 1 & 0 & 1 & 1 & 1 & 1 & 0 & 1 & 0 & 1 & 0 \\
\hline NY & 1 & 0 & 1 & 1 & 1 & 1 & 1 & 1 & 1 & 1 & 0 \\
\hline $\mathrm{PA}$ & 1 & 1 & 1 & 1 & 1 & 0 & 0 & 1 & 0 & 1 & 0 \\
\hline RI & 0 & 0 & 1 & 0 & 1 & 1 & 0 & 0 & 0 & 0 & 0 \\
\hline VT & 0 & 0 & 1 & 1 & 1 & 1 & 1 & 0 & 0 & 1 & 0 \\
\hline WV & 0 & 0 & 1 & 0 & 1 & 0 & 0 & 0 & 0 & 0 & 0 \\
\hline
\end{tabular}

Source: Adapted from "Agricultural Policy in the Northeast States: Inventory and Innovation," Northeast Sustainable Agriculture Working Group, 2003.

Note: A one means the state has the policy, zero otherwise.

Purchase of Development Rights $(P D R)$ : These are voluntary programs where state agencies, local government, or non-governmental organizations (NGOs) buy the right to develop farmland to keep the land in agriculture in perpetuity. State level programs are funded in a variety of ways. For instance, the Garden State Preservation Trust Fund of New Jersey was adopted in 1998 and allots \$98 million per year for 30 years to preserve open space, farmland, and historic places. Maryland's program uses 14 percent of the state transfer tax collected through real estate transactions when a particular parcel is converted from agriculture to development. Maryland's Rural Legacy Program was introduced to preserve large contiguous tracts of agricultural land as part of its growth 
management initiative. Vermont uses 45 percent out of the 50 percent property transfer tax for farmland, open space, and recreational land preservation. West Virginia's 2002 legislation allows counties to enact property transfer taxes for easement purchases. Pennsylvania's Installment Purchase Agreement allows payment for development rights to be made over time (NSAWG 2003).

Right-to-Farm: Right-to-farm laws focus on protecting farmers from nuisance law suits. In places that already have development pressure, urban residents may attempt to sue farmers over certain farming practices. Right-to-farm laws protect farmers from such law suits to help them stay in farming. This program is operational in all northeastern states.

Agricultural Impact Statutes: Massachusetts, New York, and Vermont run agricultural impact statute programs that require land development projects to include agricultural impact assessments. The inclusion of agricultural impact assessments in investment projects enables, to a degree, the internalization of social costs associated with development's impact on agriculture.

There are also a number of other programs that have been implemented in the Northeast to preserve farmland in its current agricultural use. All of the above mentioned farmland protection programs are focused primarily on protecting agricultural land in the face of growing development pressure. The effectiveness of the programs, however, depends on how the provided incentives compare to the benefits farmers receive from developing their land, on the extent of state budget allocations for farmland protection programs, and on the cooperation of local communities regarding agricultural land preservation initiatives. 


\section{CHAPTER 3}

\section{THE ECONOMIC THEORY OF LAND ALLOCATION, AGRICULTURAL LAND DEVELOPMENT, AND RATIONALE FOR PUBLIC SECTOR INTERVENTION}

\subsection{MICROECONOMIC FOUNDATION OF HOUSEHOLD LOCATION DEMAND: A MATHEMATICAL APPROACH}

Economic decisions involve trade-offs, and recognizing these trade-offs is vital for understanding economic decisions. Households, for instance, choose between consumption of goods and services and a housing unit at a particular location. From these trade-offs, the marginal conditions of utility maximization can be derived to infer the value of a housing unit at a specific location, along with an associated derived demand for land. Urban sprawl is an economic phenomenon that is partially driven by demand side land use decisions. The microeconomic basis for demand side analysis of land use choice is presented below.

Household utility maximization is constrained by disposable income, which can be spent on commuting, renting a house, and on other goods and services. Assuming that a household faces a choice between consumption of a flow of services from a housing unit at a particular location and a Hicksian consumption bundle (that is all other goods and services consumed aggregated into a bundle - Hicksian bundle) whose price is normalized to $\$ 1$, the constrained utility maximization problem will be:

$$
\max _{q, h} U(q, h) \text { subject to } q+p_{h} h=Y-k_{c} d,
$$

where $U(q, h)$ is the utility function,

$q=\mathrm{a}$ Hicksian consumption bundle,

$p_{h}=$ housing rental price per square foot, 
$h=$ square footage of housing,

$Y=$ total disposable income,

$k_{c}=$ per mile commuting cost,

$d=$ distance from a central business district in miles.

Rearranging the constraint equation, $q$ can be expressed as: $q=Y-k_{c} d-p_{h} h$. Hence, the utility maximization problem can be expressed as:

$$
\max _{h} U\left(Y-k_{c} d-p_{h} h, h\right) .
$$

The maximization process in this case is different from a utility maximization problem for goods and services where price remains, more or less, spatially fixed. Housing price varies significantly with distance from the central city. Hence, preference for a given size of house is first identified, and then the location is decided since the price per square foot varies with distance from the city; instead of the case in a goods market where price is given and then the utility maximizing bundle is identified.

To choose $h$ optimally, conditional on $p_{h}$, two optimization conditions need to be satisfied. First, the ratio of the marginal utility of a housing unit at a particular location $\left(u_{1}=\partial u / \partial h\right)$ to the marginal utility of the Hicksian consumption bundle $\left(u_{2}=\partial u / \partial q\right)$ has to equal the price ratio of the two consumption choices, as indicated in equation (3.3): (3.3) $\frac{u_{1}\left(Y-k_{c} d-p_{h} h, h\right)}{u_{2}\left(Y-k_{c} d-p_{h} h, h\right)}=p_{h}$.

Second, to make sure that the consumption bundle identified in equation (3.3) satisfies a predetermined utility level, $v$, set by the consumer making the decision, the following relationship should hold:

$$
U\left(Y-k_{c} d-p_{h} h, h\right)=v .
$$


Equations (3.3) and (3.4) can be solved simultaneously for the decision variable $h$ and for the parameter $p_{h}$. The solutions for $h$ and $p_{h}$ are functions of the parameters $d, Y$, $k_{c}$, and $v$. The comparative static results for $p_{h}$ and $h$ with respect to the parameters $d, Y$, $k_{c}$, and $v$ can be derived by totally differentiating (3.3) and (3.4). This information is more relevant than the solution of the system itself as it defines the economic behavior determining a household's location demand and the conditions that may contribute to sprawl.

The effect of a change in distance $(d)$ on rental price of housing $\left(p_{h}\right)$ and implication to housing size (h):

Distance from the central city is an important factor that affects the conditions for optimal location choice. Distance from urbanized locations is also a factor determining the extent of development pressure on farmland. Comparative statics of the choice variables with respect to distance from the central city $(d)$ shows the impact of distance from the central city and can be derived from equation (3.4). The complete derivation of the comparative static result of $\frac{\partial p_{h}}{\partial d}=\frac{k_{c}}{-h}<0$ is given in the Appendix.

The negative comparative static result shows that the rental price of a house is inversely related to distance from the central city; as distance from the central city increases, the rental price of a house decreases. With distance, there are two forces at play as far as land consumption is concerned. First, the higher commuting cost associated with distance reduces disposable income, and second, lower rental prices of houses per square foot associated with distance have the opposite effect of increasing purchasing power. If 
rental price of housing per square foot saving is greater than increased commuting cost, larger plot houses will be consumed.

The effect of a change in income $(Y)$ on housing price $\left(p_{h}\right)$ and implication to housing size (h):

Income growth is an important determinant of the demand for housing at a particular location and hence derived demand for land. The relationship between $Y$ and $p_{h}$ can be derived from equation (3.4). The complete derivation of the comparative static result of $\frac{\partial p_{h}}{\partial Y}=\frac{\frac{\partial u}{\partial Y}}{h}>0$ is given in the Appendix.

The positive comparative static result for the impact of a change in income on housing rental price suggests that an increase in income, $Y$, leads to an increase in the rental price of housing, $p_{h}$, ceteris paribus. This is likely due to an increased demand for housing associated with higher purchasing power from higher income, driving up the price of housing at all locations. The impact of an increase in income on land consumption depends on the income and substitution effects. Assuming housing is a normal good, an increase in income leads to larger plot housing consumption. On the other hand, higher income and resultant competition drives housing prices up hence leading to lower purchasing power offsetting part of the income effect. If the income effect dominates the substitution effect, an increase in income leads to larger plot housing consumption. 
The effect of a change in commuting cost ( $\left.k_{c}\right)$ on housing price $\left(p_{h}\right)$ and implications for housing size (h):

Commuting cost limits the amount of income available for housing as well as consumption of the Hicksian bundle. Commuting cost also directly affects the rental price of housing and square footage consumption. The impact of a change in $k_{c}$ on $p_{h}$ can be derived using comparative statics on equation (3.4). The complete derivation of the comparative static result of $\frac{\partial p_{h}}{\partial k_{c}}=\frac{d}{-h}<0$ is given in the Appendix.

The negative impact of a change in commuting cost on housing price shows that with an increase in commuting cost the rental price of housing will be lower to compensate consumers for the higher cost of commuting outside the central city. The impact of commuting cost on land consumption depends on the effect commuting cost has on income and the effect commuting cost has on housing price. At greater distance from the city center, commuting cost increases, hence reducing the purchasing power of income. The countering effect, however, is that at greater distance, rental price of housing per square foot is lower to compensate for higher commuting costs. Given rental prices of housing per square foot at all locations, a rise in commuting cost reduces the purchasing power of income, and hence results in smaller plot high density housing consumption.

To summarize, the comparative static results from the consumer utility maximization problem indicate that distance, income, and commuting costs are important factors that determine the spatial distribution of development. Regional land use change models that try to capture the influence of urban growth on agricultural land use need to capture demand side parameters that cause suburban and rural residential development and derived demand for suburban and rural farmland. Income growth, distance from 
metropolitan locations, and transportation accessibility (as a proxy for commuting cost) can be used to capture development pressure on suburban and rural lands.

\subsection{MICROECONOMIC FOUNDATION OF DEVELOPER'S DECISION: A MATHEMATICAL APPROACH}

In addition to demand for housing in suburban areas, the supply provided by developers is also important. The market rental price per square foot of housing communicates economic information to both households and developers. Given utility, urban residents adjust their location by choosing the rental price of land across space. Given investment cost on borrowed capital, developers choose profit-generating development projects given market rental prices of housing at given locations. Market prices play a crucial role

in communicating information for optimal decision making by both developers and households.

Developers are assumed to be solely interested in maximizing their profit from investment in housing. The profit maximization problem of developers can be set up by using both input and output market prices along with a housing production function, $h=h\left(l_{d}, k\right)$, where $h$ is square footage of housing, $l_{d}$ is land, and $k$ is capital. The profit maximization problem is:

$$
\max _{l_{d}, k} \pi=p_{h} h\left(l_{d}, k\right)-i k-r l_{d},
$$

where: $p_{h}=$ housing rental price per square foot,

$i=$ interest rate on borrowed capital, and $r=$ price per square foot paid for land rent.

The profit maximizing selection of land and capital can be determined by deriving the first order conditions from equation (3.5) as follows: 


$$
\frac{\partial \pi}{\partial l_{d}}=p_{h} \frac{\partial h\left(l_{d}, k\right)}{\partial l_{d}}-r=0
$$

$$
\frac{\partial \pi}{\partial k}=p_{h} \frac{\partial h\left(l_{d}, k\right)}{\partial k}-i=0
$$

The marginal condition given in equation (3.6) indicates that the developer will develop land to the point where the marginal cost of land is equal to the marginal revenue from housing put on that land. Similarly, from equation (3.7), the marginal condition indicates that the developer will borrow investment capital to the extent where the marginal productivity of capital valued at its market price equals the marginal cost of capital (interest rate).

For simplicity, a constant returns to scale production function is assumed. Varian (1992) shows that a constant returns production function, $q=f(x, y)$, where $x$ and $y$ are inputs, can be expressed as $f(x, y)=y f\left(\frac{x}{y}, 1\right)$. Assuming constant returns to housing production, $h\left(l_{d}, k\right)=l_{d} h\left(\frac{k}{l_{d}}, 1\right)$. Thus, the ratio of inputs represents a capital-land ratio which indicates the substitution of capital for land in the production of housing and the conditions that will determine capital (high density) or land (low density) intensive housing production. A land intensive (low density) housing development is the focus here as it is related to sprawl. The profit maximization problem can be redefined as:

$$
\max _{\frac{k}{l_{d}}} \pi=l_{d}\left(p_{h} h\left(\frac{k}{l_{d}}, 1\right)-i \frac{k}{l_{d}}-r\right) .
$$

Equation (3.8) allows derivation of comparative static conditions that show the sensitivity of developers' land or capital choices to changes in the model's parameters. The results 
have direct implications for the size of cities and the extent of development pressure on suburban and rural land markets.

For ease of analysis let $\omega$ represent the capital-land ratio, $\frac{k}{l_{d}}$. The profit maximization problem then becomes $\max _{\omega} \pi=l_{d}\left(p_{h} h(\omega, 1)-i \omega-r\right)$, with the first order condition $\frac{\partial \pi}{\partial \omega}=p_{h} \frac{\partial h(.)}{\partial \omega}-i=0$. This condition states that the marginal benefit of adjusting the capital-land ratio has to equal the marginal cost. Any change in the market interest rate for borrowed capital or in the rental price of housing will change the optimal capitalland ratio for the developer.

In the long-run land development should yield zero economic profit. If housing development is a profitable industry in a free market, entry of new businesses into the market will drive the return on development down for every developer in the industry, which means $p_{h} h(\omega, 1)-i \omega=r$, or the net benefit from renting a house at the market rental price minus interest payments on the house should be equal to rental payments on the land. These results link the production side of housing and land development with consumer demand. Since the price of a house is sensitive to consumer demand parameters income $(Y)$, commuting costs $\left(k_{c}\right)$, and distance $(d)$, the link between the producer and consumer side is apparent. The parameters in the developer's model, rent and the capitalland ratio, can be differentiated with respect to the consumer side parameters to identify important factors that shape the location demand of households, the decisions of developers, and the impact on urban sprawl.

To determine how income, commuting cost, distance, and the utility level will change the optimal land rent and capital-land ratio (for an exogenously given market 
interest rate), let $\varphi=f\left(Y, u, k_{c}, d\right)$. The comparative statics for the capital-land ratio and for land rent can be derived by totally differentiating $\frac{\partial \pi}{\partial \omega}=p_{h} \frac{\partial h(.)}{\partial \omega}-i=0$ and $p_{h} h(\omega, 1)-i \omega=r$, respectively.

The effect of a change in income, commuting cost, and distance on land rent:

The negative relationship between the rental value of land and distance from the urban center, $\frac{\partial r}{\partial d}=h(.) \frac{\partial p_{h}}{\partial d}<0$, indicates that with increasing distance from central city locations, land rent will decline (see derivation in the Appendix). In other words, land becomes cheaper as the commute becomes longer. To compensate long distance commuters, it is necessary for housing costs to be lower. Alternatively, at an increasing distance from urbanized locations, the demand for land is lower, and so is its economic value, which may encourage larger lots.

A positive relationship between land rent and income, $\frac{\partial r}{\partial Y}=h(.) \frac{\partial p_{h}}{\partial Y}>0$, indicates that an increase in household income leads to higher land rent (see derivation in the Appendix). Assuming that land is a normal good, an increase in income may increase demand for housing in the suburbs, which drives up suburban land rent.

The effect of changes in commuting cost on rental value of land, $\frac{\partial r}{\partial k_{c}}=h(.) \frac{\partial p_{h}}{\partial k_{c}}<0$, is negative; thus, higher commuting cost reduces the demand for land and its price (see derivation in the Appendix). To compensate commuters living in the suburbs for higher commuting costs, the land market has to adjust to a lower rental rate. 
Conversely, transportation technologies that reduce the economic cost of commuting will increase the demand for land and drive land rent up.

The effect of a change in income, commuting cost, and distance on the capital-land ratio: The effect of distance away from central city locations on the capital-land ratio is negative, $\frac{\partial \omega}{\partial d}=-\frac{\partial h(.)}{\partial \omega} \frac{\partial p_{h}}{\partial d} \frac{1}{p_{h} \frac{\partial^{2} h(.)}{\partial \omega^{2}}}<0$, showing that with increasing distance from central city locations, the capital-land ratio will decline (see derivation in the Appendix). In other words, at locations farther from the city land is substituted for capital. Lot sizes in the suburbs will, consequently, be larger taking more land from uses such as agriculture.

The relationship between an urban household's income and the capital-land ratio, $\frac{\partial \omega}{\partial Y}=-\frac{\partial h(.)}{\partial \omega} \frac{\partial p_{h}}{\partial Y} \frac{1}{p_{h} \frac{\partial^{2} h(.)}{\partial \omega^{2}}}>0$, is positive indicating that an increase in income leads to an increase in the capital-land ratio (see derivation in the Appendix). One way this may happen is through higher demand for housing and the derived demand for land. As a result of higher income, the rental price of land is bid up, leading to substitution of capital for land and the building of higher-occupancy structures that save land but use more capital.

A negative relationship exists between commuting cost and the capital-land ratio, $\frac{\partial \omega}{\partial k_{c}}=-\frac{\partial h(.)}{\partial \omega} \frac{\partial p_{h}}{\partial k_{c}} \frac{1}{p_{h} \frac{\partial^{2} h(.)}{\partial \omega^{2}}}<0$. Derivation of this relationship is provided in the 
Appendix. With higher commuting cost, land at distant locations becomes less attractive and discourages sprawl.

\subsection{URBAN SPRAWL: COMBINING HOUSEHOLD AND DEVELOPER DEMAND FOR LAND}

Urban sprawl is a phenomenon that results from the aggregate impact of household and developer choices. This section extends the analysis to the impact of demand and supply parameter changes on city size, and consequently on development pressure on farmland. The size of a city, among other things, depends on two factors; the rental value of land in agriculture compared to the rental value of land for development, and the urban population level.

First, the higher the rental value of land in development, the more land will be converted to urban uses. This condition can be stated as $r_{u}\left(\hat{d}, Y, k_{c}, u\right)=r_{a}$, where $r_{u}$ is the per square foot urban land rent, $r_{a}$ is the per square foot agricultural land rent, $\hat{d}$ is the distance from the central city to the urban edge, and $Y, k_{c}$, and $u$ are defined as before. Thus, the equilibrium city size is determined when the rental value of urban land is equal to the agricultural land value.

Second, equilibrium city size depends on fitting a given urban population inside the urban boundary. In other words, at equilibrium, given agricultural and urban land use rents, the resulting city size must accommodate the current city population.

From these two conditions, the impact of demand and supply side parameter changes on equilibrium urban size can be derived. Relevant comparative static results are presented in Table 3.1. 


\section{Table 3.1. Comparative Static Summary for City Size, Housing Price, Land Rent, and Capital-Land Ratio.}

\begin{tabular}{|c|c|}
\hline $\begin{array}{l}\text { Comparative Static } \\
\text { Condition }\end{array}$ & Interpretation \\
\hline$\frac{\partial \bar{d}}{\partial P O P}>0$ & A rise in city population expands city size (leads to urban sprawl). \\
\hline$\frac{\partial p_{h}}{\partial P O P}>0$ & A rise in city population raises rental price of land. \\
\hline$\frac{\partial \omega}{\partial P O P}>0$ & A rise in city population leads to capital-intensive housing units. \\
\hline$\frac{\partial r}{\partial P O P}>0$ & A rise in population increases urban land rent. \\
\hline$\frac{\partial \bar{d}}{\partial r_{a}}<0$ & A rise in agricultural land rent reduces city size (limits urban sprawl). \\
\hline$\frac{\partial p_{h}}{\partial r_{a}}>0$ & A rise in agricultural land rent increases the rental price of a house. \\
\hline$\frac{\partial \omega}{\partial r_{a}}>0$ & $\begin{array}{l}\text { An increase in agricultural land rent encourages capital intensive housing } \\
\text { units. }\end{array}$ \\
\hline$\frac{\partial r}{\partial r_{a}}>0$ & A rise in agricultural land rent increases urban land rent. \\
\hline$\frac{\partial \bar{d}}{\partial Y}>0$ & A rise in urban household income increases city size (leads to sprawl). \\
\hline$\frac{\partial r}{\partial Y}>0$ & An increase in urban income raises urban land rent. \\
\hline$\frac{\partial \omega}{\partial Y}>0$ & An increase in urban income encourages capital-intensive housing units. \\
\hline$\frac{\partial p_{h}}{\partial Y}>0$ & An increase in urban income increases the rental price of houses. \\
\hline
\end{tabular}


Assuming a circular city with radius from city center to city edge, $\hat{d}$, the condition that the city should accommodate the current city population is:

$\int_{0}^{\bar{d}} 2 \pi \hat{d} D\left(d, k_{c}, Y, U\right) d \hat{d}=P O P$, where $D\left(d, k_{c}, Y, U\right)$ is population density, which is a function of variables defined in equation (3.1), $P O P$ is the number of people living inside the urban boundary, 0 is the urban center, $\bar{d}$ is the urban edge, and $\pi$ is the mathematical value of $p i$. Together, these two conditions determine the equilibrium city size.

To summarize, a growing urban population, declining agricultural land rent, and urban income growth facilitate urban expansion and development of farmland. These comparative static results show that effective land use change models need to include the parameters that affect the location choices of households and developers, and need to capture population, income, and agricultural land rent information to understand regional growth and the resultant aggregate land use changes.

\subsection{FARMLAND EXTERNALITIES, THE EFFICIENCY OF LAND MARKETS, AND RATIONALE FOR LAND MARKET INTERVENTION}

A simplified dynamic model of land allocation between development and agriculture is developed to show how land markets may not be efficient when positive externalities in agriculture are present. Existence of positive farmland externalities is often used to justify public sector intervention in managing land use and in implementing "smart-growth" policies.

The first urban equilibrium condition given above shows that at the urban-rural boundary urban land rent and agricultural land rent should be equal. This condition assumes that both urban and agricultural land rents reflect all social opportunity costs. 
Though urban land rents may sufficiently reflect social opportunity costs (as capital may not be invested in development if there is a better use of it in the economy), agricultural land rents do not necessarily reflect social opportunity costs if they do not capture externalities from agriculture. Farmland may be considered a non-renewable resource that can be depleted when developed. In some regions, it may not be feasible to convert forest and rangeland to farmland due to high costs of conversion, or the forest and/or rangeland may not have the requisite soil or physical characteristics for use as farmland. It is assumed here that such lands are marginal and may not be brought into cultivation in the short-run to increase the stock of farmland. If this assumption is considered highly restrictive and unrealistic in some regions, then the land brought into agriculture through the conversion of forests and/or rangelands could be considered similar to newly discovered reserves that will then be subjected to the same process of depletion through development. In addition, farmland development may be irreversible. Changing developed land back to farming could be cost-prohibitive or very difficult to obtain the necessary agricultural soil characteristics.

This model uses a benevolent social planner whose goal is the maximization of social welfare by allocating a fixed land endowment to farmland or development. The social planner will internalize the negative and positive externalities associated with a given land use. Benefits from farmland include: production benefits $\left(B_{p}\right)$, which are profits earned from the production and sale of farm products; amenity benefits $\left(B_{a}\right)$ include open space and scenic views; environmental benefits $\left(B_{e}\right)$ are the potential air quality and carbon sequestration benefits. The benefit of allocating land to development, development benefits $\left(B_{u}\right)$, are the flow of services from commercial buildings, roads, 
housing, etc. Development generates negative externalities in terms of the option value lost $\left(V_{o}\right)$ due to developing today as opposed to keeping the land in agriculture.

The social planner is interested in maximizing total net social benefits by allocating land between development and agriculture. Given a planning horizon of $T$ (a finite time in the future), a social discount rate of $\delta$, a constraint that total land converted to development can not exceed available land in agriculture, and given the initial agricultural land stock, the net present value from a dynamic land allocation model can be formulated as follows:

$$
\begin{gathered}
\operatorname{Max} \int_{0}^{T} e^{-\delta t}\left[B_{p}\left(L_{a}, w, p\right)+\Psi B_{a}\left(L_{a}\right)+\Omega B_{e}\left(L_{a}\right)+B_{u}\left(L_{u}\right)-V_{o}\left(L_{u}\right)\right] d t, \\
\quad \text { subject to } \frac{d\left[L_{f}-L_{u}\right]}{d t}=-L_{a} \text { and } L_{a}(0)=L_{A} .
\end{gathered}
$$

Production benefits of farmland, $B_{p}$ are a function of how much land is allocated for agriculture $\left(L_{a}\right)$ and agricultural input $(w)$ and output $(p)$ prices. The amenity benefits $\left(B_{a}\right)$ and environmental benefits $\left(B_{e}\right)$ are a function of the amount of agricultural land and are multiplied by the scalars $\Psi$ and $\Omega$, respectively. These scalars are introduced to account for the possibility that externalities may or may not be internalized in land allocation and to show how the optimal conditions will be different under each case. If the values of these two parameters are equal to zero, non-market benefits associated with farmland are not considered in the allocation process. If the values are not zero, but some number between zero and 1 , then the social planner is taking into account the amenity and environmental benefits of farmland. A value of 1 for $\Psi$ or $\Omega$ would mean total internalization of these benefits, while any value between 0 and 1 indicates some, less than complete, level of benefit internalization. This allows flexibility since in many 
policy decisions it is difficult to know the exact environmental benefits associated with a given farmland endowment for a particular community. Similarly, the development benefits $\left(B_{u}\right)$ and loss of option value due to current development $\left(V_{o}\right)$ are a function of the amount of land allocated for development $\left(L_{u}\right)$. There is a total fixed supply of land that can only be allocated to development or farming, $L_{f}$, thus, $L_{f}=L_{u}+L_{a}$. The rate of land conversion over time is $\frac{d\left[L_{f}-L_{u}\right]}{d t}$. An increase in urban land will diminish the existing fixed stock of land available for agriculture. Hence, the constraints of the optimal control problem state that the rate of change in the stock of land due to development is equivalent to the reduction in farmland.

The definition of urban land $\left(L_{u}=L_{f}-L_{a}\right)$ can be substituted into the objective function above, equation (3.9), to become:

$$
\operatorname{Max} \int_{0}^{T} e^{-\delta i}\left[B_{p}\left(L_{a}, p_{i}, w_{i}\right)+\Psi B_{a}\left(L_{a}\right)+\Omega B_{e}\left(L_{a}\right)+B_{u}\left(L_{f}-L_{a}\right)-V_{o}\left(L_{f}-L_{a}\right)\right] .
$$

The current value Hamiltonian for this problem can then be specified as:

$$
H_{t}=B_{p}\left(L_{a}, p, w\right)+\Psi B_{a}\left(L_{a}\right)+\Omega B_{e}\left(L_{a}\right)+B_{u}\left(L_{f}-L_{a}\right)-V_{o}\left(L_{f}-L_{a}\right)-\rho(t) L_{a},
$$

where $\rho(t)$ is the co-state or shadow value of land in agriculture. It is also the opportunity cost of developing land in the current period as opposed to in the future.

To maximize the Hamiltonian function, the Pontryagin first order dynamic optimization conditions can be derived as follows:

$$
\frac{\partial H_{t}(.)}{\partial L_{a}}=\partial B_{p} / \partial L_{a}+\Psi \partial B_{a} / \partial L_{a}+\Omega \partial B_{e} / \partial L_{a}+\partial B_{u} / \partial L_{a}-\partial V_{o} / \partial L_{a}-\rho_{t}=0
$$

$$
\frac{\partial H(.)}{\partial \rho_{t}}=\frac{d\left(L_{f}-L_{u}\right)}{d t}=-L_{a}
$$


(3.14) $\dot{\rho}-\delta \rho(t)=\frac{-\partial H}{\partial\left(L_{f}-L_{u}\right)}=0$.

The above first order conditions indicate the optimal allocation under which the social net benefit will be maximized. Equation (3.12) states that, from the social planner's perspective, the allocation of land will be optimal if the marginal farmland production benefits, amenity benefits, environmental benefits, and urban development benefits are equal to the marginal loss of option value and the loss of farmland today due to development as opposed to preserving the land in agriculture. It is clear that land which is allocated to development will reduce benefits associated with farmland. Equation (3.13) states that the rate of decline in the agricultural land stock due to development equals the amount of agricultural land removed for development. Equation (3.14) is a capital market condition which indicates that at equilibrium, the co-state variable (agricultural land rent) grows at the rate of interest $\delta$.

From these first-order conditions, agricultural land rent can be derived as follows:

$$
\rho_{t}=\partial B_{p} / \partial L_{a}+\Psi \partial B_{a} / \partial L_{a}+\Omega \partial B_{e} / \partial L_{a}+\partial B_{u} / \partial L_{a}-\partial V_{o} / \partial L_{a}
$$

which indicates that the co-state variable not only captures the change in rent due to changes in the productive value of farmland, but also includes changes in amenity benefits, environmental benefits, urban benefits, and changes in option value associated with a land use change. Equation (3.15) shows that the rental value of agricultural land should include the marginal value of environmental and amenity benefits as well as the marginal lost option value and marginal development benefits for it to reflect the true social value of farmland. Often, agricultural land rent reflects the land's productive use but rarely its non-market benefits and any lost option value. Consequently, the market 
rental value of farmland is often under-estimated and the market process that determines the equilibrium city size is inefficient. It is this inefficiency in land markets that often gives policy makers and land use planners the motivation to intervene in land markets and to design policies that encourage farmland protection, and which makes the consideration of the non-market benefits of agricultural land in models of land use change important. 


\section{CHAPTER 4}

\section{EMPIRICAL MODELS AND DESCRIPTION OF DATA}

\subsection{GROWTH EQUILIBRIUM MODEL (MODEL 1)}

Understanding the underlying economic motives of decision makers and capturing competition across space is a complex undertaking and a critical requirement in the modeling process of land use change. In a circular flow process, households not only supply land to the land market but also demand it to maximize utility from its flow of service. Similarly, both farm and non-farm businesses not only demand land as an input to production, but they can supply land to the land market. Businesses may relinquish current land holdings back to the factor market as industry cost structures, technology, preferences of consumers, government policies, and environmental requirements change. This is consistent with the assumption that firms and households are spatially mobile to achieve location equilibrium, as location specific amenities and resources affect the level of utility and profit.

The simultaneous decisions of consumers and producers, both in the product and factor markets, affect the value of products and resources and their consequent distributional structure. Any change in the factor or product market by an exogenous event or endogenous decision affects different sectors of the economy, which in turn affects the use and distribution efficiency of resources. Consumers and agricultural and non-agricultural producers demand suburban and rural land for direct use. Consumers (households) tend to demand more suburban and rural land as population pressure and urban congestion intensifies and as demand increases for natural amenities to be used for 
housing and recreational purposes. Households can also be attracted to suburban areas for employment. Growing real income and the resultant demand for higher environmental quality may also attract residents to suburban and rural locations.

The demand for rural and suburban land for agricultural purposes is motivated by fertility and location factors affecting the profit of farmers. However, intensified competition for suburban land along with lower per acre returns to agriculture may lead to the conversion of land to non-agricultural uses. This implies that the agricultural sector not only has a demand for land, but can also be a net supplier of land for other uses.

Non-agricultural producers are similarly motivated to find a profit maximizing location. Lower transportation costs and agglomeration economies can attract firms to a location that generates better returns. Non-agricultural firms may consider regional laborcost savings and market size in their location decisions. Growing suburban population, transport savings and labor advantages can motivate firms to relocate to areas where such advantages are prevalent. This exerts pressure on the suburban and rural land markets.

In most cases, land demanded for different purposes in suburban areas satisfies certain qualities. In addition to locational convenience and nearness to markets, it could provide positive environmental externalities and physical characteristics that would be of interest to developers. As the competition over land intensifies, the value increases enabling one sector to outbid competing sectors. This competition can enhance the conversion of farmland to urban uses and contributes to further suburbanization. Though it is theoretically relevant to view firms as being mobile over space, the mobility of resources back to certain sectors is ambiguous. Though the relative strength of sectors in 
terms of bidding power can determine the flow of land, the decision to develop farmland is often irreversible.

Generally, the changes in agricultural land use may be captured by aggregate changes in population and employment densities, per capita income, and land prices in a regional growth framework. A market for farmland is provided in Figure 4.1.

\section{Figure 4.1. A Market Showing the Impact of Regional Growth on Agricultural Land Development and Value.}

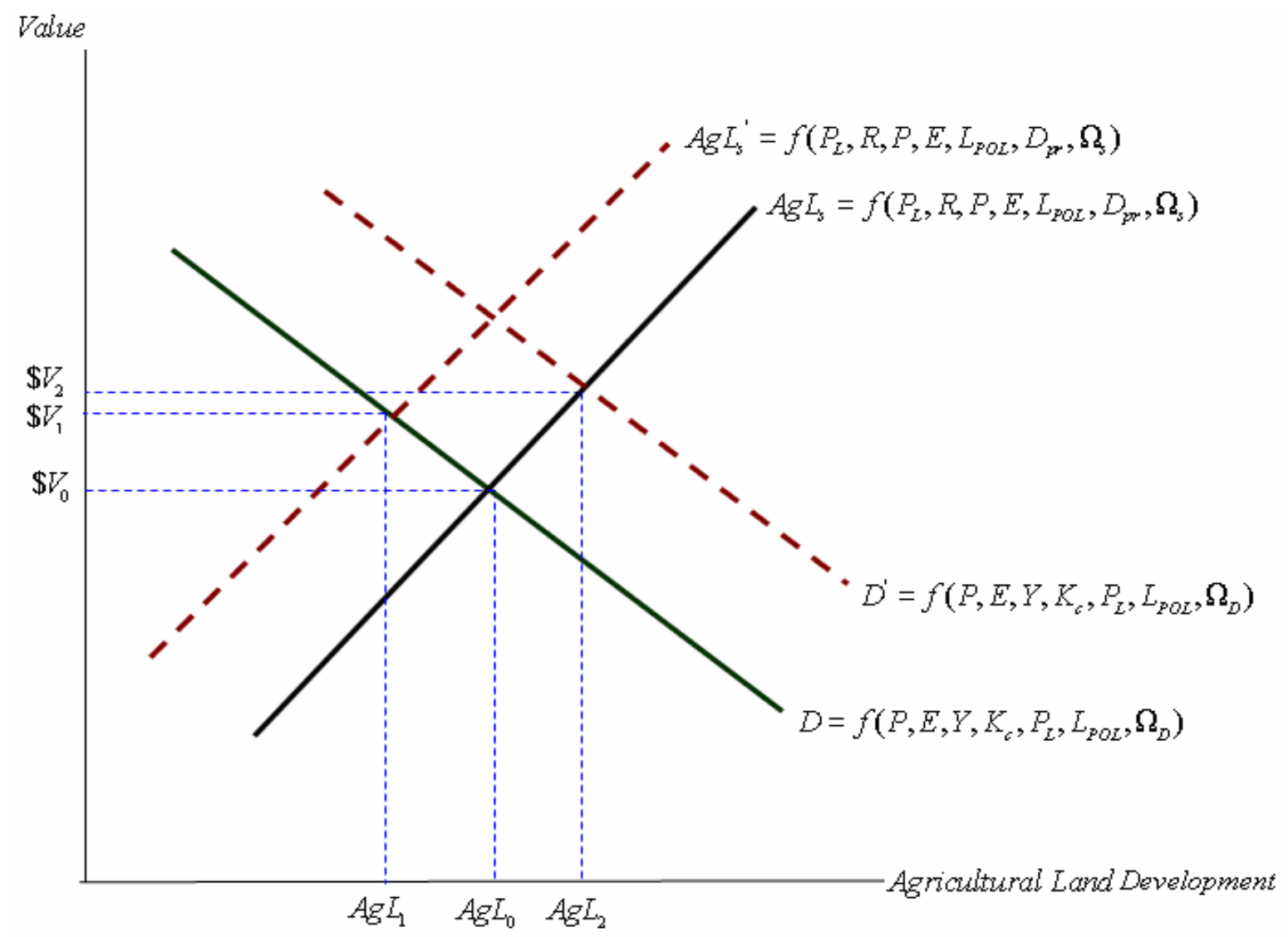

The supply of agricultural land is given by $A g L_{s}$, and is a function of the price of land, $P_{L}$, per acre agricultural land rent, $R$, population density, $P$, employment density, $E$, land use policies, $L_{P O L}$, development pressure, $D_{p r}$, and other exogenous factors affecting supply, $\Omega_{\mathrm{S}}$. The demand for rural and suburban land, $D$, is also a function of the price of 
land, population density, employment density, and land use policies. Demand for land is also determined by real income, $Y$, the round trip commuting cost from suburban/rural areas to the city center, $K_{C}$, and other exogenous factors affecting demand, $\Omega_{\mathrm{D}}$. Specific per acre values of agricultural land, $\$ V_{0}, \$ V_{1}$, and $\$ V_{2}$ correspond to varying levels of the stock of agricultural land, $A g L_{0}, A g L_{1}$, and $A g L_{2}$.,

Figure 4.1 shows the impact of regional growth patterns on rural land markets. Initially, at a given agricultural land stock of $A g L_{0}$ and value per acre of $\$ V_{0}$, the land market is assumed to be in short-term equilibrium. A change in any of the factors that determine demand and/or supply, results in changes in the amount of agricultural land at each location along with the associated per acre value of land. For example, an increase in demand results in more development of farmland and a higher per acre value.

To capture the impact of inter-temporal employment density, population density, income, and agricultural land value changes on farmland stocks, a growth equilibrium model is used in this study. Growth equilibrium models were initially developed to simultaneously explain growth in employment and population. These models have been used to examine relationships among population and employment changes, migration, and the demand for natural amenities.

The theoretical model is developed following a set of basic assumptions. It is assumed that mobile consumers maximize utility by consuming a vector of goods and services as well as location and non-market amenities. Households will migrate until marginal utilities are equalized across locations. Households are also assumed to be drawn to regions with high per capita income growth and employment opportunities. Producers are assumed to maximize profit from the production of goods and services. 
Firms select locations to capture locational cost and revenue advantages, minimize the cost of transportation, benefit from agglomeration and regional labor cost savings as well as labor quality. Firms enter and leave regions until competitive profits are equalized across regions.

It is also assumed that firms and households adjust to disequilibrium over time. In a general equilibrium framework, population, employment, and income are affected not only by each other, but also by a variety of other variables. In principle, many such variables might be simultaneously determined along with population, employment, (Carlino and Mills 1987) and income. Agricultural land values and agricultural land stock changes are also assumed to adjust with lags.

There exists a simultaneous relationship between growth factors, county per capita income, agricultural land values, and the stock of agricultural land at a particular time as represented by the following functions:

$$
\begin{aligned}
& P^{*}=f_{p}\left(E^{*}, Y^{*}, P_{L}^{*} \mid \Omega^{P}\right), \\
& E^{*}=f_{e}\left(P^{*}, Y^{*}, P_{L}^{*} \mid \Omega^{E}\right), \\
& Y^{*}=f_{y}\left(P^{*}, E^{*}, P_{L}^{*} \mid \Omega^{Y}\right), \\
& P_{L}^{*}=f_{p_{l}}\left(P^{*}, E^{*}, Y^{*}, A g L^{*} \mid \Omega^{P_{L}}\right), \\
& A g L^{*}=f_{a g l}\left(P^{*}, E^{*}, Y^{*}, P_{L}^{*} \mid \Omega^{A g L}\right),
\end{aligned}
$$

where $P^{*}, E^{*}, Y^{*}, P_{L}^{*}$, and $A g L^{*}$ refer to equilibrium levels of population, employment, per capita income, agricultural land value, and agricultural land stocks, respectively. Vectors of other exogenous variables have direct or indirect relationships with 
population, $\Omega^{P}$, employment, $\Omega^{E}$, per capita income, $\Omega^{Y}$, agricultural land value, $\Omega^{P_{L}}$, and agricultural land stocks, $\Omega^{A g L}$.

Population and employment are likely to adjust to their equilibrium values with substantial lags (Mills and Price 1984). Similarly, regional income levels and agricultural land and its value are assumed to adjust to their lagged values. The rate and level of agricultural land conversion in the base year is likely to influence the behavior of agricultural land conversion in the current year; or conversely, equilibrium levels of agricultural land adjust to previous period conversion patterns. Thus, distributed lag adjustment equations can be introduced as:

$$
\begin{aligned}
& P_{t}=P_{t-1}+\lambda_{P}\left(P^{*}-P_{t-1}\right), \\
& E_{t}=E_{t-1}+\lambda_{E}\left(E^{*}-E_{t-1}\right), \\
& Y_{t}=Y_{t-1}+\lambda_{Y}\left(Y^{*}-Y_{t-1}\right), \\
& P_{L t}=P_{L t-1}+\lambda_{P L}\left(P_{L}^{*}-P_{L t-1}\right), \\
& A g L_{t}=A g L_{t-1}+\lambda_{A g L}\left(A g L^{*}-A g L_{t-1}\right),
\end{aligned}
$$

where $\lambda_{P}, \lambda_{E}, \lambda_{Y}, \lambda_{P L}$, and $\lambda_{A g L}$ are speed-of-adjustment coefficients between zero and one, and $t-1$ is a one period lag. Current employment, population, income, land prices, and agricultural land stocks are dependent on their one period lagged levels and on the change between equilibrium values and one period lagged values adjusted at their respective speed-of-adjustment values. Rearranging terms and using $\Delta$ to represent the change in the respective variables, 
(4.11) $\Delta P=P_{t}-P_{t-1}=\lambda_{P}\left(P^{*}-P_{t-1}\right)$,

(4.12) $\Delta E=E_{t}-E_{t-1}=\lambda_{E}\left(E^{*}-E_{t-1}\right)$,

(4.13) $\Delta Y=Y_{t}-Y_{t-1}=\lambda_{Y}\left(Y^{*}-Y_{t-1}\right)$,

(4.14) $\Delta P_{L}=P_{L t}-P_{L t-1}=\lambda_{P L}\left(P_{L}^{*}-P_{L t-1}\right)$,

(4.15) $\quad \Delta A g L=A g L_{t}-A g L_{t-1}=\lambda_{A g L}\left(A g L^{*}-A g L_{t-1}\right)$.

In equations (4.11) through (4.15), the right hand side equilibrium variables are not observable; however, they can be solved from equations (4.6) through (4.10) as follows:

$$
P^{*}=P_{t-1}+\frac{1}{\lambda_{P}}\left(P_{t}-P_{t-1}\right),
$$

$$
E^{*}=E_{t-1}+\frac{1}{\lambda_{E}}\left(E_{t}-E_{t-1}\right)
$$

$$
Y^{*}=Y_{t-1}+\frac{1}{\lambda_{Y}}\left(Y_{t}-Y_{t-1}\right)
$$

$$
P_{L}^{*}=P_{L t-1}+\frac{1}{\lambda_{P L}}\left(P_{L t}-P_{L t-1}\right)
$$

$$
A g L^{*}=A g L_{t-1}+\frac{1}{\lambda_{A g L}}\left(A g L_{t}-A g L_{t-1}\right) .
$$

The expression for the equilibrium values needs to be substituted in place of equilibrium values to develop a model with measurable variables. Hence, substituting relationships identified in equations (4.16) through (4.20) and relationships specified in equations (4.1) through (4.5) into the equilibrium right hand side endogenous variables in equations (4.11) through (4.15) yields: 


$$
\begin{aligned}
& \Delta P=\lambda_{P} \cdot f_{p}\left(E_{t-1}+\frac{1}{\lambda_{E}} \Delta E, Y_{t-1}+\frac{1}{\lambda_{Y}} \Delta Y, P_{L t-1}+\frac{1}{\lambda_{P L}} \Delta P_{L}\right)-\lambda_{P} P_{t-1}+\sum_{i} \delta_{i P} \Omega^{P}+\varepsilon_{i}, \\
& \Delta E=\lambda_{E} \cdot f_{e}\left(P_{t-1}+\frac{1}{\lambda_{P}} \Delta P, Y_{t-1}+\frac{1}{\lambda_{Y}} \Delta Y, P_{L t-1}+\frac{1}{\lambda_{P L}} \Delta P_{L}\right)-\lambda_{E} E_{t-1}+\sum_{i} \delta_{i E} \Omega^{E}+\mu_{i}, \\
& \Delta Y=\lambda_{Y} \cdot f_{y}\left(P_{t-1}+\frac{1}{\lambda_{P}} \Delta P, E_{t-1}+\frac{1}{\lambda_{E}} \Delta E, P_{L t-1}+\frac{1}{\lambda_{P L}} \Delta P_{L}\right)-\lambda_{Y} Y_{t-1}+\sum_{i} \delta_{i Y} \Omega^{Y}+\tau_{i}, \\
& \Delta P_{L}=\lambda_{P L} f_{p_{l}}\left(P_{t-1}+\frac{1}{\lambda_{P}} \Delta P, E_{t-1}+\frac{1}{\lambda_{E}} \Delta E, Y_{t-1}+\frac{1}{\lambda_{Y}} \Delta Y, A g L_{t-1}+\frac{1}{\lambda_{A g L}} \Delta A g L\right)-\lambda_{P_{L}} P_{L t-1}+\sum_{i} \delta_{i_{L}} \Omega^{P_{L}}+\gamma_{i}, \\
& \Delta A g L=\lambda_{\text {AgL }} f_{a g l}\left(P_{t-1}+\frac{1}{\lambda_{P}} \Delta P, E_{t-1}+\frac{1}{\lambda_{E}} \Delta E, Y_{t-1}+\frac{1}{\lambda_{Y}} \Delta Y, P_{L t-1}+\frac{1}{\lambda_{P L}} \Delta P_{L}\right)-\lambda_{A g L} A g L_{t-1}+\sum_{i} \delta_{i g l} \Omega^{4 g L}+\psi_{i},
\end{aligned}
$$

where $\sum_{i} \delta_{i j} \Omega^{j}$ refers to the exogenous variables, and $\varepsilon_{i}, \mu_{i}, \tau_{i}, \gamma_{i}$, and $\psi_{i}$ are the error terms. Following (Deller et al. 2001), the speed-of-adjustment coefficients $\left(\lambda_{i}\right)$ are embedded in the linear coefficient parameters of $\alpha, \beta$, and $\delta$. Thus, the final econometric relationship can be specified as:

$$
\begin{aligned}
& \Delta P=\alpha_{0 P}+\beta_{1 P} P_{t-1}+\beta_{2 P} E_{t-1}+\beta_{3 P} Y_{t-1}+\beta_{4 P} P_{L_{t-1}}+\beta_{5 P} \Delta E+\beta_{6 P} \Delta Y+\beta_{7 P} \Delta P_{L}+\sum_{i} \delta_{i P} \Omega^{P}+\varepsilon_{i}, \\
& \Delta E=\alpha_{0 E}+\beta_{1 E} E_{t-1}+\beta_{2 E} P_{t-1}+\beta_{3 E} Y_{t-1}+\beta_{4 E} P_{L_{t-1}}+\beta_{5 E} \Delta P+\beta_{6 E} \Delta Y+\beta_{7 E} \Delta P_{L}+\sum_{i} \delta_{i E} \Omega^{E}+\mu_{i}, \\
& \Delta Y=\alpha_{0 Y}+\beta_{1 Y} Y_{t-1}+\beta_{2 Y} P_{t-1}+\beta_{3 Y} E_{t-1}+\beta_{4 Y} P_{L_{t-1}}+\beta_{5 Y} \Delta P+\beta_{6 Y} \Delta E+\beta_{7 Y} \Delta P_{L}+\sum_{i} \delta_{i Y} \Omega^{Y}+\tau_{i}, \\
& \Delta P_{L}=\alpha_{0 P_{L}}+\beta_{1 P_{L}} P_{L t-1}+\beta_{2 P_{L}} P_{t-1}+\beta_{3 P_{L}} E_{t-1}+\beta_{4 P_{L}} Y_{t-1}+\beta_{5 P_{L}} A g L_{t-1}+\beta_{6 P_{L}} \Delta P+\beta_{7 P_{L}} \Delta E \\
& +\beta_{8 P_{L}} \Delta Y+\beta_{9 P_{L}} \Delta A g L+\sum_{i} \delta_{i P_{L}} \Omega^{P_{L}}+\gamma_{i}
\end{aligned}
$$

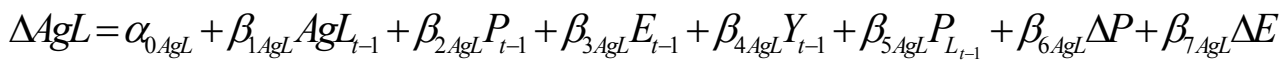

$$
\begin{aligned}
& +\beta_{8 \text { AgL } L} \Delta Y+\beta_{9 \text { Agg } L} \Delta P_{L}+\sum_{i} \delta_{i g d L} \Omega^{\text {AgL }}+\psi_{i}
\end{aligned}
$$




\subsection{SPATIAL GROWTH EQUILIBRIUM MODEL (MODEL 2)}

The previous section provided a detailed mathematical formulation of a regional agricultural land use change model. The integration of regional growth patterns to explain regional land use change helps provide a macro-perspective regarding agricultural land development and policy. This section strengthens the modeling approach by explicitly recognizing spatial dependence in regional growth patterns and agricultural land development. The review of literature in chapter two identified prior studies that argued for integration of spatial econometric approaches because growth patterns and agricultural land development are believed to have significant spatial patterns. The integration of spatial econometric approaches into single linear equation models is fairly straight forward, however, consolidating such approaches in a system of simultaneous equations is complex and computationally demanding.

Econometric estimation using traditional methods, such as ordinary least squares and two and three stage least squares assume the non-existence of spatial autocorrelation of error terms or spatial dependence of explanatory variables. Under assumptions of homoscedastic, non-serially correlated errors, and no perfect explanatory variable correlation, and under assumption of no systematic relationship between the error and independent variables, a best linear unbiased estimation can be generated using the ordinary least squares (OLS) method. Similarly, two and three stage least squares methods can be applied to simultaneous equation models under similar assumptions. However, economic data could be prone to spatial interdependence and proper spatial econometric modeling and estimation becomes relevant. This study hypothesizes simultaneous relationship among population, employment, per capita income, value of 
land per acre, and agricultural land change. Many of these variables are likely to have significant spatial dependence and appropriate spatial econometric estimation becomes necessary.

Spatial autocorrelation refers to the condition where dependent variables and/or errors at one location are correlated with observations for the dependent variable or error at another location, violating one of the classical assumptions of non-correlated errors, i.e., $E\left(Y_{i}, Y_{j}\right) \neq 0$ or $E\left(\varepsilon_{i}, \varepsilon_{j}\right) \neq 0$, where $E$ is the expected value and $Y_{i}$ and $Y_{j}$ are observations of the dependent variable at two different locations, and $\varepsilon_{I}$ and $\varepsilon_{j}$ are observations of errors at different locations. This violates the basic assumption behind linear regression model estimation. For a single equation regression model given by $Y=X \beta+\varepsilon$, if the observed spatial dependence is in the dependent variable, a spatial lag model can be estimated by using $Y=\rho W Y+X \beta+\varepsilon$, where $W Y$ is a spatially lagged dependent variable (a vector of weighted averages of neighboring dependent variable values), $W$ is a spatial weights matrix, and $\rho$ is a coefficient measuring the strength of spatial correlation. The spatial weights matrix can be based on contiguity of locations from which the data is drawn. In this case, an element in the matrix will be 1 for a contiguous county and 0 if the county does not adjoin the given county. Alternatively, the spatial weights matrix can be based on distance from a given location. Spatial autoregressive models are estimated using maximum likelihood to generate asymptotically efficient estimates.

If the observed spatial dependence is in the error terms, a spatial autoregressive model can be estimated by using $Y=X \beta+\varepsilon$, and $\varepsilon=\lambda W \varepsilon+\gamma$, where $W \varepsilon$ is the 
spatially weighted error term, $\gamma$ is a normal error, and $\lambda$ is the coefficient measuring the degree of spatial dependence in errors.

To determine whether spatial dependence is present in single equation models, and to determine whether a spatial lag or a spatial error model is appropriate, there are a number of methods that can be used. A Moran's I test on dependent variables and errors can provide information regarding the existence of spatial dependence. For dependent variables, the Moran's I statistic measures the correlation of dependent variable $Y$ with its spatial lag value $W Y$. Following Cliff and Ord (1972), the Moran's I statistic for errors is given by $I=\varepsilon^{\prime} W \varepsilon / \varepsilon^{\prime} \varepsilon$. This statistic measures the correlation between the sum of squared spatially lagged errors $\left(\varepsilon^{\prime} W \varepsilon\right)$ and the sum of squared errors $\left(\varepsilon^{\prime} \varepsilon\right)$.

A more rigorous test can be conducted by using a Lagrange Multiplier (LM) test on spatial econometric model results. Diagnostic results for LM will help identify the proper spatial econometric model in the case of spatial dependence. Burridge (1980) suggests that an LM test can be used to test for the existence of spatial autocorrelation in errors using the statistics: $L M(\varepsilon)=\left[\left(\varepsilon^{\prime} W \varepsilon / \sigma^{2}\right)^{2}\right] /\left[\operatorname{tr}\left(W^{\prime} W+W^{2}\right)\right]$, where $\left(\varepsilon^{\prime} W \varepsilon\right)$ is as defined above, $\sigma^{2}$ is the maximum likelihood estimate of error variance, $t r$ is the trace of the matrix, and $W$ is the spatial weights matrix. To test for the existence of spatial dependence in the dependent variable, a LM test can be conducted following the procedure suggested by Anselin (1988), which is given as $L M($ spatial lag $)=$ $\left[\left(\varepsilon^{\prime} W Y / \sigma^{2}\right)^{2}\right] /\left[(W X \beta)^{\prime} M W X \beta / \sigma^{2}+\operatorname{tr}\left(W^{\prime} W+W^{2}\right)\right]$, where $X \beta$ is a vector of the predicted values of the independent variables, $W Y$ is the spatially lagged dependent variable, $M$ is the projection matrix given by $\left(I-X\left(X^{\prime} X\right)^{-1} X^{\prime}\right)$, and all other parameters remain as defined above. 
In simultaneous equation models, the identification and estimation of spatial dependence are rather complex and limited work exists in this area. However, a limited number of studies, particularly in regional science, have empirically estimated simultaneous spatial econometric models (Boarnet 1995; Rey and Boarnet 1998; Henry et al. 1999).

The existence of spatial dependence in simultaneous econometric models can be examined by estimating a Moran's I statistic for the endogenous variables in the simultaneous system and for the errors, following the procedure discussed above. The correlation of each endogenous variable with its spatial lag can be computed using a Moran's I, and the degree of spatial dependence can be determined from the results. The existence of spatial dependence in errors can be tested by generating errors from reduced form equations and computing Moran's I statistics on these errors. The Moran's I statistics in this case can be estimated following Anselin's (1997) specification; $I^{*}=N\left(\hat{\varepsilon}^{\prime} W \hat{\varepsilon}\right) / S_{0}\left(\hat{\varepsilon}^{\prime} \hat{\varepsilon}\right)$, where $N$ is the sample size, and $\mathrm{S}_{0}$ is a normalizing factor given by: $S_{0}=\sum_{i} \sum_{j} W i j$ and all other parameters are as defined before.

Though identification of spatial dependence in simultaneous models is fairly straight forward, the estimation of spatial simultaneous econometric models is rather complex and computationally demanding. As a result, this study focuses on modeling, testing, and estimation of a spatial lag system of equations model. The estimation procedure for spatial simultaneous econometric models is discussed in further detail in chapter five.

The spatial simultaneous econometric model can be developed using the same behavioral assumptions as in section 4.2 regarding the spatial mobility of both producers 
and consumers and the adjustment of the endogenous variables to their lagged values. Following these assumptions, a simultaneous relationship between agricultural land development and employment growth, population growth, county per capita income, agricultural land values, the stock of agricultural land at a particular time, and the spatial lags of these variables can be specified. Spatially explicit functional relationships between growth variables and the agricultural land stock can be given as follows:

$$
\begin{aligned}
& P^{*}=f_{p}\left(E^{*}, Y^{*}, P_{L}^{*}, W P^{*}, W E^{*}, W Y^{*}, W P_{L}^{*} \mid \Omega^{P}\right), \\
& E^{*}=f_{e}\left(P^{*}, Y^{*}, P_{L}^{*}, W E^{*}, W P^{*}, W Y^{*}, W P_{L}^{*} \mid \Omega^{E}\right), \\
& Y^{*}=f_{y}\left(P^{*}, E^{*}, P_{L}^{*}, W Y^{*}, W P^{*}, W E^{*}, W P_{L}^{*} \mid \Omega^{Y}\right), \\
& P_{L}^{*}=f_{p_{l}}\left(P^{*}, E^{*}, Y^{*}, A g L^{*}, W P_{L}^{*}, W P^{*}, W E^{*}, W Y^{*}, W A g L^{*} \mid \Omega^{P_{L}}\right), \\
& A g L^{*}=f_{a g l}\left(P^{*}, E^{*}, Y^{*}, P_{L}^{*}, W A g L^{*}, W P^{*}, W E^{*}, W Y^{*}, W P_{L}^{*} \mid \Omega^{A g L}\right),
\end{aligned}
$$

where $P^{*}, E^{*}, Y^{*}, P_{L}^{*}$, and $A g L^{*}$ are the equilibrium levels of population, employment, per capita income, agricultural land value, and agricultural land stocks, respectively; and $\Omega^{P}, \Omega^{E}, \Omega^{Y}, \Omega^{P_{L}}, \Omega^{A g L}$ refer to vectors of other exogenous variables having a direct or indirect impact on the equilibrium levels. The spatially weighted equilibrium values, $W P^{*}, W E^{*}, W Y^{*}, W P_{L}^{*}$, and $W A g L^{*}$, use a county-level contiguity-based spatial weights matrix, $W$, as defined previously.

For the functional relationships indicated in equations (4.31) through (4.35), the distributed lag adjustment equations are represented by equations (4.6) through (4.10). Since the equilibrium endogenous variables indicated in the right-hand side of equations (4.6) through (4.10) are not observable, these equilibrium variables can be expressed in observable variables using equations (4.16) through (4.20). Substituting relationships 
established in these latter equations into equations (4.6) through (4.10), a spatial system of equations model can be specified as follows.

$$
\begin{aligned}
& \Delta P= \lambda_{P} f_{p}\left(E_{t-1}+\frac{1}{\lambda_{E}} \Delta E, Y_{t-1}+\frac{1}{\lambda_{Y}} \Delta Y, P_{L t-1}+\frac{1}{\lambda_{P L}} \Delta P_{L},\right. \\
& W\left(E_{t-1}+\frac{1}{\lambda_{E}} \Delta E\right), W\left(Y_{t-1}+\frac{1}{\lambda_{Y}} \Delta Y\right), W\left(P_{L t-1}+\frac{1}{\lambda_{P L}} \Delta P_{L}\right), \\
&\left.W\left(P_{t-1}+\frac{1}{\lambda_{P}} \Delta P\right)\right)-\lambda_{P} P_{t-1}+\sum_{i} \delta_{i P} \Omega^{P}+\varepsilon_{i} \\
& \Delta E= \lambda_{E}\left(P_{t-1}+\frac{1}{\lambda_{P}} \Delta P, Y_{t-1}+\frac{1}{\lambda_{Y}} \Delta Y, P_{L t-1}+\frac{1}{\lambda_{P L}} \Delta P_{L},\right. \\
& W\left(P_{t-1}+\frac{1}{\lambda_{P}} \Delta P\right), W\left(Y_{t-1}+\frac{1}{\lambda_{Y}} \Delta Y\right), W\left(P_{L t-1}+\frac{1}{\lambda_{P L}} \Delta P_{L}\right), \\
& W\left(E_{t-1}+\frac{1}{\lambda_{E}} \Delta E\right)-\lambda_{P} E_{t-1}+\sum_{i} \delta_{i E} \Omega^{E}+\mu_{i} \\
&\left(P_{L}\right) \\
& \lambda_{P L}\left(P_{t-1}+\frac{1}{\lambda_{P}} \Delta P, E_{t-1}+\frac{1}{\lambda_{E}} \Delta E, Y_{t-1}+\frac{1}{\lambda_{Y}} \Delta Y, A g L_{t-1}+\frac{1}{\lambda_{A g L}} \Delta A g L,\right. \\
&\left(P_{t-1}+\frac{1}{\lambda_{P}} \Delta P\right), W\left(E_{t-1}+\frac{1}{\lambda_{E}} \Delta E\right), W\left(Y_{t-1}+\frac{1}{\lambda_{Y}} \Delta Y\right), \\
&\left.W\left(Y_{t-1}+\frac{1}{\lambda_{Y}} \Delta Y\right)\right)-\lambda_{Y} Y_{t-1}+\sum_{i} \delta_{i E} \Omega^{E}+\tau_{i} \\
& \lambda_{Y}\left(P_{t-1}+\frac{1}{\lambda_{P}} \Delta P, E_{t-1}+\frac{1}{\lambda_{E}} \Delta E, P_{L t-1}+\frac{1}{\lambda_{P L}} \Delta P_{L},\right. \\
&\left(P_{L t-1}+\frac{1}{\lambda_{P L}} \Delta P_{L}\right)-\lambda_{P L} P_{L t-1}+\sum_{i} \delta_{i P_{L}} \Omega^{P_{L}}+\gamma_{i} \\
&\left.P_{t-1}+\frac{1}{\lambda_{E}} \Delta E\right), W\left(P_{L t-1}+\frac{1}{\lambda_{P L}} \Delta P_{L}\right),
\end{aligned}
$$




$$
\begin{aligned}
& \Delta A g L=\lambda_{A g L}\left(P_{t-1}+\frac{1}{\lambda_{P}} \Delta P, E_{t-1}+\frac{1}{\lambda_{E}} \Delta E, Y_{t-1}+\frac{1}{\lambda_{Y}} \Delta Y, P_{L t-1}+\frac{1}{\lambda_{P L}} \Delta P,\right. \\
& W\left(P_{t-1}+\frac{1}{\lambda_{P}} \Delta P\right), W\left(E_{t-1}+\frac{1}{\lambda_{E}} \Delta E\right), W\left(Y_{t-1}+\frac{1}{\lambda_{Y}} \Delta Y\right), W\left(P_{L_{t-1}}+\frac{1}{\lambda_{P_{L}}} \Delta P_{L}\right), \\
& W\left(A g L_{t-1}+\frac{1}{\lambda_{A g L}} \Delta A g L\right)-\lambda_{A g L} A g L_{t-1}+\sum_{i} \delta_{i A g L} \Omega^{A g L}+\psi_{i}
\end{aligned}
$$

As before, the speed-of-adjustment coefficients $\left(\lambda_{i}\right)$ can be embedded in the linear coefficient parameters (Deller et al. 2001) $\alpha, \beta$, and $\delta$. To simplify the equations and combine terms we can use the fact that $X+W X=(I+W) X$, where $X$ is a data matrix, $W$ is a spatial weights matrix, and $I$ is an identity matrix. The final spatially explicit econometric relationships based on equations (4.36) through (4.40) are as follows.

$$
\begin{aligned}
\Delta P= & \alpha_{0 P}+\beta_{1 P}(I+W) P_{t-1}+\beta_{2 P}(I+W) E_{t-1}+\beta_{3 P}(I+W) Y_{t-1}+\beta_{4 P}(I+W) P_{L t-1} \\
& +\beta_{5 P}(I+W) \Delta E+\beta_{6 P}(I+W) \Delta Y+\beta_{7 P}(I+W) \Delta P_{L}+\beta_{8 P} W \Delta P+\sum_{i} \delta_{i P} \Omega^{P}+\varepsilon_{i} \\
\Delta E= & \alpha_{0 E}+\beta_{1 E}(I+W) E_{t-1}+\beta_{2 E}(I+W) P_{t-1}+\beta_{3 E}(I+W) Y_{t-1}+\beta_{4 E}(I+W) P_{L t-1} \\
& +\beta_{5 E}(I+W) \Delta P+\beta_{6 E}(I+W) \Delta Y+\beta_{7 E}(I+W) \Delta P_{L}+\beta_{8 E} W \Delta E+\sum_{i} \delta_{i E} \Omega^{E}+\mu_{i} \\
\Delta Y= & \alpha_{0 Y}+\beta_{1 Y}(I+W) Y_{t-1}+\beta_{2 Y}(I+W) P_{t-1}+\beta_{3 Y}(I+W) E_{t-1}+\beta_{4 Y}(I+W) P_{L t-1} \\
& +\beta_{5 Y}(I+W) \Delta P+\beta_{6 Y}(I+W) \Delta E+\beta_{7 Y}(I+W) \Delta P_{L}+\beta_{8 Y} W \Delta Y+\sum_{i} \delta_{i Y} \Omega^{Y}+\tau_{i} \\
& \\
\Delta P_{L}= & \alpha_{0 P_{L}}+\beta_{1 P_{L}}(I+W) P_{L t-1}+\beta_{2 P_{L}}(I+W) P_{t-1}+\beta_{3 P_{L}}(I+W) E_{t-1}+\beta_{4 P_{L}}(I+W) Y_{t-1} \\
& +\beta_{5 P_{L}}(I+W) A g L_{t-1}+\beta_{6 P_{L}}(I+W) \Delta P+\beta_{7 P_{L}}(I+W) \Delta E+\beta_{8 P_{L}}(I+W) \Delta Y \\
& +\beta_{9 P_{L}}(I+W) \Delta A g L+\beta_{10 P_{L}} W \Delta P_{L}+\sum_{i} \delta_{i P_{L}} \Omega^{P_{L}}+\gamma_{i} \\
& \\
\Delta A g L & =\alpha_{0 A g L}+\beta_{1 A g L}(I+W) A g L_{t-1}+\beta_{2 A g L}(I+W) P_{t-1}+\beta_{3 A g L}(I+W) E_{t-1}+\beta_{4 A g L}(I+W) Y_{t-1} \\
& +\beta_{5 A g L}(I+W) P_{L t-1}+\beta_{6 A g L}(I+W) \Delta P+\beta_{7 A g L}(I+W) \Delta E+\beta_{8 A g L}(I+W) \Delta Y \\
& +\beta_{9 A g L}(I+W) \Delta P_{L}+\beta_{10 A g L} W \Delta A g L+\sum_{i} \delta_{i A g L} \Omega^{A g L}+\psi
\end{aligned}
$$


Estimating equations (4.41) through (4.45) should provide insight into the factors that affect regional agricultural land development. If spatial correlation is present, this model gives an unbiased and efficient estimate of coefficients by directly integrating spatial dependence into the model. The equations are estimated using county level data from the Northeast states.

\subsection{DEFINITIONS OF DATA AND STATISTICAL SUMMARY}

Estimation of the growth equilibrium model and its spatial version requires a variety of county-level data ranging from population and employment growth to an assortment of agricultural information. This section discusses data sources, defines the variables, and presents summary statistics.

Tables 4.1, 4.2, and 4.3 give the definition and sources of each variable used in this study. The endogenous variables, including their initial values, are structural variables of the model that define the interaction between population, employment, and income growth and their impacts on the amount and value of agricultural land (Table 4.1). County-level data for changes in population density, employment density (total employment per square mile), and per capita income were computed from the Regional Economic Information System (REIS) (U.S. Census 2001) and the County and City Data Book (C\&CDB) and represent changes from 1987 to 1999. County-level changes in the per acre value of farmland and agricultural land density (farmland per square mile) were calculated from the U.S. Census of Agriculture (USDA 1992; USDA 2002) and the County and City Data Book showing changes from 1987 to 2002. Initial conditions for these variables, for 1987, are from the same data sources. 


\section{Table 4.1. Definition and Data Source for Endogenous and Initial Condition Variables.}

\begin{tabular}{|c|c|c|}
\hline Variable & Definition & Source of Data \\
\hline \multicolumn{3}{|c|}{ Endogenous Variables } \\
\hline$\Delta \mathrm{P}$ & Change in Population Density from 1987 to 1999 & REIS and C\&CDB \\
\hline$\Delta \mathrm{E}$ & Change in Employment Density from 1987 to 1999 & REIS and C\&CDB \\
\hline$\Delta \mathrm{Y}$ & Change in Per Capita Income from 1987 to 1999 & REIS and C\&CDB \\
\hline$\Delta \mathrm{P}_{\mathrm{L}}$ & Change in Per Acre Value of Farmland from 1987 to 2002 & U.S. Census of Agriculture and C\&CDB \\
\hline$\Delta \mathrm{AgL}$ & Change in Agricultural Land Density from 1987 to 2002 & U.S. Census of Agriculture and C\&CDB \\
\hline \multicolumn{3}{|c|}{ Initial Conditions } \\
\hline$P_{t-1}$ & Population Density in 1987 & REIS and C\&CDB \\
\hline $\mathrm{E}_{\mathrm{t}-1}$ & Employment Density in 1987 & REIS and C\&CDB \\
\hline $\mathrm{Y}_{\mathrm{t}-1}$ & Per Capita Income in 1987 & REIS and C\&CDB \\
\hline $\mathrm{P}_{\mathrm{Lt}-1}$ & Per Acre Value of Land in 1987 & U.S. Census of Agriculture \\
\hline $\mathrm{AgL}_{\mathrm{t}-1}$ & Agricultural Land Density in 1987 & U.S. Census of Agriculture \\
\hline
\end{tabular}

Several variables measure agricultural performance and its impact on farmland development, agricultural income per farm, and average government payment per farm (Table 4.2). All are computed from the U.S. Census of Agriculture (1992) for 1987. The percentage of county land in farms (U.S. Census of Agriculture) is included to test whether concentration of farming activity influences the value of land per acre and the extent of farmland development. Variables for the variety of farmland protection policies previously discussed examine their impacts on farmland development. The farmland protection policies included in this study are agricultural districts, farmland protection zoning, transfer of development rights, and tax incentives for donation of farmland preservation easements. County level data was not available for these farmland protection policies, thus a dummy variable is used which indicates the presence or absence of these policies at the state level. All policy data are from the Northeast Sustainable Agriculture Working Group (NSAWG) for 2002. 
Table 4.2. Definition and Data Source for Agricultural Performance Variables and Farmland Protection Policies.

\begin{tabular}{lll}
\hline Variable & Definition & Source of Data \\
\hline Agricultural Performance and Land Variables & \\
AgIncPF $_{\mathrm{t}-1}$ & Agricultural Income Per Farm in 1987 (thousands of dollars) & U.S. Census of Agriculture \\
GvPayPF $_{\mathrm{t}-1}$ & Average Government Payment Per Farm in 1987 (dollars) & U.S. Census of Agriculture \\
$\%$ CLFarm $_{\mathrm{t}-1}$ & Percentage of County Land in Farms in 1987 & U.S. Census of Agriculture \\
Farmland Protection Policies & \\
TaxEasemt & Tax Incentive for Donation of Farmland Preservation Easement & NSAWG \\
AgDistrc & Agricultural District & NSAWG \\
AgPZone & Agricultural Land Protection Zoning & NSAWG \\
TDR & Transfer of Development Rights & NSAWG \\
\hline
\end{tabular}

The employment classification variables, number of people working on farms, in the service sector, in mining, and in construction (Table 4.3) are used in the employment equation (4.42) to test the contribution of each sector to overall employment growth.

Significantly more employment growth from the service sector and construction may be an indication of sprawl. The government tax and expenditure variables, per capita local government taxes (total taxes paid in a county divided by county population), property taxes as a percentage of total taxes, and per capita local government expenditures (at the county level), are used to examine whether spatial tax differentials and/or public sector spending have an impact on growth. Per capita local government expenditures were computed from the REIS and C\&CDB.

A series of county-level characteristics are used to analyze the impact of local conditions on farmland development (Table 4.3). The urban influence code, developed by the USDA Economic Research Service (ERS) (2003), measures the extent of development pressure from urbanized places and ranges from 1 to 9 . A code of 1 indicates a county that is in a metro area with at least 1 million residents or more; 2 indicates a metro area with fewer than 1 million residents; 3 means the county is in a 
micropolitan area adjacent to a large metro area; 4 indicates a non-core county adjacent to a large metro area; and 5 represents a micropolitan area adjacent to a small metro area. A code of 6 indicates a non-core county which is adjacent to a small metro area and which contains a town of at least 2,500 residents; 7 is for a non-core county adjacent to a small metro and which does not contain a town of at least 2,500; 8 indicates a micropolitan area not adjacent to a metro area; and code 9 represents a non-core county which is adjacent to a micro area and which contains a town of 2,500 to 9,999 residents.

The median value of owner-occupied housing, unemployment rate, and number of hospital beds per 100,000 people represent county characteristics which reflect the attractiveness of moving to a county or staying there based on access to affordable housing, economic opportunities and healthcare services. These variables help measure the indirect impact of these local characteristics on farmland development.

The percentage of a county's population (age 25 and above) with a bachelor's degree and higher, along with the percentage of persons in a county below the federal poverty line reflect county characteristics regarding the degree of human capital formation and distribution of poverty. These variables may have significant bearing on county income and employment growth, which consequently may affect the extent of farmland development.

State and interstate road density, calculated as miles per square mile, reflect the degree of infrastructure development, which could have a significant influence on county economic growth, demographic change, and consequent farmland development. These variables were calculated by the West Virginia University (WVU) Natural Resources Analysis Center (NRAC) using 2003 data. 
Table 4.3. Definition and Data Source for Employment, Government Taxes and Expenditures, and Local County Characteristics Variables.

\begin{tabular}{|c|c|c|}
\hline Variable & Definition & Source of Data \\
\hline \multicolumn{3}{|c|}{ Employment Classifications } \\
\hline FarmEmp $_{\mathrm{t}-1}$ & Number of persons in Farm Employment in 1987 & REIS \\
\hline ServEmp $_{\mathrm{t}-1}$ & Number of persons in Service Employment in1987 & REIS \\
\hline $\operatorname{MinEmp}_{\mathrm{t}-1}$ & Number of persons in Mining Employment in 1987 & REIS \\
\hline ConstEmp $_{t-1}$ & Number of persons in Construction Employment in 1987 & REIS \\
\hline \multicolumn{3}{|c|}{ Local Government Taxes and Expenditures } \\
\hline PCTax $_{t-1}$ & Per Capita Taxes in 1987 & $\mathrm{C} \& \mathrm{CDB}$ \\
\hline Prop $\% \mathrm{Tax}_{\mathrm{t}-1}$ & Property tax as Percentage of Total Taxes in 1987 & $\mathrm{C} \& \mathrm{CDB}$ \\
\hline PCGovExp $\mathrm{p}_{\mathrm{t}-1}$ & Per Capita Local Government Expenditures in 1987 & C\&CDB and REIS \\
\hline \multicolumn{3}{|c|}{ Local County Characteristics } \\
\hline UInfCode & Urban Influence Code (1 to 9) & ERS USDA \\
\hline MVOwnOcc $_{t-1}$ & Median Value of Owner Occupied Housing in 1990 & $\mathrm{C} \& \mathrm{CDB}$ \\
\hline UnempRate $_{t-1}$ & Unemployment Rate in 1991 & $\mathrm{C} \& \mathrm{CDB}$ \\
\hline HospB100k $\mathrm{k}_{\mathrm{t}-1}$ & Number of Hospital Beds per 100,000 Population in 1991 & $\mathrm{C} \& \mathrm{CDB}$ \\
\hline$\%$ Degree $_{t-1}$ & Percentage of County Population with Bachelor's degree or Higher in 1990 & $\mathrm{C} \& \mathrm{CDB}$ \\
\hline$\% \mathrm{BlPov}_{\mathrm{t}-1}$ & Percent of Persons in a County Below Poverty Level in 1989 & $\mathrm{C} \& \mathrm{CDB}$ \\
\hline StateRD & State Road Density (miles of state road per square mile) & NRAC, WVU \\
\hline InterstD & Interstate Road Density (miles of interstate per square mile) & NRAC, WVU \\
\hline
\end{tabular}

Tables 4.4, 4.5, and 4.6 summarize the descriptive statistics of the variables in the two models. There are 299 counties in the northeastern states; however, the descriptive statistics are based on 290 counties. One of the excluded counties is Baltimore, Maryland, which was excluded because it is not included in the Census of Agriculture (1992 and 2002). The other 8 counties excluded from this study are: Suffolk, Massachusetts; Hudson, New Jersey; Bronx, New York; Kings, New York; New York, New York; Queens, New York; Richmond, New York; and Philadelphia, Pennsylvania. Each of these counties, except Philadelphia, reported zero agricultural employment for the study period. Seven of the counties had less than 26 acres in agricultural land, and by 2002 , Philadelphia had only 31 acres of farmland. Although these counties are fast growth centers, attempting to measure the impact of their growth on the negligible amount of 
farmland in these counties will be misleading as there will be almost no change.

However, the impact of other fast growing counties on agricultural land in neighboring counties is important and will maintain some of this information from the excluded counties. In addition, the urban influence code for each of the included counties is used to capture part of the missing information due to the excluded counties.

Table 4.4. Descriptive Statistics - Endogenous and Initial Condition Variables.

\begin{tabular}{|c|c|c|c|c|}
\hline Variable & Mean & Standard Deviation & Minimum & Maximum \\
\hline \multicolumn{5}{|c|}{ Endogenous Variables } \\
\hline$\Delta P$ & 16.87 & 55.28 & -494.91 & 326.32 \\
\hline$\Delta E$ & 22.55 & 44.67 & -240.37 & 265.28 \\
\hline$\Delta Y$ & $8,015.08$ & $4,465.55$ & $2,027.00$ & $29,382.00$ \\
\hline$\Delta P_{L}$ & $2,904.74$ & $6,328.51$ & -492.00 & $74,107.00$ \\
\hline$\triangle A g L$ & -7.69 & 24.49 & -143.92 & 115.14 \\
\hline \multicolumn{5}{|c|}{ Initial Conditions } \\
\hline$P_{t-1}$ & 361.14 & 711.11 & 2.89 & $6,426.30$ \\
\hline$E_{t-1}$ & 194.75 & 414.46 & 1.34 & $3,656.26$ \\
\hline $\mathrm{Y}_{\mathrm{t}-1}$ & $14,847.90$ & $3,879.12$ & $7,311.00$ & $27,680.00$ \\
\hline $\mathrm{P}_{\mathrm{Lt}-1}$ & $2,131.66$ & $2,740.89$ & 385.00 & $29,697.00$ \\
\hline $\mathrm{AgL}_{\mathrm{t}-1}$ & 157.64 & 105.84 & 0.67 & 478.84 \\
\hline \multicolumn{5}{|c|}{ Endogenous Variables (Spatially Weighted) } \\
\hline $\mathrm{W} \Delta \mathrm{P}$ & 17.57 & 28.41 & -66.00 & 124.75 \\
\hline $\mathrm{W} \Delta \mathrm{E}$ & 22.55 & 22.79 & -30.75 & 120.00 \\
\hline $\mathrm{W} \Delta \mathrm{Y}$ & $8,059.06$ & $3,750.00$ & $2,937.50$ & $19,245.75$ \\
\hline $\mathrm{W} \Delta \mathrm{PL}$ & $3,026.56$ & $4,690.82$ & -800.50 & $31,159.50$ \\
\hline $\mathrm{W} \Delta \mathrm{AgL}$ & -7.92 & 12.35 & -41.75 & 21.75 \\
\hline \multicolumn{5}{|c|}{ Initial Conditions (Spatially Weighted) } \\
\hline $\mathrm{WP}_{\mathrm{t}-1}$ & 371.66 & 542.55 & 21.50 & $3,827.25$ \\
\hline $\mathrm{WE}_{\mathrm{t}-1}$ & 201.88 & 316.66 & 9.25 & $2,165.00$ \\
\hline $\mathrm{WY}_{\mathrm{t}-1}$ & $14,892.84$ & $3,448.73$ & $8,593.00$ & $25,786.25$ \\
\hline $\mathrm{WP}_{\mathrm{Lt}-1}$ & $2,213.10$ & $2,400.39$ & 451.25 & $15,380.25$ \\
\hline $\mathrm{WAgL}_{\mathrm{t}-1}$ & 158.47 & 83.31 & 5.50 & 421.00 \\
\hline
\end{tabular}


Table 4.5. Descriptive Statistics - Agricultural Performance Variables and Farmland Protection Policies.

\begin{tabular}{|c|c|c|c|c|}
\hline Variable & Mean & Standard Deviation & Minimum & Maximum \\
\hline \multicolumn{5}{|c|}{ Agricultural Performance and Land Variables } \\
\hline $\mathrm{AgIncPF}_{\mathrm{t}-1}$ & $50,475.71$ & $39,302.73$ & $1,695.00$ & $260,507.00$ \\
\hline GvPayPF $_{\mathrm{t}-1}$ & $5,492.16$ & $4,498.59$ & 0.00 & $24,741.00$ \\
\hline$\%$ CLFarm $_{t-1}$ & 24.06 & 15.92 & 0.40 & 75.00 \\
\hline \multicolumn{5}{|c|}{ Farmland Protection Policies } \\
\hline TaxEasemt & 0.33 & 0.47 & 0.00 & 1.00 \\
\hline AgDistrc & 0.63 & 0.48 & 0.00 & 1.00 \\
\hline AgPZone & 0.32 & 0.47 & 0.00 & 1.00 \\
\hline TDR & 0.67 & 0.47 & 0.00 & 1.00 \\
\hline
\end{tabular}

Table 4.6. Descriptive Statistics - Employment, Government Taxes and Expenditures, and Local County Characteristics Variables.

\begin{tabular}{lrrrr}
\hline Variable & Mean & Standard Deviation & Minimum & Maximum \\
\hline Employment Classifications & & & & \\
FarmEmp $_{\mathrm{t}-1}$ & $1,008.19$ & 927.60 & 0.00 & $8,337.00$ \\
ServEmp $_{\mathrm{t}-1}$ & $22,594.19$ & $41,970.38$ & 53.00 & $326,659.00$ \\
MinEmp $_{\mathrm{t}-1}$ & 376.32 & 717.65 & 0.00 & $5,479.00$ \\
ConstEmp $_{\mathrm{t}-1}$ & $5,083.02$ & $7,893.12$ & 48.00 & $48,511.00$ \\
Local Government Taxes and Expenditures & 602.16 & & & \\
PCTax $_{\mathrm{t}-1}$ & 83.94 & 13.67 & 90.00 & $2,503.00$ \\
Prop\%Tax $_{\mathrm{t}-1}$ & 1.38 & 0.49 & 50.10 & 99.90 \\
PCGovExp $_{\mathrm{t}-1}$ & & & 0.65 & 3.54 \\
Local County Characteristics & 4.10 & 2.73 & 1.00 & \\
UInfCode & $86,228.28$ & $49,036.48$ & $15,800.00$ & $299,400.00$ \\
MVOwnOcc $_{\mathrm{t}-1}$ & 7.89 & 2.93 & 2.90 & 22.00 \\
UnempRate $_{\mathrm{t}-1}$ & 335.91 & 270.70 & 0.00 & $3,224.00$ \\
HospB100 $_{\mathrm{t}-1}$ & 17.01 & 7.94 & 4.60 & 49.90 \\
\%Degree $_{\mathrm{t}-1}$ & 12.14 & 6.39 & 2.60 & 39.20 \\
\%BlPov $_{\mathrm{t}-1}$ & 0.36 & 0.16 & 0.00 & 0.91 \\
StateRD $_{\text {InterstD }}$ & 0.08 & 0.10 & 0.00 & 0.63 \\
\hline
\end{tabular}




\section{CHAPTER 5}

\section{EMPIRICAL RESULTS AND ANALYSIS}

\subsection{EMPIRICAL ESTIMATION}

The two models previously presented are estimated and results are presented in this chapter. The first model (equations 4.26 through 4.30) estimates the relationship between the endogenous variables of population density change, employment density change, per capita income growth, change in the value of farmland per acre, and agricultural land density change as well as a number of exogenous variables. The second model estimates the same relationships while explicitly accounting for spatial interdependence by introducing spatially weighted endogenous variables into the system.

Estimation using ordinary least squares (OLS) will be biased and inconsistent when endogenous variables are used as explanatory variables. This simultaneity bias results from the correlation of right hand side endogenous variables with the error terms. In the models presented in chapter 4 , there is implied theoretical interdependence (simultaneity) among the endogenous variables. To account for this three-stage least squares estimation is used. Unlike OLS estimation, the three-stage least squares procedure provides consistent estimates of model parameters. It is also preferred to twostage least squares because it is a full-information estimation procedure that estimates all parameters simultaneously. As a result, three-stage least squares provides asymptotically more efficient results than that of two-stage least squares (Ma and Yasuo 2003). 
The dependent variables in the first model are changes in population density, employment density, per capita income, per acre farmland value, and agricultural land density. The estimated coefficients for all of the right hand side variables are shown in Table 5.2. The model is estimated using changes in right hand side endogenous variables, a vector of initial condition endogenous variables (which are one period lagged variables), and a set of exogenous variables. The model is estimated using LIMDEP software (Greene 2002).

The Durban-Watson test statistics for the two models were estimated as 1.98 and 1.99, respectively, indicating no problem with autocorrelation in either model. Multicollinearity generally results in larger standard errors and may result in unexpected coefficient signs. It is addressed in both models by transforming some variables and/or dropping highly correlated variables (from pair-wise correlation tests) to maximize model efficiency while maintaining model information. Cross-sectional data is also prone to heteroscedasticity due to variation in the variance of errors resulting from differences in size of geographic areas or distribution of economic variables. The larger the variation in the size of observations in a sample, the more likely the associated error terms will be heteroscedastic (Studenmund 2001). The results presented in Tables 5.2 and 5.3 are corrected for heteroscedasticity using White's heteroscedasticity-consistent variance and standard error estimation.

The existence of spatial autocorrelation in the data for the northeastern U.S. is tested using Moran's I statistics, as they indicate the degree of correlation between variables and their spatial lags. The Moran's I statistics are reported in Table 5.1 for the endogenous variables in the spatial model. 
Table 5.1. Moran's I Statistics for spatial autocorrelation.

\begin{tabular}{lrrrrr}
\hline $\begin{array}{c}\text { Moran's I } \\
\text { Statistic }\end{array}$ & $\Delta \boldsymbol{P}$ Equation & $\Delta \boldsymbol{E}$ Equation & $\Delta \boldsymbol{Y}$ Equation & $\Delta \boldsymbol{P}_{\boldsymbol{L}}$ Equation & $\Delta \boldsymbol{A g L}$ Equation \\
\hline$W \Delta \hat{P}$ & 0.358 & 0.373 & 0.211 & 0.166 & -0.230 \\
$W \Delta \hat{E}$ & 0.381 & 0.351 & 0.166 & 0.167 & -0.187 \\
$W \Delta \hat{Y}$ & 0.182 & 0.185 & 0.776 & 0.467 & -0.191 \\
$W \Delta \hat{P}_{L}$ & 0.162 & 0.240 & 0.514 & 0.542 & -0.065 \\
$W \Delta \hat{A g} L$ & - & - & - & -0.056 & 0.411 \\
\hline
\end{tabular}

For the population density change equation $(\Delta P)$, some spatial autocorrelation is detected for spatial lags of population density change and employment density change, with Moran's I estimates of 0.358 and 0.381 , respectively. The spatial autocorrelation of population density change with changes in per capita income and land value change was minimal.

For the employment density change equation $(\Delta E)$, spatial autocorrelation measures of 0.373 and 0.351 show some spatial autocorrelation for spatial lags of the population density change and employment density change variables, respectively. Spatial autocorrelation for the other spatially-weighted endogenous variables of per capita income change and changes in value of land per acre were fairly low, estimated at 0.185 and 0.24 , for the respective Moran's I measures.

For the per capita income change equation $(\Delta Y)$, Moran's I statistics of 0.776 for the spatial lag in per capita income change and 0.514 for the value of land change indicate strong positive spatial autocorrelation. Spatial autocorrelation for the spatial lag of population and employment appears to be minimal. 
Measures of spatial autocorrelation between the change in land value $\left(\Delta P_{L}\right)$ and its spatial lag and the spatial lag of income growth, at 0.542 and 0.467 , respectively, indicate relatively strong positive spatial autocorrelation. The measures for spatial lag of population change, employment change, and agricultural land change indicate little spatial autocorrelation. Finally, in the agricultural land change equation $(\triangle A g L)$, positive spatial autocorrelation is reported for its spatial lag variable, 0.411 . Little spatial autocorrelation is indicated for the other variables.

The preceding evidence from each equation suggests that the simultaneous growth model shows evidence of spatial interdependence for some of the endogenous variables with their spatial lag values and the spatial lags of other endogenous variables in the system. In this case, the efficiency of the model can be improved by estimating the second model using the spatial econometric approach for simultaneous systems discussed in this section.

Limited literature exists regarding estimation of simultaneous systems of equations when spatial autocorrelation is present. Even though the estimation of spatial econometric models using ordinary least squares is well developed and extensively applied, similar estimation of spatial econometric models with simultaneous equations systems is not common and in the early stages of development. Theoretical discussion of estimation of such models is available in the literature, however, application of the theory in empirical research is rare. This study estimates a spatial simultaneous equations model following some early applications. The estimation of the second model (equations 4.31 through 4.45) benefits from earlier works by Boarnet (1995), Henry et al. (1999), and 
Rey and Boarnet (1998) which used instrumental variable estimation in spatial systems of equations models.

The second model is also estimated using three-stage least squares. One problem with this estimation procedure is the existence of right-hand-side spatially weighted endogenous variables as presented in equations 4.41 through 4.45 . One theoretical approach for solving this problem has been suggested by Anselin (1980) where righthand-side spatially-weighted endogenous variables can be instrumented on exogenous variables in the system. Using this method, first, the right hand side endogenous variables are predicted using instrumental variables (initial condition variables and a set of exogenous variables). The resulting predicted endogenous variable values are postmultiplied by the appropriate weights matrix to generate predicted spatially weighted variables. Mathematically, this can be represented as: $W\left[X\left(X^{\prime} X\right)^{-1} X^{\prime} \Delta Y\right]=W(X \beta)$, where $W$ is the spatial weights matrix, $X$ represents a matrix of all exogenous variables, and $\Delta Y$ represents a vector for a right-hand side endogenous variable, and $\beta$ is a vector of coefficients being estimated. These estimated, spatially-weighted values for the righthand-side endogenous variables are then substituted into the right-hand side of the original model for estimation using three-stage least squares. This procedure is used for estimation of the spatial growth equilibrium model. To test whether these predicted endogenous variables mimic the underlying pattern of the original endogenous variables, the original and predicted endogenous variables are graphed together (see Figures 5.15.5).

Predicted population density change is graphed with actual population density change in Figure 5.1 and shows that the predicted values properly mimic patterns in the 
actual population density change data. Aside from some outliers, the movement of the two variables is similar. The same can be seen in Figure 5.2 for predicted employment density change and actual employment density change. The predicted values from instrumental variable estimation properly mimic the original data.

Figure 5.1. Actual and Predicted Change in Population Density.

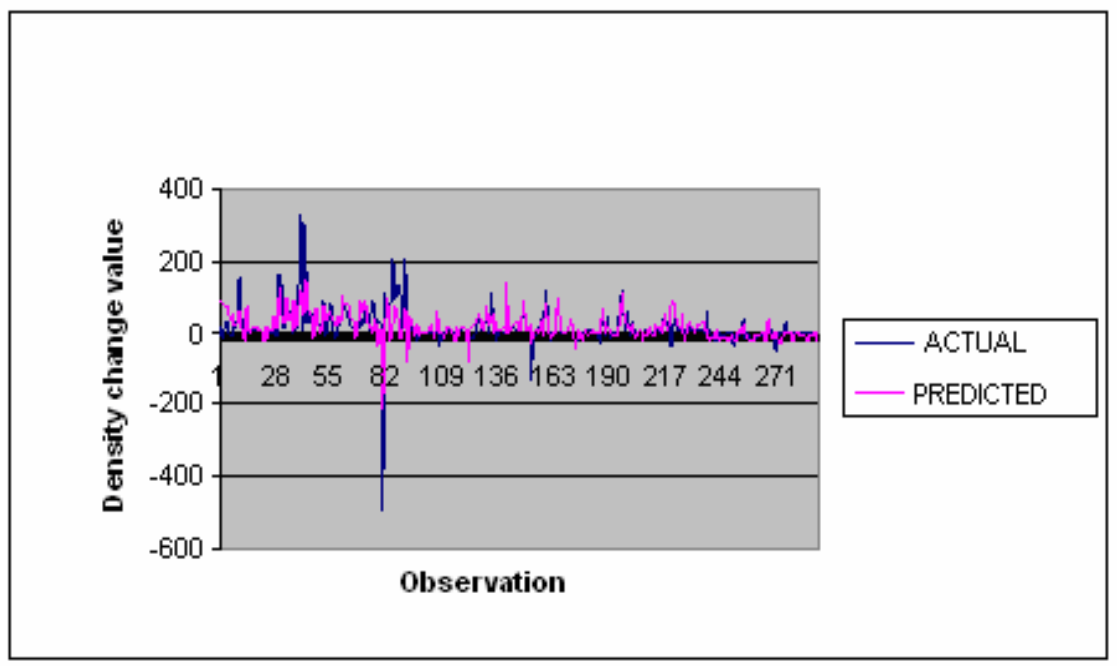

Figure 5.2. Actual and Predicted Change in Employment Density.

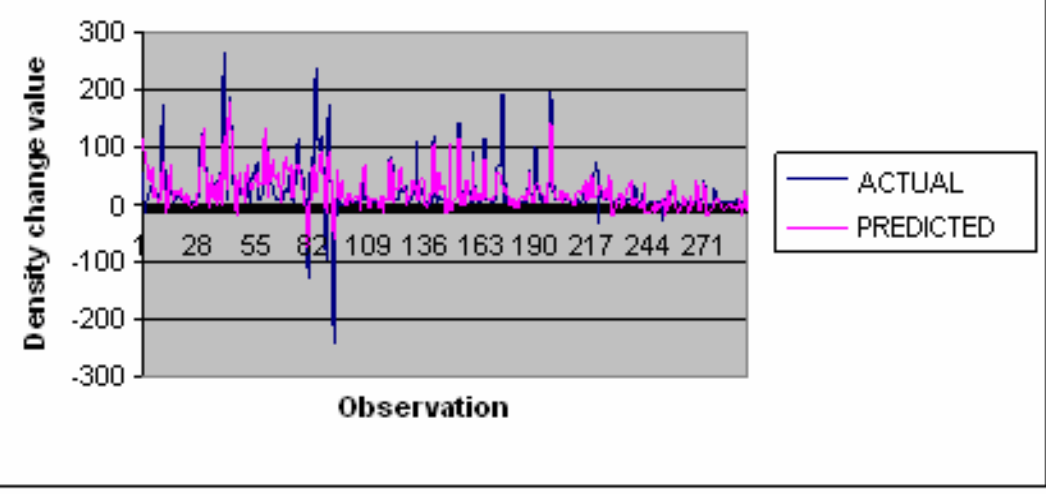


Graphing predicted per capita income change and actual per capita income change (in dollars) in Figure 5.3 reveals that the predicted values behave like the non-stochastic reported values. Similarly, in Figure 5.4, plotting the predicted change in the per acre value of agricultural land, and the actual dollar change reveals that the predicted values are similar to the actual data. Figure 5.5 shows predicted changes in agricultural land density against actual values.

Figure 5.3. Actual and Predicted Change in Per Capita Income.

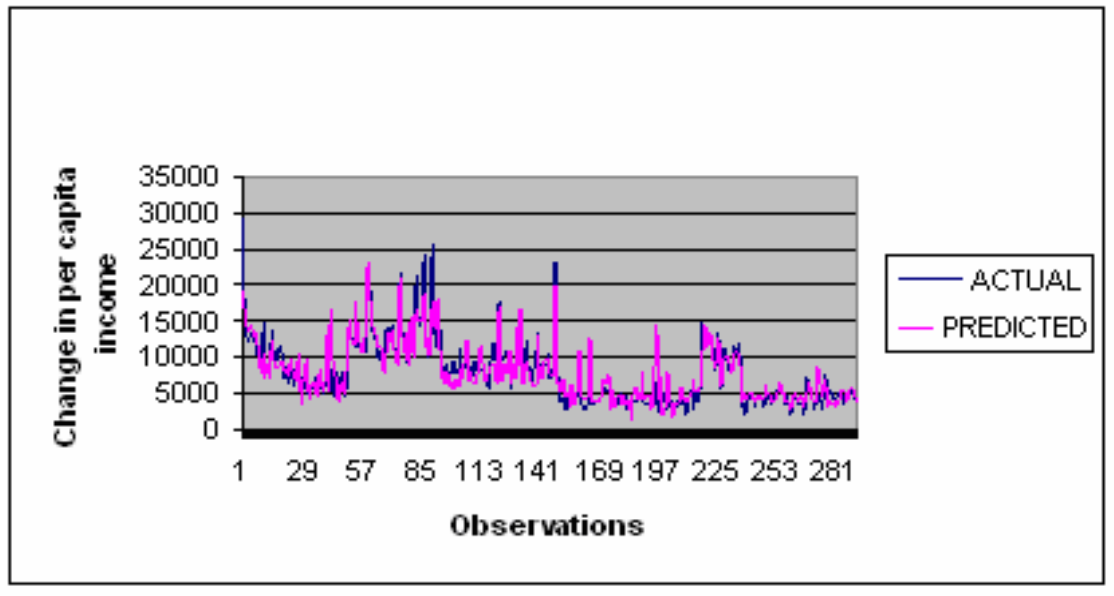

Figure 5.4. Actual and Predicted Change in Per Acre Farmland Value.

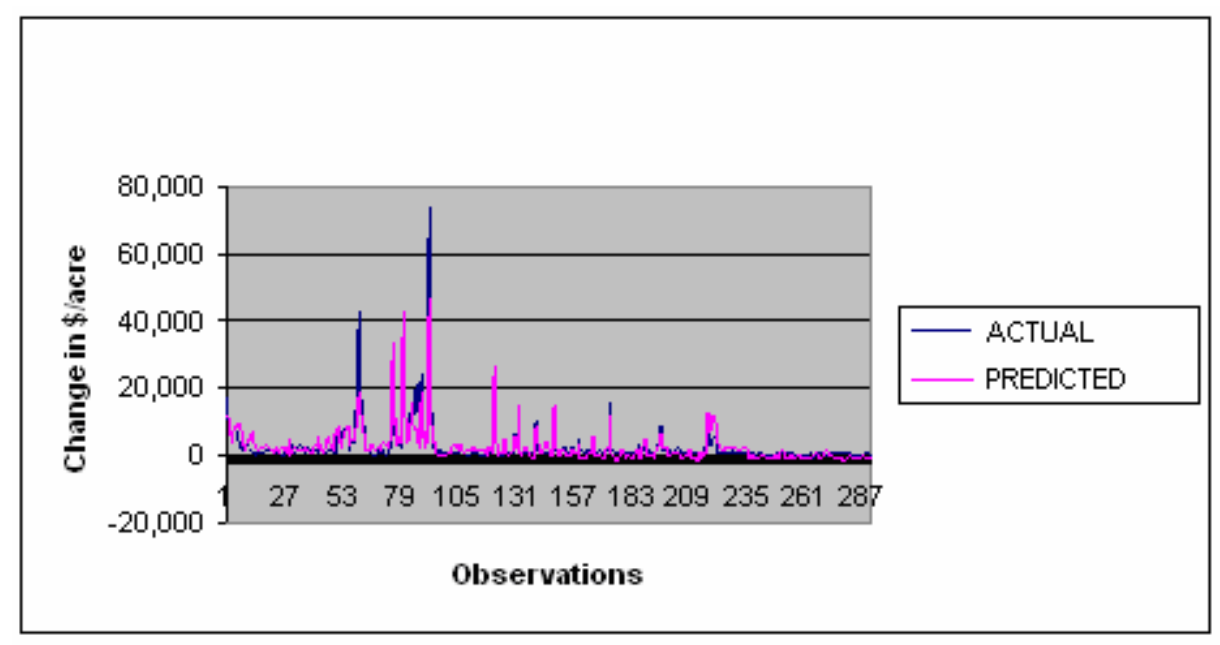


Figure 5.5. Actual and Predicted Change in Agricultural Land Density.

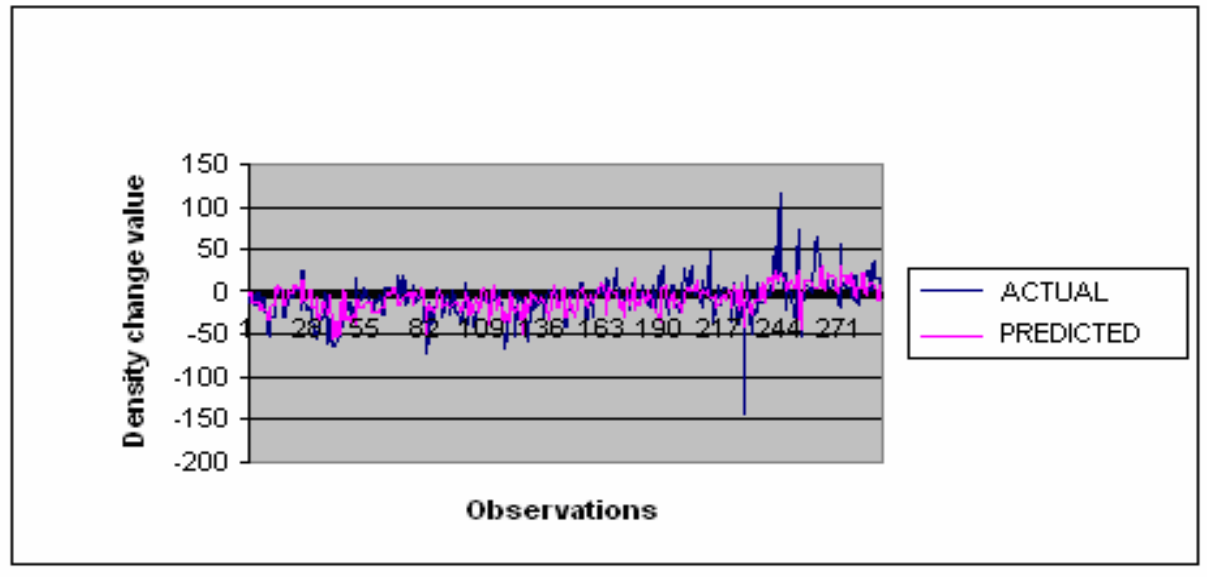

From the above five graphs, it can be inferred that predicted values behave in the same way the original data does, and can be used for spatial estimation. For the purpose of spatial estimation, the predicted endogenous variables matrix is post-multiplied with a contiguity-based spatial weights matrix to generate spatially-weighted endogenous predicted values. The results are used as variables on the right hand side of equations 4.41 through 4.45 and are estimated using three-stage least squares.

\subsection{ANALYSIS OF RESULTS: GROWTH EQUILIBRIUM MODEL ${ }^{2}$}

\subsubsection{Population Density Change}

The population density change equation is estimated as a function of the endogenous variables, initial population density, fiscal factors, county characteristics, and accessibility variables. Results are reported in Table 5.2.

Population density change $(\Delta P)$ is significantly and positively associated with employment density change $(\Delta E)$. This result reinforces similar conclusions in other studies that regions with employment growth attract population. The relationship with per

\footnotetext{
${ }^{2}$ Coefficient estimates are significant if associated p-values (given in Table 5.2) are $\leq 0.10$.
} 
capita income change $(\Delta Y)$ is negative and significant. Even though it can be expected $a$ priori that counties with income growth will experience higher population growth, this result for the Northeast indicates that population density is growing in counties with declining per capita income. This result may be picking up an increase in population at suburban and rural locations where income is not growing very quickly. The last endogenous variable in the population density change equation is change in per acre value of land $\left(\Delta P_{L}\right)$. It was expected that higher land prices would lead to a decline in population density; however, the result was statistically insignificant.

The initial population level $\left(P_{t-1}\right)$ is negatively and significantly related to population density change. Counties with higher initial population experienced negative growth. This result confirms a similar conclusion by Deller et al. (2001) that counties with higher population density have lower population growth.

Population growth is also significantly affected by the distribution of the tax burden and local government expenditures. Consistent with prior expectations, counties with a higher per capita tax burden $\left(\mathrm{PCTax}_{\mathrm{t}-1}\right)$ and higher proportion of government income coming from property taxes $\left(\operatorname{Prop}^{0} \mathrm{Tax}_{\mathrm{t}-1}\right)$ experienced less population growth. The distribution of population growth, in this case, is inversely related with the distribution of per capita and property tax burdens. The per capita local government expenditures variable (PCGovExp $\left.\mathrm{t}_{\mathrm{t}-1}\right)$ is positively and significantly related to population density change. Differences in local government spending may affect the provision of local public goods overtime, which can affect people's migration decisions. This result is observed for the Northeast, as counties with higher per capita local government spending experienced significantly positive population growth. 
Table 5.2. Growth Equilibrium Model Econometric Estimation Results.

\begin{tabular}{|c|c|c|c|c|c|c|c|c|c|c|}
\hline \multirow[t]{2}{*}{ Variable } & \multicolumn{2}{|c|}{$\Delta \mathrm{P}$ Equation } & \multicolumn{2}{|c|}{$\Delta \mathrm{E}$ Equation } & \multicolumn{2}{|c|}{$\Delta \mathrm{Y}$ Equation } & \multicolumn{2}{|c|}{$\Delta \mathbf{P}_{\mathrm{L}}$ Equation } & \multicolumn{2}{|c|}{$\Delta$ AgL Equation } \\
\hline & Coeff. & p-value & Coeff. & p-value & Coeff. & $\mathrm{p}$-value & Coeff. & p-value & Coeff. & p-value \\
\hline Constant & 127.766 & 0.017 & -6.418 & 0.465 & 8954.27 & 0.002 & -4437.10 & 0.002 & 232.31 & 0.000 \\
\hline \multicolumn{11}{|c|}{ Endogenous Variables } \\
\hline$\Delta P$ & - & - & 0.538 & 0.000 & -21.70 & 0.000 & 9.23 & 0.091 & -0.052 & 0.520 \\
\hline$\Delta E$ & 0.582 & 0.003 & - & - & 21.50 & 0.002 & -42.25 & 0.000 & 0.331 & 0.037 \\
\hline$\Delta Y$ & -0.005 & 0.035 & 0.003 & 0.001 & - & - & 0.28 & 0.000 & -0.004 & 0.049 \\
\hline$\Delta P_{L}$ & 0.002 & 0.282 & -0.003 & 0.000 & 0.26 & 0.000 & - & - & 0.000 & 0.781 \\
\hline$\triangle A g L$ & - & - & - & - & - & - & -5.49 & 0.625 & - & - \\
\hline \multicolumn{11}{|l|}{ Initial Conditions } \\
\hline$P_{t-1}$ & -0.042 & 0.000 & - & - & & & & & & \\
\hline$E_{t-1}$ & - & - & -0.010 & 0.475 & - & - & - & - & - & - \\
\hline$Y_{t-1}$ & - & - & - & - & -0.59 & 0.003 & & & & \\
\hline$P_{L t-1}$ & - & - & - & - & - & - & 1.20 & 0.000 & & \\
\hline$A g L_{t-1}$ & - & - & - & - & - & - & -10.65 & 0.620 & 0.130 & 0.080 \\
\hline \multicolumn{11}{|c|}{ Local Government Taxes and Expenditures } \\
\hline PCTax $_{t-1}$ & -0.064 & 0.061 & - & - & -0.81 & 0.509 & - & - & - & - \\
\hline Prop $\% \operatorname{Tax}_{\mathrm{t}-1}$ & -0.909 & 0.060 & -0.075 & 0.744 & - & - & - & - & - & - \\
\hline PCGovExp $\mathrm{t}_{\mathrm{t}-1}$ & 43.880 & 0.025 & - & - & - & - & - & - & - & - \\
\hline \multicolumn{11}{|c|}{ Local County Characteristics } \\
\hline UInfCode & - & - & - & - & - & - & 231.76 & 0.203 & - & - \\
\hline MVOwnOcc $_{t-1}$ & 0.001 & 0.005 & - & - & - & - & - & - & - & - \\
\hline UnempRate $_{t-1}$ & -0.949 & 0.659 & -2.294 & 0.016 & - & - & - & - & - & - \\
\hline HospB100k $\mathrm{k}_{\mathrm{t}-1}$ & -0.303 & 0.000 & - & - & - & - & - & - & - & - \\
\hline$\%$ Degree $_{t-1}$ & - & - & - & - & 387.98 & 0.000 & - & - & - & - \\
\hline$\% \mathrm{BlPov}_{\mathrm{t}-1}$ & - & - & - & - & -924.69 & 0.000 & - & - & - & - \\
\hline StateRD & 87.380 & 0.289 & 59.152 & 0.071 & 3791.59 & 0.218 & 5548.98 & 0.097 & -76.655 & 0.014 \\
\hline InterstD & 73.730 & 0.277 & 41.596 & 0.092 & 521997 & 0.015 & 15598.15 & 0.000 & 53.933 & 0.192 \\
\hline \multicolumn{11}{|c|}{ Agricultural Performance and Land Variables } \\
\hline $\mathrm{AgIncPF}_{\mathrm{t}-1}$ & - & - & - & - & - & - & 0.03 & 0.000 & 0.000 & 0.139 \\
\hline GvPayPF $_{t-1}$ & - & - & - & - & - & - & - & - & -0.005 & 0.183 \\
\hline$\%$ CLFarm $_{\mathrm{t}-1}$ & - & - & - & - & - & - & 34.82 & 0.803 & - & - \\
\hline \multicolumn{11}{|c|}{ Farmland Protection Policies } \\
\hline TaxEasemt & - & - & - & - & - & - & - & - & -189.84 & 0.001 \\
\hline AgDistrc & - & - & - & - & - & - & - & - & -42.003 & 0.268 \\
\hline AgPZone & - & - & - & - & - & - & - & - & -20.104 & 0.274 \\
\hline TDR & - & - & - & - & - & - & - & - & -149.85 & 0.000 \\
\hline \multicolumn{11}{|c|}{ Employment Classifications } \\
\hline FarmEmp $_{t-1}$ & - & - & - & - & - & - & - & - & -0.002 & 0.687 \\
\hline ServEmp $_{t-1}$ & - & - & 0.001 & 0.000 & - & - & - & - & - & - \\
\hline MinEmp $p_{t-1}$ & - & - & 0.027 & 0.009 & - & - & - & - & - & - \\
\hline ConstEmp $_{\mathrm{t}-1}$ & - & - & -0.004 & 0.013 & - & - & - & - & - & - \\
\hline
\end{tabular}


Additional variables in the population density change equation captured county differences in local characteristics. These were median value of owner-occupied housing (MVOwnOcc $\left.\mathrm{t}_{-1}\right)$, unemployment rate (UnempRate $\left.\mathrm{t}_{\mathrm{t}-1}\right)$, and number of hospital beds per

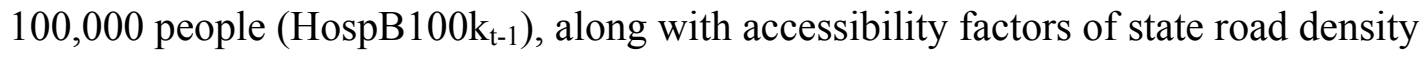
(StateRD) and interstate highway density (InterstD). Increase in population density is significantly higher in areas with higher median housing values and lower unemployment rates. Number of hospital beds per 100,000 people was significant in the model, but contrary to prior expectation had an inverse relationship with population density. This variable could be a weak proxy for county health care facilities, but the result indicates that population growth is higher in counties with a relatively low number of hospital beds. Population density appears to be higher in counties with higher state and interstate highway densities; however, neither variable was significant.

\subsubsection{Employment Density Change}

Results for the employment density change equation $(\Delta E)$ are reported in Table 5.2. Included are the endogenous variables, initial employment density, two local community characteristics, accessibility variables and several employment sectors.

Employment density change is positively and significantly related with population density change $(\Delta P)$. Other things being equal, a 1 person per square mile increase in county population attracts 0.538 jobs per square mile. This result reinforces the argument that jobs follow population movements. Change in employment density is also positively and significantly related with growth in per capita income $(\Delta Y)$. Counties in the Northeast with higher income growth experienced increases in employment density. This may be 
due to the fact that, from a regional perspective, places with higher income (economic) opportunities attract investment. Employment density change, however, was negatively and significantly related with the value of land per acre $\left(\Delta P_{L}\right)$. Counties with higher farmland values experienced slower employment growth. This may be due to the fact that counties with high land values are less attractive for building manufacturing facilities or office or shopping complexes. Moreover, initial employment density $\left(E_{t-1}\right)$ was not significant in determining employment density change.

Local and fiscal factors are included to examine their relationships with employment density change. Counties with higher property taxes (Prop\% $\left.\operatorname{Tax}_{t-1}\right)$ experienced slower increases in employment, however, this result was not significant. Counties with a higher unemployment rate $\left(\right.$ UnempRate $\left._{t-1}\right)$ experienced slower employment growth. The unemployment rate may be measuring the local business climate, with higher unemployment rates indicating a less attractive place to do business. State road (StateRD) and interstate highway densities (IntersD) are included to understand the relationship between access and job creation. The result confirms previous findings, like Carlino and Mills (1987), that development of road infrastructure accelerates job creation. An increase of 1 mile of road per square mile results in a 59.2 increase in jobs per square mile for state roads and a 41.6 increase for interstate highways.

Employment is classified by sectors to see whether employment growth is significantly associated with job creation in specific industries. Both service sector employment $\left(\right.$ ServEmp $\left._{\mathrm{t}-1}\right)$ and mining sector employment $\left(\mathrm{MinEmp}_{\mathrm{t}-1}\right)$ are positively and significantly related with overall employment growth. However, construction 
employment $\left(\right.$ ConstEmp $\left._{t-1}\right)$ is significantly and negatively related with overall job growth. Counties with more construction jobs experienced slower employment creation, which may reflect construction and development activities in rural counties where overall job growth is usually slower.

\subsubsection{Per Capita Income Change}

The per capita income equation $(\Delta Y)$ is estimated as a function of the endogenous variables, initial per capita income, county characteristics, and accessibility variables with results reported in Table 5.2.

Change in per capita income is negatively and significantly related to population growth $(\Delta P)$. Counties with higher population growth experienced lower per capita income growth. Average county income with a growing population may decline if income growth doesn't keep pace with population growth. Per capita income growth is positively and significantly related with employment density growth $(\Delta E)$. Counties with more employment expansion see more growth in income. Other things being equal, for a 1 job per square mile increase, per capita income is expected to grow by $\$ 21.50$. Per capita income growth is also positively related with the per acre value of farmland $\left(\Delta P_{L}\right)$. This relationship may be measuring the effect that per capita income growth has on agricultural land. First, through the creation of better local markets for agricultural products, income growth may indirectly increase the value of agricultural land based on expected farm income. Second, by directly competing for land for development, income growth may exert demand pressure that pushes up land values at suburban and rural locations. In both cases, a positive and significant relationship between income growth 
and farmland values could occur. The negative and significant relationship between per capita income change and lagged per capita income $\left(Y_{t-1}\right)$ suggests that counties with lower income initially experienced greater income growth than counties with higher income in the earlier period. This may suggest a trend in regional growth towards development in rural areas (Deller et al. 2001).

Local characteristics and fiscal factors may also impact per capita income. The per capita tax burden $\left(\mathrm{PCTax}_{\mathrm{t}-1}\right)$ is negatively but not significantly related to per capita income change. The relationship between the proportion of a county's population with a bachelor's degree or higher (\% $\%$ Degree $\left._{t-1}\right)$, a measure of human capital, and per capita income growth indicates that counties with high human capital endowments experienced higher income growth. Other things being equal, a $1 \%$ increase in the proportion of a county with a higher degree would raise per capita income by $\$ 387.98$. The proportion of county population below the poverty line $\left(\% \mathrm{BlPov}_{\mathrm{t}-1}\right)$ is negatively and significantly related to per capita income change. A $1 \%$ increase in the percentage of poor results in an overall decline in per capita income of $\$ 924.69$. These two results suggest that while a better human capital endowment accelerates income growth, a high degree of poverty in a region slows it down.

Accessibility within counties, measured by road density, is used to understand the impact of access on income growth. Both state (StateRD) and interstate (InterstD) road density are positively related with income growth, however, only interstate road density is significant. Other things being equal, a 1 mile of interstate per square mile increase is expected to result in a per capita income change of $\$ 5,219.97$. This reaffirms earlier 
findings by Carlino and Mills (1987) that infrastructure development accelerates economic growth.

\subsubsection{Per Acre Agricultural Land Value Change}

As reported in Table 5.2, the per acre agricultural land value change $\left(\Delta P_{L}\right)$ equation is estimated as a function of the usual endogenous variables, initial land value and stock, accessibility variables, urban influence, and farm characteristics.

Per acre change in agricultural land value is significantly and positively associated with population density change $(\Delta P)$. This result confirms a prior expectation that in counties with high population growth pressures are put on existing land uses to accommodate the growing population. Some of the land used for growth comes from agriculture, hence its per acre value should rise. This is consistent with prior studies that found that fast growing areas have significantly higher increases in land prices (Plantinga and Miller 2001; Nelson 1992; Shi, Phipps, and Colyer 1997). Change in the value of land is significantly and negatively related with employment density change $(\Delta E)$. This is contrary to an expectation that employment growth exerts pressure on existing land uses and results in higher land values. This result may indicate that significant employment density changes are occurring in rural areas where agricultural land values are lower. Agricultural land value is positively and significantly related with per capita income change $(\Delta Y)$, which confirms prior thinking that regions with high per capita income growth will have increasing land values. With growing income, environmental and amenity factors may enter into quality of life considerations and individuals' utility functions, leading to increased demand for first or second homes in suburban and rural 
areas. The negative coefficient associated with the stock of agricultural land $(\triangle A g L)$ was not statistically significant.

Change in per acre value of agricultural land is positively and significantly related with initial land values $\left(P_{L t-1}\right)$. Counties with higher initial land values are expected to experience positive change in their land values, indicating upward momentum in farmland prices. The initial stock of agricultural land $\left(A g L_{t-1}\right)$ was not significant in explaining agricultural land value changes.

Accessibility has a significant and positive influence on the value of land in a county. Other things being equal, an increase of 1 mile of road per square mile increases the per acre value of agricultural land by $\$ 5,548.98$ for state roads (StateRD) and $\$ 15,598.15$ for interstates (InterstD). A positive relationship was expected, and the result indicates that interstate development will have a much stronger impact on land values than a similar change in state roads. The urban influence code (UInfCode), used as a proxy for development pressure, was not significant in the land value change equation.

Agricultural income per farm $\left(\mathrm{AgIncPF}_{\mathrm{t}-1}\right)$ is positively and significantly related with the per acre value of agricultural land. Other things being equal, a $\$ 100$ increase in agricultural income per farm, would increase the value of land by $\$ 2.70$ per acre. Proportion of county land in farms $\left(\% \mathrm{CLFarm}_{\mathrm{t}-1}\right)$ was not significant in determining value of agricultural land per acre.

\subsubsection{Agricultural Land Density Change}

The endogenous variables, initial agricultural land density, accessibility variables, farmland protection policies, farm characteristics, and agricultural employment are used 
as explanatory variables in the agricultural land density change equation; results are reported in Table 5.2.

Population density change $(\Delta P)$ is inversely related with agricultural land density. Even though this result indicates that population growth may contribute to agricultural land development, it was not statistically significant. Change in employment density $(\Delta E)$ is significantly and positively related with agricultural land density. This result is contrary to prior expectations that expansion of jobs demands more land for development. Employment growth can have a positive and a negative effect on agricultural land - higher demand for farm products helps to maintain farming in the area while demand for land for development makes farming more difficult. This latter effect was not found in this study. Per capita income growth $(\Delta Y)$ is negatively and significantly related with agricultural land density change. Confirming prior expectations, counties with increases in per capita income experienced more farmland development. Other things being equal, a $\$ 1,000$ increase in per capita income would reduce the amount of farmland by 4 acres. Change in per acre value of agricultural land $\left(\Delta P_{L}\right)$ was not significant in explaining agricultural land density change.

The initial stock of farmland $\left(A g L_{t-1}\right)$ is positively and significantly related with the change in agricultural land density. Counties with a higher initial endowment of farmland gained agricultural acreage while counties with a lower initial endowment lost farmland. This may indicate the existence of a threshold density, a critical mass of farms, below which it may not be feasible to maintain farmland for agricultural use. Farmland losses could in part be a function of the endowment of productive farmland acres (Lynch and Carpenter 2003). 
The effect of accessibility on agricultural land density change is also tested. The result indicates that while state road density (StateRD) is negatively and significantly related with agricultural land density change, interstate road density (InterstD) does not have a significant impact. Other things being equal, an increase in state roads of 1 mile per square mile results in a 76.7 acre loss in agricultural land per square mile. Not surprisingly, agricultural lands that are more accessible face more development pressure.

A number of farmland protection policy variables are included in the agricultural land density change equation to capture the impact of these policies on farmland conversion. Tax easements (TaxEasemt), agricultural districts (AgDistrc), agricultural zoning (AgPZone), and transfer of development rights (TDR) are among the widely applied farmland protection measures used today. Prior expectations suggest that states with farmland protection policies would have fewer agricultural land losses compared to states that do not have these policies. Data on farmland protection polices were available by state and not at the county level so comparisons are made between states and not counties. The results for these variables are perplexing because they suggest that counties in states with farmland protection policies have comparatively higher farmland losses. Counties in states with a tax easement policy lose 189.84 acres per square mile more than those in states that do not provide tax easements. Similarly, counties in states that have a TDR program lose 149.85 acres per square mile more compared to states without this program. One possible explanation for this unexpected result could be that these farmland protection policies were not introduced early enough to decrease sprawl, but rather as a response to already existing rapid growth and farmland losses. Another explanation is that in areas where development pressure is severe, these farmland protection programs 
are not sufficient to reduce farmland loss. It could be that tax easements are no match for the high price a farmer can receive when selling land for development in a fast growing region. TDR programs may reduce farmland loss in one part of the state only to accelerate it in another part of the state, resulting in a net loss in agricultural land statewide. There was no significant difference in agricultural land development patterns in states with agricultural districts or agricultural zoning compared to states that have not implemented these policies.

Government payments per farm $\left(\mathrm{GvPayPF}_{\mathrm{t}-1}\right)$, agricultural income per farm $\left(\mathrm{AgIncPF}_{\mathrm{t}-1}\right)$, and county farm employment $\left(\right.$ FarmEmp $\left._{\mathrm{t}-1}\right)$ were not significant in explaining agricultural land density change.

\subsubsection{Major Findings of the Growth Equilibrium Model}

The main goal of the growth equilibrium land use model was to understand the relationship between regional growth trends and agricultural land development. For this reason, changes in population, employment, and income are modeled as endogenous variables, and their impact on agricultural land values and agricultural land development was examined. Understanding these relationships first requires understanding what drives each variable and how it is then related with all other endogenous variables. This section provides the major findings and their relevance to the agricultural land development discussion.

- County population change is due to employment and income changes, the initial population density, the county tax burden, local government spending, median housing value, and hospital availability. High population growth increases the per 
acre value of agricultural land due to development pressure, but no significant negative impact on agricultural land density was found.

- Change in county employment is driven by population and per capita income changes, change in the value of agricultural land, the county unemployment rate, and state and interstate road development. A negative impact of county employment growth on agricultural land development was not established; however, a negative and significant relationship exists between employment growth and agricultural land value per acre.

- County per capita income change is influenced by population and employment change, change in the value of agricultural land, initial per capita income, proportion of a county's population with higher education degrees and below the poverty line, and development of interstate highways. County per capita income growth positively affects the value of agricultural land and negatively impacts the density of farmland (encourages development).

- County per acre agricultural land value change is affected by population, employment and per capita income changes, initial agricultural land values, state and interstate road infrastructure, and farm income per acre. Change in per acre agricultural land value is not significant in explaining patterns in agricultural land development.

- County agricultural land density change is driven by employment and per capita income changes, initial agricultural land density, state road development, and two farmland protection policies (tax easements and transferable development rights). Agricultural land development is accelerated through county per capita income growth. State road density also negatively influences agricultural land density. States 
in the Northeast which have implemented tax easement and transferable development rights policies experienced more agricultural land development (per square mile) than those that did not, evidence of the strength of development pressure even in the presence of farmland protection policies, stimulating discussion of the effectiveness of such policies. There is no evidence that a better performing agricultural sector, in terms of farm income and employment creation, helps slow agricultural land development.

\subsection{ANALYSIS OF RESULTS: SPATIAL GROWTH EQUILIBRIUM MODEL ${ }^{3}$}

The spatial econometrics model specification is different from the non-spatial model in two ways. One, that it includes spatial components and two, that exogenous variables specification in the two models are slightly different. As a result, direct comparison of results from the two models is not possible due to the mentioned specification differences. However, results from the two models can be compared based on general conclusions driven from the two models.

\subsubsection{Population Density Change}

The spatial model specification for the population density equation is based on the observations of spatial dependence indicated by the Moran's I statistics for this equation (reported in Table 5.1). The population density equation is estimated as a function of the endogenous variables, initial population density, spatially-weighted endogenous variables, spatially-weighted initial population density (all reported in Table 5.3), fiscal factors, county characteristics, and accessibility variables (see Table 5.4).

\footnotetext{
${ }^{3}$ Coefficient estimates are significant if associated p-values (given in Tables 5.2 and 5.4) are $\leq 0.10$.
} 
The relationship between change in population density and the endogenous variables employment density change, per capita income change, and change in the per acre value of agricultural land is robust as these results have the same signs even though the model has changed. For the same reasons discussed previously, change in population density is significantly and positively related with employment density change, negatively and significantly related with per capita income change, and insignificantly related with change in the value of agricultural land.

The spatial lag endogenous variables of change in population density, employment density change, per capita income change, and change in the per acre value of agricultural land are introduced to test for cross county growth interdependence. The significant and negative coefficient associated with change in population density $(W \Delta \hat{P})$ indicates that population growth in neighboring counties decreases population density in the county in question. It was expected that population growth in a neighboring county would spillover and result in increasing population due to commuting residents. However, it may be the case that better economic opportunities in fast growing areas are attracting residents away from a rural county resulting in decreasing population there, or that decreasing population density due to flight from urban areas is reflected in increasing population density in a neighboring rural county. Population density change is not significantly related with neighboring county employment density change $(W \Delta \hat{E})$. Per capita income change in neighboring counties $(W \Delta \hat{Y})$ has a positive and significant relationship with population density change. Interestingly, once income is made it has no spatial fixity; people can maximize their utility across locations given their income. Hence, a county surrounded by counties with increasing income may attract some 
commuters to move there, raising overall population density. For example, counties

surrounding cities with high income growth may see increases in population as demand increases for characteristics provided by the surrounding counties.

Population density is negatively and significantly related with the spatial lag of the change in farmland value $\left(W \Delta \hat{P}_{L}\right)$. It was expected that higher land values in neighboring counties would drive some residents to locate in the county of interest. One possible explanation for this counterintuitive result may be that counties with increasing land values also have high economic growth and the economic opportunity in these locations outweighs the disincentive associated with higher land prices.

Table 5.3. Spatial Growth Equilibrium Model Econometric Results.

\begin{tabular}{|c|c|c|c|c|c|c|c|c|c|c|}
\hline \multirow[t]{2}{*}{ Variable } & \multicolumn{2}{|c|}{$\Delta \mathrm{P}$ Equation } & \multicolumn{2}{|c|}{$\Delta \mathrm{E}$ Equation } & \multicolumn{2}{|c|}{$\Delta \mathrm{Y}$ Equation } & \multicolumn{2}{|c|}{$\Delta \mathbf{P}_{\mathrm{L}}$ Equation } & \multicolumn{2}{|c|}{$\Delta$ AgL Equation } \\
\hline & Coeff. & p-value & Coeff. & $\mathrm{p}$-value & Coeff. & $p$-value & Coeff. & p-value & Coeff. & p-value \\
\hline Constant & 127.768 & 0.005 & 7.303 & 0.474 & 15.41 & 0.996 & -18336.91 & 0.000 & 90.701 & 0.094 \\
\hline \multicolumn{11}{|c|}{ Endogenous Variables } \\
\hline$\Delta P$ & - & - & 0.443 & 0.000 & -8.38 & 0.009 & 9.74 & 0.219 & -0.041 & 0.605 \\
\hline$\Delta E$ & 0.679 & 0.000 & - & - & 8.25 & 0.076 & -74.84 & 0.000 & 0.424 & 0.002 \\
\hline$\Delta Y$ & -0.005 & 0.039 & 0.001 & 0.390 & - & - & 0.74 & 0.000 & -0.004 & 0.005 \\
\hline$\Delta P_{L}$ & 0.001 & 0.384 & -0.003 & 0.000 & 0.09 & 0.005 & - & - & 0.006 & 0.000 \\
\hline$\triangle A g L$ & - & - & - & - & - & - & 58.31 & 0.000 & - & \\
\hline \multicolumn{11}{|c|}{ Spatially-weighted Endogenous Variables } \\
\hline$W \Delta \hat{P}$ & -1.289 & 0.030 & 0.597 & 0.002 & -13.65 & 0.189 & 56.11 & 0.078 & -1.256 & 0.000 \\
\hline$W \Delta \hat{E}$ & 0.032 & 0.950 & -0.534 & 0.059 & -9.28 & 0.589 & 27.52 & 0.439 & 0.667 & 0.083 \\
\hline$W \Delta \hat{Y}$ & 0.008 & 0.070 & -0.001 & 0.527 & 0.43 & 0.001 & -0.74 & 0.072 & 0.009 & 0.060 \\
\hline$W \Delta \hat{P}_{L}$ & -0.008 & 0.068 & 0.001 & 0.676 & 0.06 & 0.506 & 0.04 & 0.892 & -0.005 & 0.009 \\
\hline$W \Delta \hat{A g} L$ & - & - & - & - & & & 144.07 & 0.025 & -0.794 & 0.274 \\
\hline \multicolumn{11}{|c|}{ Initial Conditions } \\
\hline$P_{t-1}$ & -0.043 & 0.000 & - & - & - & - & - & - & - & \\
\hline$E_{t-1}$ & - & - & -0.038 & 0.042 & - & - & - & - & - & - \\
\hline$Y_{t-1}$ & - & - & - & - & 0.15 & 0.206 & - & - & - & - \\
\hline$P_{L t-1}$ & - & - & - & - & - & - & 0.80 & 0.000 & - & 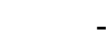 \\
\hline$A g L_{t-1}$ & - & - & - & - & - & - & - & - & 0.024 & 0.721 \\
\hline \multicolumn{11}{|c|}{ Spatially-weighted Initial Conditions } \\
\hline$W P_{t-1}$ & 0.031 & 0.319 & - & - & - & - & - & - & - & - \\
\hline$W E_{t-1}$ & - & - & 0.034 & 0.282 & - & - & - & - & - & \\
\hline$W Y_{t-1}$ & - & - & - & - & -0.38 & 0.054 & - & - & - & - \\
\hline$W P_{L t-1}$ & - & - & - & - & 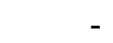 & - & 0.93 & 0.029 & - & - \\
\hline$W A g L_{t-1}$ & - & - & - & - & - & - & - & - & 0.228 & 0.011 \\
\hline
\end{tabular}


Lagged population density is significant and negative, indicating counties with higher initial population density have less population growth in the following time period. The spatial lag initial condition variable $\left(W P_{t-1}\right)$ is positively related with population density change, however, this result is not statistically significant, indicating that earlier population density in neighboring areas does not have an impact on the change in population density in the county of interest.

Local characteristics such as taxes, local government spending, owner-occupied housing values, the unemployment rate, and accessibility are also included in the change in population density equation. The results indicate that per capita taxes and property taxes are significantly associated with decreasing population density, as expected. Local government spending has a positive and significant impact in the non-spatial model, however, in the spatial model, even though the sign is the same, the variable is not significant. The value of owner-occupied housing is positive and significant. Counties with high housing values are associated with population growth.

\subsubsection{Employment Density Change}

Spatial autocorrelation is observed between employment density change and the spatial lag of change in population density $(W \Delta \hat{P})$ and employment density $(W \Delta \hat{E})$ leading to the spatial model specification for this equation. Explanatory variables include the endogenous variables and initial employment density, both spatially weighted and not (all in Table 5.3) and the unemployment rate, accessibility variables, and employment levels in several sectors (in Table 5.4). 
Table 5.4. Spatial Growth Equilibrium Model Econometric Results (continued).

\begin{tabular}{|c|c|c|c|c|c|c|c|c|c|c|}
\hline \multirow[t]{2}{*}{ Variable } & \multicolumn{2}{|c|}{$\Delta \mathbf{P}$ Equation } & \multicolumn{2}{|c|}{$\Delta E$ Equation } & \multicolumn{2}{|c|}{$\Delta Y$ Equation } & \multicolumn{2}{|c|}{$\Delta \mathbf{P}_{\mathrm{L}}$ Equation } & \multicolumn{2}{|c|}{$\Delta$ AgL Equation } \\
\hline & Coeff. & p-value & Coeff. & $\mathrm{p}$-value & Coeff. & $\mathrm{p}$-value & Coeff. & $\mathrm{p}$-value & Coeff. & $\mathrm{p}$-value \\
\hline \multicolumn{11}{|c|}{ Local Government Taxes and Expenditures } \\
\hline PCTax $_{t-1}$ & -0.054 & 0.098 & - & - & -1.08 & 0.202 & - & - & - & - \\
\hline Prop\%Tax ${ }_{t-1}$ & -1.594 & 0.004 & - & - & 53.14 & 0.000 & - & - & - & - \\
\hline PCGovExp $\mathrm{t}_{\mathrm{t}-1}$ & 20.662 & 0.225 & - & - & - & - & - & - & - & - \\
\hline \multicolumn{11}{|c|}{ Local County Characteristics } \\
\hline MVOwnOcc $_{t-1}$ & 0.001 & 0.013 & - & - & - & - & - & - & - & - \\
\hline UnempRate $_{t-1}$ & -0.940 & 0.591 & -1.389 & 0.107 & - & - & - & - & - & - \\
\hline$\%$ Degree $_{t-1}$ & - & - & - & - & 225.73 & 0.000 & - & - & - & - \\
\hline$\% \mathrm{BlPov}_{\mathrm{t}-1}$ & - & - & - & - & -429.53 & 0.000 & - & - & - & - \\
\hline StateRD & 54.694 & 0.414 & 67.618 & 0.024 & 205.25 & 0.919 & 1660.98 & 0.671 & -32.696 & 0.048 \\
\hline InterstD & 23.703 & 0.664 & 41.214 & 0.083 & 2850.07 & 0.054 & 10339.18 & 0.005 & -37.048 & 0.233 \\
\hline UInfCode & - & - & - & - & - & - & - & - & 11.057 & 0.001 \\
\hline \multicolumn{11}{|c|}{ Agricultural Performance and Land Variables } \\
\hline $\mathrm{AgIncPF}_{\mathrm{t}-1}$ & - & - & - & - & - & - & 0.026 & 0.015 & -0.0002 & 0.043 \\
\hline GvPayPF $_{t-1}$ & - & - & - & - & - & - & 0.405 & 0.229 & -0.0004 & 0.915 \\
\hline$\%$ CLFarm $_{\mathrm{t}-1}$ & - & - & - & - & - & - & -92.510 & 0.016 & - & - \\
\hline \multicolumn{11}{|c|}{ Farmland Protection Policies } \\
\hline TaxEasemt & - & - & - & - & - & - & 16019.16 & 0.000 & -197.99 & 0.000 \\
\hline AgDistrc & - & - & - & - & - & - & 7491.819 & 0.019 & -45.767 & 0.183 \\
\hline AgPZone & - & - & - & - & - & - & 296.215 & 0.887 & -7.156 & 0.738 \\
\hline TDR & - & - & - & - & - & - & 9756.587 & 0.003 & -176.00 & 0.000 \\
\hline \multicolumn{11}{|c|}{ Employment Classifications } \\
\hline FarmEmp $_{\mathrm{t}-1}$ & - & - & - & - & - & - & - & - & 0.005 & 0.202 \\
\hline ServEmp $_{\mathrm{t}-1}$ & - & - & 0.001 & 0.000 & - & - & - & - & - & - \\
\hline MinEmp $p_{t-1}$ & - & - & 0.015 & 0.069 & - & - & - & - & - & - \\
\hline ConstEmp $_{t-1}$ & - & - & -0.431 & 0.022 & - & - & - & - & - & - \\
\hline
\end{tabular}

Change in employment density is significantly and positively related with population density change. An increase of one person per square mile increases jobs per square mile by 0.443 . A $\$ 1$ per acre increase in the value of agricultural land would result in a decrease in employment density of 0.003 . Although population growth encourages employment growth, higher land values do not. 
Spatially weighted endogenous variables, population density change, change in employment density, per capita income change, and change in the value of agricultural land, are introduced to test for cross-county employment growth interdependence. The spatial lag of population density change $(W \Delta \hat{P})$ is positively and significantly related with county employment growth, suggesting that population growth in neighboring counties can increase job growth in own county. However, employment growth in a neighboring county $(W \Delta \hat{E})$ is negatively related with employment growth in own county. Counties experiencing high employment growth may attract opportunities from a neighboring county causing employment to decline in that county. Neighboring county income growth $(W \Delta \hat{Y})$ was not significant in explaining county population growth. The spatial lag of agricultural land value $\left(W \Delta \hat{P}_{L}\right)$ was not a significant predictor of own county employment density change.

The initial employment density situation is negatively and significantly related with employment density change. This result suggests that counties with high initial employment density saw a decline in employment expansion compared to counties with low initial employment density. This may indicate a rural renaissance (Deller et al. 2003). The spatial lag of initial employment density $\left(W E_{t-1}\right)$ was not significant.

The relationship with the unemployment rate is similar to the non-spatial model negative but not significant. There is a significant and positive relationship between employment density change and state and interstate road densities in the spatial model, reinforcing the same finding in the non-spatial model. Other things remaining constant, a 1 mile of road per square mile increase would cause employment to increase by 
approximately 68 jobs and 41 jobs per square mile for state and interstate roads, respectively.

Employment is analyzed by sectors to see whether employment growth is significantly associated with job creation in specific industries. Both service sector and mining sector employment are positively and significantly related with overall employment growth, however, construction employment is negative (and significant). This result reinforces the same conclusion reached in the non-spatial model. Counties with higher construction jobs experienced slower overall employment creation. This may indicate construction and development activities in rural counties where overall job growth may have been slower.

\subsubsection{Per Capita Income Change}

Moran's I statistics for per capita income change show spatial dependence (Table 5.1) with the spatial lag of per capita income change $(W \Delta \hat{Y})$ and agricultural land value change $\left(W \Delta \hat{P}_{L}\right)$. Tables 5.3 and 5.4 indicate the variables used to estimate the per capita income change equation.

Change in per capita income is significantly and negatively related with population density change, and positively and significantly related with change in employment density. A one person per square mile increase in population is expected (on average) to reduce per capita income by $\$ 8.38$, a similar 1 job per square mile increase in employment would increase per capita income by $\$ 8.25$. These marginal impacts on income of changes in population and employment are not as large in the spatial model compared to the non-spatial model. The non-spatial model may be showing a larger 
marginal impact due to the exclusion of cross-county effects. The relationship with the value of land is positive and significant. This result is contrary to prior expectations that high per acre land values drive jobs to lower land value counties and reduce per capita income. The result suggests that counties with significant increases in land values experienced increases in per capita income. There is a two directional effect here, the impact of land values on income and the impact of income on land values. Perhaps this result may be picking up the fact that counties with income growth also experience land value increases.

The initial per capita income condition is not significant in explaining income changes, however, spatially-weighted initial per capita income $\left(W Y_{\mathrm{t}-1}\right)$ is negative and significant. This suggests that a county with high initial per capita income in neighboring counties experienced less income growth.

The cross county effects of all of the endogenous variables, except per capita income, are not significant, thus, income growth in a county is not determined by population, employment and land value changes in neighboring counties. However, income growth in neighboring counties has a significant effect on own county income changes. A $\$ 100$ increase in per capita income in neighboring counties is expected to result in a $\$ 43$ increase in income in the county of interest, ceteris paribus. This result suggests that county income growth is significantly affected by regional income growth patterns.

Local factors related to taxes, human capital development, poverty distribution, and accessibility are also included in the per capita income change equation. The results indicate that the per capita tax burden is not associated with per capita income change. A 
positive and significant relationship is found between income growth and property taxes. This result is unexpected but suggests that counties with a high proportion of tax income from property taxes experienced per capita income growth. The proportion of county population with a bachelor's degree or higher is positively and significantly related with changes in per capita income. A $1 \%$ increase in this percentage should increase per capita income by $\$ 225.73$, ceteris paribus. But, the proportion of a county's population below the poverty line has a greater negative impact such that a $1 \%$ increase in the percentage in poverty leads to a $\$ 429.53$ decrease in per capita income, ceteris paribus. Thus, while human capital development increases income growth, increasing poverty may hinder it.

The results for county accessibility are consistent with the non-spatial model in that both road density coefficients are positive, but only the interstate density variable is significant. However, the marginal impact is lower in the spatial model. This may be due to the exclusion of cross-county impacts in the non-spatial model which attributed more of the marginal impacts to own county variables. A 1 mile per square mile increase in interstate leads to an increase in per capita income of $\$ 2,850.07$ compared to $\$ 5,219.97$ in the non-spatial model.

\subsubsection{Per Acre Agricultural Land Value Change}

Spatial dependence was indicated by the relevant Moran's I statistics (Table 5.1) between the spatial lag of per capita income change $(W \Delta \hat{Y})$ and agricultural land value change $\left(W \Delta \hat{P}_{L}\right)$. Thus, this equation includes the endogenous variables, initial agricultural land value, and accessibility variables (as in the non-spatial model), and farmland protection 
polices and spatially lagged endogenous and initial condition variables. The results of this estimation are reported in Tables 5.3 and 5.4.

As in the non-spatial model, change in per capita income has a positive relationship with change in per acre value of land and change in employment density has a negative relationship. Unlike the non-spatial model, population density change is not significant. Counties with high income growth are expected to see increases in land values. Adjusting for spatial interdependence, the marginal impact of income growth on land values is higher; a $\$ 1$ increase in per capita income results in a $\$ 0.74$ increase in the value of agricultural land compared to a $\$ 0.28$ increase in the non-spatial model. This suggests that regional income growth pushes land values upwards through its impact on development of farmland. The negative coefficient estimate for employment density change is contrary to prior expectations that employment growth exerts pressure on existing land uses and results in higher land values. Compared to the non-spatial model, the agricultural land change coefficient has the reverse sign (positive) and is significant (it was not significant in the non-spatial model). This may indicate that counties with positive agricultural land density changes have higher value of land per acre. Or, counties with more agricultural land stock have higher values of land per acre. One possible explanation for this is that farmland in counties with an expanding agricultural land area is more productive, leading to higher per acre values for farmland.

To test for cross county growth interdependence spatial lag endogenous variables for changes in population density, employment density, per capita income, the value of agricultural land, and agricultural land acres are introduced. Increases in population density in neighboring counties $(W \Delta \hat{P})$ are positively associated with land value 
increases in the relevant county. A 1 person per square mile increase in a neighboring county's population is expected to increase agricultural land values by $\$ 56.11$ per acre. This result is consistent with prior expectations that increasing population in neighboring counties puts pressure on agricultural land use increasing the value of farmland. Employment density growth $(W \Delta \hat{E})$ in one county is also expected to increase land values in its neighbor; however, this variable was not statistically significant. Spatially weighted per capita income change $(W \Delta \hat{Y})$ is significant and negatively related with land values. This is unexpected as income growth in neighboring counties is expected to result in high land values nearby. This result may be capturing the effect that population and businesses tend to be attracted to high income regions, which would reduce pressure on land values in neighboring counties. The estimated impact is very small, with a $\$ 1$ increase in per capita income in a neighboring county reducing land values by $\$ 0.74$ per acre. The spatial lag of land values $\left(W \Delta \hat{P}_{L}\right)$ in neighboring counties is positive but not significant. Agricultural land density change in neighboring counties $(W \Delta \hat{A g} L)$ was significant in predicting own county agricultural land value per acre. A rise in agricultural land density in neighboring counties is associated with an increase in the value of land per acre in own county.

Counties surrounded by high land value counties experience increases in land value as indicated by the estimated coefficient on the spatial lag of initial land value $\left(W P_{L t-1}\right)$ which is positive and significant. Similarly, counties with high initial own county agricultural land values experience upward movement in land prices with the estimated coefficient positive and significant. 
Road density variables have positive relationships with land value; however, state road density is not significant. For interstate road density, a 1 mile per square mile increase results in an increase in farmland values of $\$ 10,339.18$ per acre. This may be due to the effect of interstate development on regional population, employment, and income growth which directly and indirectly impose pressure on existing land use at local levels in addition to decreasing the supply of land. Development of road infrastructure itself claims some land from other sectors, including agriculture.

Agricultural income per farm and government payments per farm test the effect of farm income and government support programs on agricultural land values. The positive coefficients confirm prior expectations that farm income and government support payments increase farmland values, although the government payments variable is not significant. All other variables remaining fixed, a $\$ 100$ increase in agricultural income per farm is expected to raise the value of agricultural land by $\$ 2.60$ per acre.

A number of farm characteristics and farmland protection policy variables are introduced to measure the impact of policy and performance on agricultural land value. The proportion of county land devoted to farming is significant and negatively related with county agricultural land value per acre. For every $1 \%$ increase in the amount of county land used for agriculture, the per acre value of agricultural land is expected to decrease by $\$ 92.51$. This coefficient simply captures the relationship between county farmland supply and its price, indicating that a higher proportion of land in agriculture reduces its scarcity, hence lowering its value.

A set of farmland protection policies is introduced in the spatial model to study their effects on agricultural land value. Dummy variables capture differences in land use 
policies across states in the Northeast. Four land use policy instruments are included - tax easements, agricultural districts, agricultural protection zoning, and a transfer of development rights program. The coefficient estimates for these policy variables indicate that states which have these policies have significantly higher land values compared to states that have not implemented these policies. Aside from agricultural zoning, which was insignificant, all of the other policy instruments have positive and significant coefficient estimates. States that have implemented tax easements, agricultural districts, and TDR have higher agricultural land values with per acre marginal impacts of these policies of $\$ 16,019.16, \$ 7,491.82$, and $\$ 9,756.59$, respectively. These impacts could mean that states which have implemented these policies were already experiencing significant increases in land values. Hence, this result suggests that farmland protection policies have been in response to high growth and rapid farmland conversion rather than being implemented as preventive measures.

\subsubsection{Agricultural Land Density Change}

Moderate spatial autocorrelation is observed between agricultural land density change and its spatial lag variable ( $W \Delta \hat{A g L})$ and the spatial lag of population density change $(W \Delta \hat{P})$, as indicated by the Moran's I statistics for this equation (Table 5.1). The endogenous variables, initial agricultural land density, accessibility variables, agricultural land use policy instruments, and farm income characteristics as well as agricultural employment (as in the non-spatial model) are included in this equation, along with an urban influence variable, the spatially weighted initial stock of farmland and spatially lagged endogenous variables. The results are reported in Tables 5.3 and 5.4. 
As in the non-spatial model, change in population density is not significant and change in per capita income is significant and negative. In line with theoretical expectations, increases in income result in agricultural land conversation to satisfy the demand for growth. Holding other factors constant, a $\$ 1,000$ increase in per capita income would lead to conversion of 4 acres of farmland per square mile. The positive marginal effect of employment growth on agricultural land conversion was not as anticipated. Employment growth may have two effects, market creation and an increase in the demand for land. The net impact will determine the overall change in agricultural land use. In this case, an increase in employment density increases agricultural land density, however, an increase in per capita income decreases it. A significant and positive relationship is observed between change in agricultural land value and agricultural land density change, whereas in the non-spatial model this variable was not statistically significant. This positive impact suggests that counties with increasing agricultural land values have less agricultural land conversion. This result confirms that development is more likely in low land value counties compared to counties with high prices for farmland. The initial condition variable (agricultural land density in 1987) was not significant. The spatially lagged initial condition variable $\left(W A g L_{\mathrm{t}-1}\right)$, however, was significant and positive, indicating that agricultural land density is expected to be high in counties bordering those with high initial agricultural land density.

Estimates of the spatially lagged endogenous variables indicate that population growth in neighboring counties $(W \Delta \hat{P})$ has a significant and negative effect on agricultural land. Similarly, increasing agricultural land values in neighboring counties $\left(W \Delta \hat{P}_{L}\right)$ lead to a greater loss of farmland in the county of interest. Increasing land values 
may encourage local farmers to develop their land if the gain from selling is greater than the discounted benefits of using the land in agriculture. Both the spatial lag of income $(W \Delta \hat{Y})$ and of employment $(W \Delta \hat{E})$ are positive and significant. This result, in conjunction with own-county effects, generally suggests that while own-county income growth increases pressure on existing agricultural land, the increase of these variables in neighboring counties has the opposite impact. Income and employment growth in neighboring counties may create market outlets for farmers in a nearby county while decreasing development pressure in their own county. This conclusion is supported by the negative and significant coefficient for the farm income variable, which indicates that less farmland is developed in counties where farm income is higher.

Accounting for spatial interdependence, the marginal effects of road access are lower than in the non-spatial model. The interstate variable is negative in the spatial model and positive in the non-spatial, however, it is insignificant in both. The coefficient estimate for state road density supports the idea that better access increases the susceptibility of agricultural land to development. An increase of 1 mile of state road per square mile results in a loss of 32.7 farmland acres per square mile. A variable that measures the influence which urban areas exert on farmland development (ranging from 1 for urbanized areas to 9 for rural areas) is positive and significant, meaning that counties close to highly urbanized areas are likely to experience greater farmland losses than counties which are rural.

Four land use policy instruments are included - tax easement, agricultural districts, agricultural protection zoning, and transfer of development rights. Consistent with the non-spatial model, the spatial coefficients show that states which have 
implemented tax easements and transfer of development rights programs experience higher levels of agricultural land development compared to states that did not implement these policies. States using these programs have higher agricultural land conversion at the margin of 198 and 176 acres per square mile, respectively. However, states with agricultural districts and zoning did not see a significant difference in farmland development compared with states that did not have these policies, as these coefficients were not significant. This raises questions regarding the effectiveness of these farmland protection policies and whether land use policies are introduced as a response to already existing development pressure or as a preventive land management tool.

\subsubsection{Major Findings of the Spatial Growth Equilibrium Model}

The main goal of the spatial growth equilibrium model is to understand the relationship between regional growth trends, their spatial interdependence, and agricultural land development. For this reason, changes in population, employment, and income and their spatial lags are modeled as endogenous variables, and their impact on agricultural land values and agricultural land development and their spatial lags is traced. This section provides the major findings as follows.

- County population change is significantly driven by changes in employment and income growth, initial population density, per capita and property taxes, and by the spatial lags of per capita income growth, agricultural land value changes, and of population growth itself. The relationship established between non-spatial variables and population density change is the same in the two models. Focusing on spatial variables, population density change is positively influenced by neighboring counties income growth and negatively related with neighboring county changes in population 
density and value of land per acre. This result indicates that movements in neighboring county population, income, and land values will have an effect on own county population density changes, showing interdependence between land use change, spatial land value differences, and spatial income growth variability.

- County employment density change is significantly driven by changes in population density, value of land per acre, initial employment density, road infrastructure, and the spatial lags of population and employment. The relationship established between non-spatial variables and employment density change is the same in the spatial and non-spatial models. The spatial variables provide additional insights. Employment density change is positively influenced by neighboring county population growth, but negatively influenced by neighboring county employment growth. This result indicates that county employment growth in not only affected by county specific socio-economic variables, but also by growth in neighboring county population and employment.

- County per capita income change is significantly affected by population and employment density, value of agricultural land per acre, property taxes, interstate development, county educational attainment and poverty level, and the spatial lag of per capita income and initial levels of per capita income in neighboring counties. Change in county per capita income is positively related with neighboring counties income growth and negatively related with neighboring counties initial per capita income. This result suggests that income growth is not only determined by county specific conditions, but also depends on the spatial distribution of per capita income growth. 
- Per acre changes in agricultural land value are significantly affected by changes in employment density, per capita income, agricultural land density, initial period value of land, interstate road density, several land use policies, agricultural income per farm, proportion of county land in agriculture, and spatial lags of population growth, changes in per capita income, changes in agricultural land density, as well as initial farmland values in neighboring counties.

- The results for the change in agricultural land value equation for the spatial and nonspatial models indicate the same directional relationships for the own-county variables except for agricultural land density, which has a negative and insignificant result in the non-spatial model and a positive and significant relationship in the spatial model.

- Focusing on spatial variables, change in the value of agricultural land is negatively influenced by neighboring county income growth, but positively affected by neighboring counties population and agricultural land density changes as well as neighboring counties initial agricultural land value per acre. This result indicates that county land value change is not only driven by own-county socio-economic factors, but also by neighboring county growth in population and agricultural land density changes, indicating spatial interdependence regarding land value changes.

- County agricultural land density change is driven by changes in county employment, per capita income, and value of land per acre, spatial lag of population, employment, income, and land value changes, state road infrastructure density, land use policies, and influence of urban areas. 
- Agricultural land development is accelerated through county per capita income growth and increases in state road density, while it is lessened through county job growth and the initial stock of agricultural land in neighboring counties.

- The impact of farmland protection policies is similar to the non-spatial results, in that northeastern states with tax easement and transferable development rights programs experienced more agricultural land development per square mile than states that did not implement these policies, while there was no statistical difference between states that used agricultural districts and agricultural zoning and those that did not. While farm employment has no significant impact on agricultural land development, farm income per acre is positively associated with agricultural land development.

- The spatial econometric model further informs that agricultural land development is encouraged by neighboring county population growth and increases in agricultural land value per acre while discouraged by neighboring counties employment and income growth. Not surprisingly, agricultural land density is higher in more rural areas, as indicated by the urban influence code.

- Overall, though the spatial and non-spatial models provide similar information as to what drives county agricultural land density change, the spatial model indicates that agricultural land density changes in a county are also dependent on the distribution of population, land values, and income in neighboring counties.

\subsection{REVISITING STATED HYPOTHESES}

This section revisits the seven hypotheses introduced in chapter one in light of the empirical evidence presented. 
Hypothesis \#1: Regional growth, as measured by population and employment density changes and changes in per capita income, increases land development, reducing the amount of farmland.

This hypothesis emphasizes the theory based expectation that higher growth in population, employment, and income across counties uses more land than would otherwise be converted from agriculture. The evidence to test the validity of this hypothesis can be found in the agricultural land density change equation in both the spatial and the non-spatial models. The results show that growth in county population (although not significant) and per capita income are negatively related with changes in agricultural land density, however, a positive and significant relationship is found for employment growth. In light of this evidence, hypothesis 1 can only be partially accepted, since population and per capita income growth negatively influence agricultural land density, but employment growth does not.

Hypothesis \#2: A more competitive agricultural sector, as measured by higher income per farm and agriculture's contribution to employment in the county, can limit the loss of farmland to development.

One important question in understanding agricultural land development is whether improving the performance of the sector can reduce development pressure. Both farm employment and agricultural income per farm are introduced in the agricultural land equation in both the spatial and non-spatial models to examine this. In both models, farm employment is not statistically significant. Income per farm is not significant in the nonspatial model; however, after accounting for spatial interdependence, agricultural income 
per farm has a negative and significant relationship with changes in agricultural land density. This result suggests that development of farmland is higher in counties with higher per farm income. Development raises expected farmland values, but at the same time can improve markets for local farmers increasing income per farm. This result could also be due to intensive use of agricultural land under development pressure that is often used to produce high value agricultural products. Thus, in light of this evidence the original hypothesis cannot be supported.

Hypothesis \#3: Regional growth in per capita income can accelerate regional population and employment growth, and reduce the stock of farmland.

This hypothesis is measuring an indirect effect of income on agricultural land development through acceleration of regional population and employment growth. Per capita income is allowed in both models to have a direct and an indirect effect on agricultural land development. Change in county per capita income has a positive effect on change in county employment density in the non-spatial model (and is not significant in the spatial model), thus counties with growing per capita income create more employment. The relationship between per capita income growth and population density is negative and significant in both models, meaning that growing per capita income leads to declines in population. This seems counterintuitive; however, increases in per capita income may cause residents to move to slower growing areas with more environmental amenities causing population growth in areas (typically rural and suburban) with less growth in income. This result is reinforced by the spatial population density change equation which indicates that per capita income increases in neighboring counties 
increase population density in own county. Together, these results suggest that while income growth within a county reduces population density, similar growth in income in neighboring counties may actually increase it. Thus, the impact of income on changes in population density depends on where income is growing. Results from the agricultural land density change equation suggest that population growth (which is partially motivated by income growth) has a negative (although insignificant) impact, and per capita income change has a direct negative impact on changes in farmland density. Employment growth has a direct positive relationship with agricultural land density in both models. Bringing all this information together, it can be concluded that the effect of income on population depends on where per capita income is growing, but the effect of population growth on agricultural land is unambiguously negative. The effect of income growth on employment creation is positive, but employment growth does not lead to a loss of farmland. Hence, the hypothesis can be partially accepted. Per capita income growth can accelerate population and employment growth, but while population growth reduces changes in agricultural land density, employment growth does not.

Hypothesis \#4: Government transfer payments to farmers and state farmland protection programs are effective in reducing agricultural land development.

This hypothesis puts forth the argument that government transfer payment programs and land use policy interventions could be effective tools for reducing development of farmland. The agricultural land density change equation in both the spatial and nonspatial models includes variables on government payments per farm and a set of farmland protection policies and the results are robust. Both models indicate that government 
payments per farm are not a significant predictor of changes in agricultural land density. The coefficient estimates for the policy dummy variables, in both models, suggest that agricultural land density change is negative in states that implement tax easements and TDR programs compared to states that have not implemented these policies, implying a greater loss of farmland in the states with policies compared to states without. Based on these results, the hypothesis that government transfer programs effectively reduce agricultural land development is rejected. Because the state-level farmland protection program data is only for one time period, no conclusion regarding the ability of these programs to reduce agricultural land development over time can be made. As such, it is difficult to make generalized conclusions regarding the effectiveness of state farmland protection programs in the context of this study.

Hypothesis \#5: Accessibility factors, such as road density, distance from major metropolitan centers, and being adjacent to growing communities can increase the susceptibility of farmland to development.

State and interstate road density and urban influence code variables are introduced to account for the effect of accessibility on agricultural land development. Higher density in state roads is significantly and inversely related with changes in agricultural land density. Similarly, counties adjacent to metropolitan and urbanized locations (captured by the urban influence code) have greater farmland losses. These results imply that counties with more road access are more likely to face development pressure. To account for being adjacent to growing communities, a spatial lag of the endogenous variables of population, employment, and per capita income growth are introduced in the spatial 
model. While a significant negative relationship is established between own-county agricultural land density change and neighboring county population growth, employment and income growth are significant and positive. Therefore, the stated hypothesis that accessibility negatively affects agricultural land density is an acceptable proposition based on the road results, however, the hypothesis that growth in neighboring communities results in loss of farmland is true only for population growth.

Hypothesis \#6: Agricultural land prices play a key role both in determining patterns of regional growth and the extent of agricultural land development.

Agricultural land value per acre is introduced as an explanatory variable in four equations in the two models used in this study. After adjusting for spatial dependence, it is significant in explaining changes in all the endogenous variables, except population growth. A negative relationship with employment growth and a positive relationship with change in agricultural land density suggest that counties with high land values experience slower employment growth and less farmland development. The results also establish a positive relationship with per capita income. Similar results are observed in the nonspatial model for the effect of value of agricultural land per acre on employment growth, income growth, and agricultural land density change. From these results, the hypothesis that agricultural land values play a role in determining patterns of growth and the extent of agricultural land development is justified. 
Hypothesis \#7: Economic, demographic, income, agricultural land price, and agricultural land stock changes in a county are significantly affected by trends in neighboring counties. Hence, spatial distribution of economic activity and spatial land price differentials are important in shaping agricultural land development.

This hypothesis claims the importance of cross county interdependence in growth and farmland development. The existence of cross county spatial interdependence is tested using Moran's I statistics that measure the existence of spatial autocorrelation. Using these statistics, spatial autocorrelation for all the specified endogenous variables is established with their spatial lags and/or with spatial lags of other endogenous variables. This suggests that spatial interdependence in regional growth and farmland development is present. The spatial econometric model results show significant estimates for spatial lag variables. Population growth is significantly affected by spatial lags of changes in population density, per capita income, and the per acre value of farmland. Employment density change is significantly impacted by the spatial lags of population and employment growth. Growth in per capita income is significantly related to the spatial lag of changes in per capita income and initial per capita income values. Change in farmland value is significantly affected by spatial lags of growth in population and per capita income, agricultural land density change, and initial farmland values. Finally, agricultural land density change is significantly related to spatial lags of changes in population, employment, per capita income, value of land per acre, and initial agricultural land densities. This evidence supports the hypothesis that there are cross county economic impacts and agricultural land development interdependence. 


\section{CHAPTER 6}

\section{SUMMARY AND CONCLUSION}

\subsection{SUMMARY AND CONCLUSION}

This study focuses on understanding the relationship between regional growth and development of farmland. Development in rural and suburban locations may bring recreational and environmental benefits as well as other benefits associated with suburban and rural living, however, from a social perspective, the development of agricultural land may not be efficient and socially desirable. Agricultural land provides benefits to society not only in terms of production of food and fiber (for which there are efficient markets) but also in terms of open space and scenic values for which there are no markets. As a result, a number of places have initiated local and state land use policies to balance development and preservation through what are called "smart-growth" initiatives.

In order to understand the relationship between regional growth and agricultural land development, a growth model using a system of equations was developed and estimated using data from 12 states in the northeastern United States. The rate of conversion of agricultural land in this area is among the fastest in the country. This region of the U.S. also has some of the oldest land use policies, making it ideal for examining their impact on the patterns of agricultural land development. The Northeast provides a heterogeneous study area to better understand the relationship between current trends of development and agricultural land conversion. 
By outlining a theoretical model of household spatial location choice for residential purposes using a microeconomic model, the motivation for household location decisions was analyzed. Comparative static results identified important parameters that affect household location demand, such as income, land prices, commuting costs, rent, and urban population growth. This theoretical understanding assisted in selecting theoretically sound variables for estimation of the econometric model. The developer's theoretical microeconomic model identified the factors that determine development location decisions, such as house price per square foot, land rent, interest on capital, per unit cost of house production, commuting costs, and urban population growth.

The case for market failure in agricultural land allocation and the motivation for public sector intervention into the land market was examined by developing a theoretical dynamic model of land allocation between agriculture and development. The theoretical model reveals the inefficiency of land markets by underestimating the value of agricultural land from a social perspective. This market failure may induce policy intervention in land markets and trigger agricultural land preservation initiatives.

Two econometric models were empirically estimated. A system of equations was used to examine relationships between changes in population, employment, per capita income, per acre value of agricultural land, and agricultural land acreage. A model containing five equations for these five endogenous variables was estimated using threestage-least-squares. A spatial system of equations model was also estimated using the three-stage least squares method. Spatially lagged endogenous variables were created by multiplying predicted endogenous variables by a contiguity-based spatial weights matrix. This method helped examine whether any spatial interdependence exists between growth 
and agricultural land development. These two models contribute to the literature by effectively integrating agricultural land use research into a regional growth framework and by setting-up a system of equations econometric estimation procedure to capture spatial interactions in agricultural land use change.

The results from these two models were robust as most coefficient estimates were not sensitive to changes in specification between the two models, in terms of the direction of the relationship between variables. The change in population equation coefficient estimates indicated that regions with increasing employment opportunities experience more population growth. While increases in per capita taxes, property taxes, and the unemployment rate reduce county population density, increases in road access, per capita local government spending, and jobs increase county population density. The spatial econometric model provided the same conclusions, but also demonstrated that income growth in neighboring counties increases population, and an increase in the per acre value of land in neighboring counties reduces population.

When examining the econometric estimation results for changes in employment density, both models indicated that while growth in county population and per capita income are positively related with increases in employment density, growth in agricultural land values reduces employment growth. The results also show that higher taxes and a higher county unemployment rate reduce employment density, and higher interstate and state road densities increase employment expansion.

Results for the change in per capita income equation were robust under both spatial and non-spatial econometric estimations; however, the marginal effects were different. Per capita income was negatively related with population density, and 
positively related with employment density and agricultural land values. Increases in per capita taxes and the percentage of the county population below the poverty line tend to slow income growth, whereas state and interstate road density and the percentage of the county population with a bachelor's degree or higher have a positive impact on income growth. The spatial model results also found that income growth exhilarates when income growth occurs in neighboring counties, showing economic interdependence among counties.

Results for the change in per acre value of farmland were robust in both the spatial and non-spatial models for most estimated coefficients. The positive coefficient estimates for the endogenous variables of population density change and change in per capita income indicated that counties with population and income growth are likely to experience significant increases in the per acre value of agricultural land. The endogenous variable of change in agricultural land density is negatively but insignificantly related with value of land per acre in the non-spatial model but positively and significantly related in the spatial model. This may suggest that, although the overall estimate was not robust, counties with agricultural land expansion had higher land values, and counties with agricultural land losses had lower values. Interstate and state road densities have a positive relationship with the per acre value of farmland. The more accessible farmland is the higher its value. Similarly, agricultural income per farm has a positive relationship with land values. An examination of farmland protection policies indicates that states which have implemented these policies have significantly higher land values, possibly because land use policies were introduced in areas where farmland was already increasing in value due to development pressure. The spatial model results further 
suggested that agricultural land values are influenced by neighboring county population (positive and significant), income growth (negative and significant), and farmland density (positive and significant).

Results for the change in agricultural land density estimations were also robust for most coefficient estimates in both the spatial and non-spatial models. Agricultural land acreage is negatively related to changes in population and per capita income. Counties with significant increases in per capita income and population density are likely to experience farmland losses. Changes in per acre value of land and employment density are positively related with agricultural land density. This may indicate that counties with employment growth and increasing farmland values have increasing agricultural land density. Proximity to a metropolitan area and higher state road density encourage development of farmland. A surprising negative relationship was found between tax breaks for farmland preservation easements and a TDR farmland protection program, indicating that states that implemented these policies have significantly more agricultural land loss per square mile compared to states that did not implement these policies. This could be the case if these policies were implemented in response to already existing strong development pressure which has continued. Results from the spatial econometric model suggest that population growth in neighboring counties encourages own-county farmland development. Income and employment growth in neighboring counties have positive impacts on changes in agricultural land density. 


\subsection{POLICY RECOMMENDATIONS}

Based on empirical findings in this study about the nature of relationships between regional growth patterns, agricultural land protection policies, agricultural sector performance, and agricultural land development, a number of recommendations can be suggested for effective agricultural land protection and management in the northeastern United States.

1. Agricultural land protection policies, programs, and initiatives may be better coordinated at a regional level. Findings in this study on agricultural land development indicate that land use change is not only affected by growth within a county, but also by growth patterns in neighboring counties. This cross-county interdependence may indicate the need for coordinated regional farmland protection policies and programs for effective land use management. To achieve this goal, open cooperation across states is important.

2. Farmland protection policies and programs might be more effective if integrated within overall state economic development objectives. In view of the findings of this study, that regional growth patterns affect agricultural land development, consideration should be given to the impact of economic development on agriculture, and agriculture should be taken into account when making economic development decisions. This may help achieve a balance between state economic development goals and protection of farmland. Some states already have in place agricultural impact statutes that require consideration of the impact of economic development on the agricultural sector. Similar policy approaches may help harmonize growth and farmland protection. 
3. Resources for farmland protection programs may be better targeted to counties or locations with a high degree of susceptibility to development. Raising money for farmland protection can be challenging, and resource scarcity may hinder countylevel land protection initiatives. It may be more effective to focus federal and state farmland protection resources on counties with high susceptibility to development based on accessibility, adjacency to major urban centers, current population and income growth, and agricultural land development trends. This prioritization of scarce farmland protection funds at state and county levels may assist in targeting areas which are most at risk.

4. Programs targeted at improving farm income through local market development and adaptation in the face of development pressure may help reduce agricultural land losses. Agricultural income per acre has to grow at a faster rate than development return per acre for agricultural land to remain in farming. Hence, farm support policies which encourage local market development and production of high value crops should be tried as alternative land protection tools to help threatened farms adapt to development pressure.

5. The impact of transportation policies, particularly state road expansion, on development of agricultural land should be considered. Development of transportation infrastructure facilitates economic expansion and housing development. Agricultural land will be developed at a faster pace to accommodate this increased development encouraged through improved transportation access. Though transportation infrastructure development is an important social investment, 
analysis of the impact of road development on agricultural lands may help minimize the social cost of building roads in terms of lost farmland.

6. Introduction of a 'development tax' could be effective in protecting agricultural land as it may help land markets reflect the true value of farmland. The fact that the market value of farmland may not necessarily compensate for non-market values associated with agricultural land means that, from a social perspective, farmland may be undervalued. Introduction of a 'development tax' per acre of converted farmland may help reflect the true value of agricultural land. The average willingness to pay of county residents to keep an acre of land in farming could be used as a basis for the tax, compensating for losses of non-market benefits due to agricultural land development.

\subsection{LIMITATIONS AND FUTURE RESEARCH}

\subsubsection{Limitations}

The usefulness of this study comes from its ability to improve understanding of the relationship between regional growth patterns and agricultural land development. It expanded on earlier works by bringing agricultural land use questions into a regional framework and by introducing a system of equations model that integrates cross-county spatial interactions. However, there are limitations in this study that could be improved upon in future work.

The first limitation relates to data. A number of theoretically relevant variables were not included in the models. For example, amenity indicators (for instance, proportion of county land covered by water, forest, and public lands) could explain 
differences in population growth, and land quality differences may explain changes in land values. Degree of implementation of farmland protection policies at the county level might better explain differences in farmland conversion. Even though the desired data may enhance the performance of the models and provide relevant policy information, difficulty in getting such data limited their inclusion in this study.

The second limitation concerns adjusting nominal variables to real variables. Based on fundamental economic arguments, people respond to real prices and income as opposed to nominal prices and income. The relationships among the endogenous variables in this study are based on nominal data. Though the underlying econometric relationships and significance of coefficient estimates should not significantly change with this adjustment of the data, such an adjustment is relevant for interpretation of the results.

\subsubsection{Future Research}

The limitations of this study discussed in the previous section provide an opportunity to further expand and improve this study. Additional research in this area could focus on and significantly contribute to land use research by expanding in to the following areas:

1. Integrating more relevant variables: growth patterns in population, employment, income, land value, and agricultural land changes are affected by a series of important factors such as amenity and land quality differences along with county level differences in agricultural land use policies. Integration of such relevant variables in future work can enhance the understanding of regional growth and land use change. 
2. Spatial econometric modeling: this study introduced a spatial econometric model based on a spatial lag approach. The spatial aspects of the methodology could be extended by exploring spatial error testing and modeling. Such models enable a complete analysis of spatial interactions which can enhance the quality of results.

3. Scope: extending this study from a regional to a national level could bring in more variation within the data and yield results with more general application. A national study would eliminate biases that result from the unique characteristics of the Northeast and allow for regional variations in economic, demographic and agricultural sector variables. A national study is the logical next step for expansion of this regional model. 


\section{REFERENCES}

Abler, D. (2004) "Multifunctionality, Agricultural Policy, and Environmental Policy." Agricultural and Resource Economics Review 33(1), 8-17.

Aldrich, L. and L. Kusmin. (1997) "Rural Economic Development: What Makes Rural Communities Grow?” USDA, Agricultural Information Bulletin No. 737.

Allen, J. S., K. S. Lu, and T. D. Potts. (1999) "A GIS Based Analysis and Prediction of Parcel Land-use Change in a Coastal Tourism Destination Area." Paper Presented at the 1999 World Congress on Coastal and Marine Tourism, Vancouver, British Columbia, Canada.

Alonso, W. (1964) Location and Land Use: Towards a General Theory of Land Rent. Cambridge, MA: Harvard University Press.

Anselin, L. (1980) "Estimation Methods for Spatial Autoregressive Structures: A Study in Spatial Econometrics." Cornell University Program in Urban and Regional Studies, Regional Science Dissertation and Monograph Series Number 8. Ithaca, NY: Cornell University, Program in Urban and Regional Studies.

Anselin, L. (1988) "Lagrange Multiplier Tests Diagnostics for Spatial Dependence and Spatial Heterogeneity." Geographical Analysis 20, 1-17.

Anselin, L. (1997) The Moran Scatterplot as an ESDA Tool to Assess Local Instability in Spatial Association. In Fischer M, Scholten H, Urwin (eds.): Spatial Analytical Perspectives on GIS in Environmental and Socio-economic Sciences. London: Taylor and Francis.

Batie, S. S. (2003) "The Multifunctional Attributes of Northeastern Agriculture: A Research Agenda.” Agricultural and Resource Economics Review 32(1), 1-8.

Bell, K. P., and E. G. Irwin. (2002) "Spatially Explicit Micro-Level Modeling of Land Use Change at the Rural-Urban Interface.” Agricultural Economics 27, 217-232.

Boarnet, M. G. (1995) “Transportation Infrastructure, Economic Productivity, and Geographic Scale: Aggregate Growth versus Spatial Distribution.” [Online] available from http://www.uctc.net/papers/255.pdf; accessed 17 October 2005.

Bowker, J. M., and D. D. Didychuk. (1994) "Estimation of the Nonmarket Benefits of Agricultural Land Retention in Eastern Canada." Agricultural and Resource Economics Review 23, 218-225. 
Brown, D. L., G. V. Fuguitt, T. B. Heaton, and S. Waseem. (1997) "Continuities in size of place preferences in the United States, 1972-1992.” Rural Sociology 62(4), 408-428.

Brueckner, J. K. (1987) The Structure of Urban Equilibrium, in Handbook of Regional and Urban Economics (edited by E.S. Mills), Vol. 2, Ch. 20.

Brueckner, J. K. and D. A Fansler. (1983) "The Economics of Urban Sprawl: Theory and Evidence on the Spatial Size of Cities." The Review of Economics and Statistics 65(3), 479-482.

Brueckner, J. K. (2000) “Urban Sprawl: Diagnosis and Remedies.” International Regional Science Review 23(2): 160-171.

Burchell, R.W. and N.V. Shad. (1998) The Costs of Sprawl versus Compact Development, prepared for Metropolitan Planning Council. Chicago, IL: Metropolitan Planning Council.

Burridge, P. (1980) "On the Cliff-Ord Test for Spatial Autocorrelation.” Journal of the Royal Statistical Society B 42, 107-8.

Cantilon, R. (1755) Essai sur la nature du commerce en general. (English Translation). [Online] available from http://socserv2.socsci.mcmaster.ca/ econ/ugcm/ 3113/cantillon/essay1.txt; accessed 14 September 2002.

Carlino, G. A., and E. S. Mills. (1987) “The Determinants of County Growth.” Journal of Regional Science 27, 39-54.

Chandra, A., and E. Thompson. (2000) "Does Public Infrastructure Affect Economic Activity? Evidence from the Rural Interstate Highway System." Regional Science and Urban Economics 30, 457-490.

Claassen, R., and A. Tegene. (1999) "Agricultural Land Use Choice: a Discrete Choice Approach.” Agricultural and Resource Economics Review 28(1), 26-36.

Cliff, A. D. and J. K. Ord. (1972) "Testing for Spatial Correlation among Regression Residuals." Geographic Analysis 4, 267-285.

County and City Data Book (C\&CDB), (1994 and 2000) County Level Data. [Online] available from http://fisher.lib.virginia.edu/collections/stats/ccdb; accessed 9 May 2005.

Crihfield, J. (1994) “Modeling Land-Use Decisions in Rural Areas." Review of Agricultural Economics 16, 103-112.

Daniels, T. L. (1986) "Hobby Farming in America: Rural Development or Threat to Commercial Agriculture?” Journal of Rural Studies 2, 31-40. 
Daniels, T. L., and A. C. Nelson (1986). "Is Oregon's Farmland Preservation Program Working?" Journal of the American Planning Association 52, 22-32.

Deller, S. C., T. Tsai, D. W. Marcouiller, and D. B.K. English. (2001) "The Role of Amenities and Quality of Life in Rural Economic Growth." American Journal of Agricultural Economics 83(2), 352-365.

Dissart, J. C., and S. C. Deller. (2000) "Quality of Life in the Planning Literature." Journal of Planning Literature 15, 135-161.

Endicott, E. (ed.). (1993) Land Conservation through Public/Private Partnerships. Washington, DC: Island Press.

English, D. B. K, D. W. Marcouiller, and H.K. Cordell. (2000) "Linking Local Amenities with Rural Tourism Incidence: Estimates and Effects." Natural Resources 13(3), $185-202$.

Economic Research Service (ERS), USDA. (2001) "Development at the Urban Fringe and Beyond." [Online] available from http://www.farmfoundation.org/pdicdata2/ FarmBill/pdfs/aer803.pdf; accessed 22 July 2005.

Frey, W. H. (1993) “The New Urban Revival in the United States.” Urban Studies 30, 741-774.

Fuguitt, G. V., and D. L. Brown. (1990) "Residential Preferences and Population Redistribution, 1972-1988." Demography 27, 589-600.

Garcia-Mila, T., and T. J. McGuire. (1992) "The Condition of Publicly Provided Inputs to States' Economies." Regional Science and Urban Economics 22, 229-241.

Gardner, B. D. (1977) "The Economics of Agricultural Land Preservation.” American Journal of Agricultural Economic 59, 1027-1036.

Goetz, S. J. (2002) "Land Use Programs and Activities, 2001-02.” [Online] available at http://www.cas.nercrd.psu.edu/morgantown.2002.ppt; accessed 15 August 2005.

Gottlieb, P. D. (1994) “Amenities as an Economic Development Tool: Is There Enough Evidence?" Economic Development Quarterly 8, 270-85.

Graves, P. E. (1983) "Migration with a Composite Amenity: The Role of Rents." Journal of Regional Science 23, 541-546.

Greene, W. H. (2002) LIMDEP Version 8.0: Econometric Modeling Guide Vol. 1. Plainview, NY: Econometric Software, Inc. 
Hailu, Y. G., and R. S. Rosenberger. (2004) "Modeling Migration Effects on Agricultural Lands: A Growth Equilibrium Model." Agricultural and Resource Economics Review 33(1), 50-60.

Harvest New England (HNE). (2003) "Agricultural Promotion for the New England States." [Online] available at http://www.thebige.com/detpages/bige10203.html; accessed 10 August 2005.

Heimlich, R. E. and W. D. Anderson (2001) "Development at the Urban Fringe and Beyond: Impacts on Agriculture and Rural Land.” Economic Research Service, U. S. Department of Agriculture, Agricultural Economic Report No. 803.

Henneberry, D. M. and R. L. Barrows. (1990) "Capitalization of Exclusive Agricultural Zoning into Farmland Prices.” Land Economics 66(3), 249-258.

Henry, M. S., B. Schmitt, K. Kristensen, D. L. Barkley, and S. Bao. (1999) "Extending Carlino-Mills Models to Examine Urban Size and Growth Impacts on Proximate Rural Areas." Growth and Change 30, 526-548.

Hite, D., B. Sohngen, and J. Templeton. (2003) "Zoning, Development Timing, and Agricultural Land Use at the Suburban Fringe: A Competing Risks Approach.” Agricultural and Resource Economics Review 32(1), 145-157.

Hunter, L. M., M. J. Gonzalez, M. Stevenson, K. S. Karish, R. Toth, T. C. Edwards, R. J. Lilieholm, and M. Caulk. (2003) "Population and Land Use Change in the California Mojave: Natural Habitat Implications of Alternative Futures." Population Research and Policy Review 22: 373-397.

Inman, K., D. M. McLeod, and D. J. Menkhaus. (2002) "Rural Land Use and Sale Preferences in a Wyoming County." Land Economics 78(1), 72-87.

Irwin, E. G. (2002) “The Effects of Open Space on Residential Property Values.” Land Economics 78(4), 465-481.

Irwin, E. G., and N. E. Bockstael. (2001) "The Problem of Identifying Land Use Spillovers: Measuring the Effects of Open Space on Residential Property Values." American Journal of Agricultural Economics 83, 698-704.

Irwin, E. G., K. P. Bell, and J. Geoghegan. (2003) "Modeling and Managing Urban Growth at The Rural-Urban Fringe: A Parcel-Level Model of Residential Land Use Change." Agricultural and Resource Economics Review 32(1), 83-102.

Johnson, R. J., S. K. Swallow, D. M. Bauer, and C. M. Anderson. (2003) "Preferences for Residential Development Attributes and Support for the Policy Process: Implications for Management and Conservation of Rural Landscapes." Agricultural and Resource Economics Review 32(1), 65-82. 
Keeler, T. E. and J. S. Ying. (1988) "Measuring the Benefits of a Large Public Investment: the Case of the U.S. Federal-aid Highway System." Journal of Public Economics 36, 69-85.

Kline, J., and D. Wichelns. (1996) "Public Preferences Regarding the Goals of Farmland Preservation Programs." Land Economics 72, 538-49.

Knapp, T. A., and P. E. Graves. (1989) "On the Role of Amenities in Models of Migration and Regional Development.” Journal of Regional Science 29, 71-87.

Kusmin, L. D. (1994) "Factors Associated with the Growth of Local and Regional Economies: A Review of Selected Empirical Literature.” Staff Report AGES9405, U.S. Department of Agriculture, Economic Research Service.

Lapping, M. B., and J. F. Fitzsimmons. (1982) "Beyond the Land Issue: Farm Viability Strategies." Geo Journal 6, 519-24.

Lewis, D. J., G. L. Hunt, and A. J. Plantinga. (2002) "Public Conservation Land and Employment Growth in the Northern Forest Region." Land Economics 78, 245 259.

Lopez, R. A., A. O. Adelaja, and M. S. Andrews. (1988) "The Effects of Suburbanization on Agriculture." American Journal of Agricultural Economics 70(2), 346-358.

Lopez, R. A., F. A. Shah, and M. A. Altobello. (1994) “Amenity Benefits and the Optimal Allocation of Land." Land Economics 70, 53-62.

Lynch, L., and J. Carpenter. (2003) "Is There Evidence of a Critical Mass in the MidAtlantic Agricultural Sector Between 1949 and 1997?" Agricultural and Resource Economics Review 32(1), 116-128.

Ma, W., and H. Yasuo. (2003) “A Methodical Approach to Analyze Adjustments in Capital and Risk: Japanese Banks in Perspective.” Journal of Financial Management and Analysis 16(2), 1-13.

McLeod, D. M., J. Woirhaye, and D. J. Menkhaus. (1999) "Factors Influencing Support for Rural Land Use Control: A Case Study." Agricultural and Resource Economics Review 28(1), 44-56.

McMillen, D. P. (1989) “An Empirical Model of Urban Fringe Land Use.” Land Economics 65(2).

Mieszkowski, P., and E. S. Mills. (1993) “The Causes of Metropolitan Suburbanization.” The Journal of Economic Perspectives 7, 135-147. 
Mills, E. S. (1972) Studies in the Structure of the Urban Economy. Baltimore, MD: John Hopkins University Press.

Mills, E. S., and R. Price. (1984) "Metropolitan Suburbanization and Central City Problems." Journal of Urban Economics 15, 1-17.

Muth, R. F. (1969) Cities and Housing. Chicago, IL: University of Chicago Press.

Natural Resource Analysis Center (NRAC), West Virginia University. [Online] available at http://www.nrac.wvu.edu.

Nelson, A. C. (1992) "Preserving Prime Farmland in the Face of Urbanization: Lessons from Oregon.” Journal of the American Planning Association 58(4), 467-481.

Nickerson, C. J., and D. Hellerstein. (2003) "Protecting Rural Amenities through Farmland Preservation Programs." Agricultural and Resource Economics Review, 32(1), 129-144.

Nickerson, C. J., and L. Lynch. (2001) "The Effect of Farmland Preservation Programs on Farmland Prices." American Journal of Agricultural Economics 83(2), 341351.

Northeast Regional Center for Rural Development (NRCRD). (2002) "Land Use Problems and Conflicts in the U.S.: A Comprehensive Research Agenda for the $21^{\text {st }}$ Century." Rural Development Paper No. 10.

Northeast Sustainable Agriculture Working Group (NSAWG). (2003) “Agricultural Policy in the Northeast States: Inventory and Innovation."

Pennsylvania $21^{\text {st }}$ Century Environmental Commission. [Online] available at http://www.dcnr.state.pa.us/brc/rivers/riversconservation/registry/63glossary.pdf; accessed 16 July 2005.

Peterson, G., and W. Vrooman. (1992) "Urban Labor Markets and Economic Opportunity." In G. Peterson and W. Vrooman (eds.), Urban Labor Markets and Job Opportunity. Washington, DC: The Urban Institute Press.

Plantinga, A. J., and D. J. Miller. (2001) “Agricultural Land Values and the Value of Rights to Future Land Development." Land Economics 77, 56-67.

Plantinga, A. J., and D. J. Miller. (1997) "Maximum Entropy Estimation of Land Use Shares and Transitions.” Maine Agricultural and Forest Experiment Station Technical Bulletin 166.

Power, T. M. (1996) Lost Landscapes and Failed Economies: The Search for a Value of Place. Washington, D.C.: Island Press. 
Ready, R.C., M. C. Berger, and G. C. Blomquist. (1997) "Measuring Amenity Benefits from Farmland: Hedonic Pricing vs. Contingent Valuation." Growth and Change $28,438-458$.

Rey, S. J. and M. G. Boarnet. (1998) “A Taxonomy of Spatial Econometric Models for Simultaneous Equations Systems." Paper presented in the 45th Annual North American Meetings of the Regional Science Association International, Santa Fe, NM.

Roback, J. (1988) "Wages, Rents, and Amenities: Differences among Workers and Regions." Economic Inquiry 26, 23-41.

Roe, B., E. G. Irwin, and H. A. Morrow-Jones. (2004) "The Effects of Farmland, Farmland Preservation, and Other Neighborhood Amenities on Housing Values and Residential Growth." Land Economics 80(1), 55-75.

Rosenberger, R. S., and J. B. Loomis. (1999) "The Value of Ranch Open Space to Tourists: Combining Contingent and Observed Behavior Data." Growth and Change 30, 366-383.

Rosenberger, R. S., and R. G. Walsh. (1997) "Nonmarket Value of Western Valley Ranch Land Using Contingent Valuation." Journal of Agricultural and Resource Economics 22, 296-309.

Seto, K. C., and R. K. Kaufmann. (2003) "Modeling the Drivers of Urban Land Use Change in the Pearl River Delta, China: Integrating Remote Sensing with Socioeconomic Data." Land Economics 79(1), 106-121.

Shi, Y. J., T. T. Phipps, and D. Colyer. (1997) "Agricultural Land Values under Urbanizing Influences." Land Economics 73, 90-100.

Smith, M. D., and R. S. Krannich. (2000) 'Culture Clash' Revisited: Newcomer and Long-Term Residents' Attitude Toward Land Use, Development, and Environmental Issues in Rural Communities in the Rocky Mountain West." Rural Sociology 65(3), 396-421.

Studenmund, A. H. (2001) Using Econometrics: A Practical Guide. Massachusetts, U.S.A: Addison Wesley Longman, Inc.

U.S. Census. (2001). Regional Economic Information System (REIS), 1969-1999. Washington, D.C.: Bureau of Economic Analysis, Regional Economic Measurement Division.

USDA, National Agricultural Statistics Service. (1992) U.S. Census of Agriculture. [Online] available from http://www.nass.usda.gov/Census_of_Agriculture/1992/ index.asp; accessed 12 May 2005. 
USDA, National Agricultural Statistics Service. (2002) U.S. Census of Agriculture. [Online] available from http://www.nass.usda.gov/Census_of_Agriculture/ index.asp; accessed 14 July 2005.

USDA, Economic Research Service (ERS). "Urban Influence Code (2003).." [Online] available from http://www.ers.usda.gov/Data/UrbanInfluenceCodes/2003; accessed 16 May 2005.

Vaillancourt, F., and L. Monty. (1985) "The Effect of Agricultural Zoning on Land Prices, Quebec, 1975-1981.” Land Economics 61(1), 36-42.

Varian, H. R. (1992) Microeconomic Analysis, $3^{\text {rd }}$ Edition. New York: W.W. Norton \& Company.

Vesterby, M., and R. E. Heimlich. (1991) "Land Use and Demographic Change: Results from Fast-Growing Counties.” Land Economics 67(3), 279-91.

Vitaliano, D. F., and C. Hill. (1994) "Agricultural Districts and Farmland Prices." Journal of Real Estate Finance and Economics 8(3), 213-223

Wasylenko, M., (1991) "Empirical Evidence on Interregional Business Location Decisions and the Role of Fiscal Incentives in Economic Development," in Industry Location and Public Policy, H. Herzog and A. Schlottmann (eds.), Knoxville, TN: Tennessee University Press.

Wheaton, W. C. (1974) "A Comparative Static Analysis of Urban Spatial Structure." Journal of Economic Theory 9, 223-237.

Wheaton, W. C. (1977). "Income and Urban Residence: An Analysis of Consumer Demand for Location.” American Economic Review 67, 620-631.

Wu, J., R. M. Adams, and A. J. Platinga. (2004) "Amenities in an Urban Equilibrium Model: Residential Development in Portland, Oregon.” Land Economics 80(1), 19-32.

Zollinger, B. (1998) "Factors Influencing Agricultural Operators' Expectations to Sell Agricultural Land for Non-Agricultural Uses." Unpublished Ph.D. Dissertation, Utah State University. 


\section{APPENDIX}

The effect of a change in distance (d) on rental price of housing $\left(p_{h}\right)$ :

From equation (3.4), $u\left(Y-k_{c} d-p_{h} h, h\right)=v$. Totally differentiating this equation with respect to distance from the central city $(d)$ and rearranging terms yields:

$$
\left(\frac{\partial u}{\partial Y} \cdot \frac{\partial Y}{\partial d}\right)-\left(\frac{\partial u}{\partial d} \cdot \frac{\partial d}{\partial d}\right)-\left(\frac{\partial u}{\partial h} \cdot \frac{\partial h}{\partial d}\right)-\left(\frac{\partial u}{\partial p_{h}} \cdot \frac{\partial p_{h}}{\partial d}\right)+\left(\frac{\partial u}{\partial h} \cdot \frac{\partial h}{\partial d}\right)=0
$$

Household income is exogenously given and does not change with distance and utility of a household is fixed in advance at the level of $v$, hence these terms do not respond to a change in the distance parameter and can be reduced to zero. Equation (a), thus, can be expressed as:

(b) $\quad-k_{c}-p_{h} \frac{\partial h}{\partial d}-h \frac{\partial p_{h}}{\partial d}+\left(\frac{\partial u}{\partial h} \frac{\partial h}{\partial d}\right)=0$

From equation (3.3) it follows that $u_{1}=\frac{\partial u}{\partial h}=p_{h}$ and $u_{2}=\frac{\partial u}{\partial q}=1$ as the price of the Hicksian good is normalized to 1 . Substituting this relationship, equation (b) can be further simplified as:

(c) $\quad-u_{2}\left(k_{c}+p_{h} \cdot \frac{\partial h}{\partial d}+h \cdot \frac{\partial p_{h}}{\partial d}\right)+u_{1} \cdot \frac{\partial h}{\partial d}=0$

From equation (3.3), we can drive $u_{1}=p_{h} u_{2}$. Using this relationship, equation (c) can be rearranged and the comparative static result showing the impact of a change in distance on housing price can be given as:

$$
-k_{c}-h \frac{\partial p_{h}}{\partial d}=0, \text { thus } \ldots \frac{\partial p_{h}}{\partial d}=\frac{k_{c}}{-h}<0
$$


The effect of a change in income (Y) on housing price $\left(p_{h}\right)$ :

The comparative static results for the impact of a change in income and on housing price and square footage can be derived by totally differentiating equation (3.4) with respect to $Y$.

$$
\left(\frac{\partial u}{\partial Y} \frac{\partial Y}{\partial Y}\right)-\left(\frac{\partial u}{\partial k_{c}} \frac{\partial k_{c}}{\partial Y}\right)-\left(\frac{\partial u}{\partial d} \frac{\partial d}{\partial Y}\right)-\left(\frac{\partial u}{\partial p_{h}} \frac{\partial p_{h}}{\partial Y}\right)-\left(\frac{\partial u}{\partial h} \frac{\partial h}{\partial Y}\right)+\left(\frac{\partial u}{\partial h} \frac{\partial h}{\partial Y}\right)=0
$$

Commuting cost is assumed to be exogenously given and fixed. Distance is, of course, physically fixed. Hence, the partial derivatives of commuting cost and distance from the central city is invariant with respect to income, and equation (e) can be simplified as:

$$
\frac{\partial u}{\partial Y}-h \frac{\partial p_{h}}{\partial Y}-p_{h} \frac{\partial h}{\partial Y}+\left(\frac{\partial u}{\partial h} \frac{\partial h}{\partial Y}\right)=0
$$

Again letting $u_{1}=\frac{\partial u}{\partial h}=p_{h}$ and $u_{2}=\frac{\partial u}{\partial q}=1$, equation (f) can be expressed as:

(g) $\quad-u_{2}\left(-h \frac{\partial p_{h}}{\partial Y}+p_{h} \frac{\partial h}{\partial Y}-\frac{\partial u}{\partial Y}\right)+u_{1} \frac{\partial h}{\partial Y}=0$

Rearranging and recalling that $u_{1}=P_{h} u_{2}$, this comparative static result can be written as:

(h) $\frac{\partial u}{\partial Y}-h \cdot \frac{\partial p_{h}}{\partial Y}=0$, thus $\ldots \frac{\partial p_{h}}{\partial Y}=\frac{\frac{\partial u}{\partial Y}}{h}>0$

The sign of equation (12) is easy to determine. $h$ is positive, but to determine the sign of $\frac{\partial u}{\partial Y}$, envelop theorem can be used. By this theorem, the marginal utility of money is basically $\lambda$, which indicates the additional utility that can be derived if one more dollar is available to spend. But $\lambda$ equals the optimization (first order) condition $\partial u / \partial q$, which 
at optimal must equal the price of the Hicksian good, which is normalized to 1 . Since $\lambda$ is 1 in this case, so will $\frac{\partial u}{\partial Y}$, hence it is positive.

The effect of a change in commuting cost ( $\left.k_{c}\right)$ on housing price $\left(p_{h}\right)$ :

The impact of a change in $k_{c}$ on $P_{h}$ and $h$ can be derived using comparative statics on equation (3.4). Totally differentiating equation (3.4) with respect to $k_{c}$ yields:

$$
\left(\frac{\partial u}{\partial Y} \frac{\partial Y}{\partial k_{c}}\right)-\left(\frac{\partial u}{\partial k_{c}} \frac{\partial k_{c}}{\partial k_{c}}\right)-\left(\frac{\partial u}{\partial d} \frac{\partial d}{\partial k_{c}}\right)-\left(\frac{\partial u}{\partial p_{h}} \frac{\partial p_{h}}{\partial k_{c}}\right)-\left(\frac{\partial u}{\partial h} \frac{\partial h}{\partial k_{c}}\right)+\left(\frac{\partial u}{\partial h} \frac{\partial h}{\partial k_{c}}\right)=0
$$

Income is exogenously determined and hence it is not sensitive to a change in commuting cost, at least in the short-run. Distance is also a fixed physical state that can not be altered by commuting cost (though commuting cost can determine economic distance in the long-run through investment in transportation technologies). Following these arguments, equation (i) can be rearranged as:

$$
-\frac{\partial u}{\partial k_{c}}-h \frac{\partial p_{h}}{\partial k_{c}}-p_{h} \frac{\partial h}{\partial k_{c}}+\left(\frac{\partial u}{\partial h} \frac{\partial h}{\partial k_{c}}\right)=0 .
$$

Letting $u_{1}=\frac{\partial u}{\partial h}=p_{h}$ and $u_{2}=\frac{\partial u}{\partial q}=1$, and because $\frac{\partial h}{\partial k_{c}}=d$, equation (j) can be rewritten as:

(k) $\quad-u_{2}\left(d+h \frac{\partial p_{h}}{\partial k_{c}}+p_{h} \frac{\partial h}{\partial k_{c}}\right)+u_{1} \frac{\partial h}{\partial k_{c}}=0$.

Rearranging and recalling that $u_{l}=P_{h} u_{2}$, equation (k) can be expressed as:

(1) $\quad-d-h \frac{\partial p_{h}}{\partial k_{c}}=0$, thus $\ldots \frac{\partial p_{h}}{\partial k_{c}}=\frac{d}{-h}<0$ 
The effect of a change in income, commuting cost, and distance on land rent:

In the long-run, land development should yield zero economic profit. This condition is expressed as $p_{h} h(\omega, 1)-i \omega=r$. Totally differentiating this equation with respect to the parameters $\varphi=f\left(Y, u, k_{c}, d\right)$ yields:

(m) $\quad p_{h} \cdot \frac{\partial h(.)}{\partial \omega} \cdot \frac{\partial \omega}{\partial \varphi}+h(.) \cdot \frac{\partial p_{h}}{\partial \varphi}-\omega \cdot \frac{\partial i}{\partial \varphi}-i \cdot \frac{\partial \omega}{\partial \varphi}=\frac{\partial r}{\partial \varphi}$

Rearranging,

(n)

$$
\left(p_{h} \cdot \frac{\partial h(.)}{\partial \omega}-i\right) \frac{\partial \omega}{\partial \varphi}+h(.) \cdot \frac{\partial p_{h}}{\partial \varphi}=\frac{\partial r}{\partial \varphi}
$$

From profit maximization first order condition, $p_{h} \cdot \frac{\partial h(.)}{\partial \omega}=i$ hence, the above equation can be simplified to:

(o) $\frac{\partial r}{\partial \varphi}=h(.) \cdot \frac{\partial p_{h}}{\partial \varphi}$

The sign of the partial derivative of rent with respect to the consumer side parameters depends on the sign of the derivative of rental price of house with respect to the consumer side parameters. Substituting the consumer side parameters represented by $\varphi=\left(Y, u, k_{c}, d\right)$, the implications of changes in these parameters on the rental value of land can be computed as follows: $\frac{\partial r}{\partial Y}=h(.) \frac{\partial p_{h}}{\partial Y}>0, \frac{\partial r}{\partial k_{c}}=h(.) \frac{\partial p_{h}}{\partial k_{c}}<0$, and $\frac{\partial r}{\partial d}=h(.) \frac{\partial p_{h}}{\partial d}<0$. 
The effect of a change in income, commuting cost, and distance on the capital-land ratio:

Totally differentiating the profit maximization first order condition

$\left(\frac{\partial \pi}{\partial \omega}=p_{h} \frac{\partial h(.)}{\partial \omega}-i=0\right)$ with respect to the parameters $\varphi=f\left(Y, u, k_{c}, d\right)$ gives the

comparative static results for parameter changes on capital land ratio. The expression can be given as:

(p) $\quad \frac{\partial}{\partial \varphi}\left(\frac{\partial \pi}{\partial \omega}\right)=0 \Rightarrow \frac{\partial h(.)}{\partial \omega} \cdot \frac{\partial p_{h}}{\partial \varphi}+p_{h} \cdot \frac{\partial\left(\frac{\partial h(.)}{\partial \omega}\right)}{\partial \omega} \cdot \frac{\partial \omega}{\partial \varphi}=0$

From equation (p), the comparative static condition of the partial derivative of capital-land ratio with respect to the consumer side parameters can be solved as:

(q) $\quad \frac{\partial \omega}{\partial \varphi}=-\frac{\partial h(.)}{\partial \omega} \cdot \frac{\partial p_{h}}{\partial \varphi} \cdot \frac{1}{p_{h} \cdot \frac{\partial^{2} h(.)}{\partial \omega^{2}}}$

The sign of $\frac{\partial \omega}{\partial \varphi}$ can easily be determined. $-\frac{\partial h(.)}{\partial \omega}<0$ and $\frac{1}{p_{h} \cdot \frac{\partial^{2} h(.)}{\partial \omega^{2}}}<0$ due to

diminishing returns on input use. Hence, the sign of $\frac{\partial \omega}{\partial \varphi}$ depends on the sign of $\frac{\partial p_{h}}{\partial \varphi}$. The comparative static results for consumer side parameters $\left(\varphi=f\left(Y, u, k_{c}, d\right)\right)$, thus, can be given as: $\frac{\partial \omega}{\partial Y}=-\frac{\partial h(.)}{\partial \omega} \frac{\partial p_{h}}{\partial Y} \frac{1}{p_{h} \frac{\partial^{2} h(.)}{\partial \omega^{2}}}>0, \frac{\partial \omega}{\partial k_{c}}=-\frac{\partial h(.)}{\partial \omega} \frac{\partial p_{h}}{\partial k_{c}} \frac{1}{p_{h} \frac{\partial^{2} h(.)}{\partial \omega^{2}}}<0$, and $\frac{\partial \omega}{\partial d}=-\frac{\partial h(.)}{\partial \omega} \frac{\partial p_{h}}{\partial d} \frac{1}{p_{h} \frac{\partial^{2} h(.)}{\partial \omega^{2}}}<0$. 